\title{
Evidence From the Scientific Assessment of Electronic Cigarettes and Their Role in Tobacco Harm Reduction*
}

\author{
by \\ Oscar M. Camacho, James K. Ebajemito, Steven Coburn, Krishna Prasad, Sandra Costigan, and James J. Murphy
}

British American Tobacco, R\&D Centre, Southampton, SO15 8TL, United Kingdom

\section{SUMMARY}

While smoking remains a main global cause of preventable morbidity and mortality, a potential inflection point has arrived where it could become possible for non-combustible nicotine products to displace cigarettes and reduce risk for smokers who transition completely from smoking. These have proven consumer satisfaction and are now widely and increasingly available globally. One of the most prominent of these nicotine products are electronic cigarettes (ECs), which are used daily by millions of current and former smokers. The category is not without controversy as these products are not risk free and can cause nicotine dependence. The differing interpretation of science assessing ECs has transpired into inconsistent regulation and product standards, providing an environment for its fragmented manufacturing base which allows for variable product quality and in turn, product quality variability has impacted on how they are viewed. In this review, we assess published scientific evidence to evaluate whether, on balance, ECs fulfil a tobacco harm reduction role by reducing health risks relative to smoking and providing a viable alternative for smokers while having limited appeal to nonsmokers. [Contrib. Tob. Nicotine Res. 30 (2021) 63-108]

\section{ZUSAMMENFASSUNG}

Während das Rauchen global weiterhin eine Hauptursache für vermeidbare Morbidität und Mortalität darstellt, scheint ein Wendepunkt in Sicht: Zukünftig könnten Zigaretten möglicherweise von nicht brennbaren Nikotinprodukten verdrängt und somit das Risiko für Raucher reduziert werden, die sich hierdurch das Tabakrauchen vollständig abgewöhnen. Die Zufriedenheit der Konsumenten mit diesen Produkten ist erwiesen und sie sind zunehmend weltweit erhältlich. Eines der bekanntesten derartigen Nikotinprodukte ist die elektronische Zigarette (EZ), die täglich von Millionen von ehemaligen und aktuellen Rauchern genutzt wird. Diese Produktart ist nicht unumstritten, da die Produkte nicht frei von Risiken sind und $\mathrm{zu}$ Nikotinabhängigkeit führen können. Die Unterschiede in der Bewertung der EZ durch die Wissenschaft schlagen sich in uneinheitlichen Regulierungen und Produktstandards nieder. Dieses Regulierungsumfeld führt, gepaart mit einer fragmentierten Herstellerbasis, zu einer schwankenden Produktqualität und diese Schwankungen bei der Produktqualität haben wiederum einen Einfluss auf die Wahrnehmung der Produkte. In der vorliegenden Untersuchung wurde anhand von publizierter wissenschaftlicher Evidenz der Frage nachgegangen, ob nach Abwägung aller Vor- und Nachteile, EZ einen Beitrag zur Reduzierung von Schäden durch Tabakkonsum leisten können, indem sie die gesundheitlichen Risiken des Rauchens verringern und eine akzeptable Alternative für Raucher darstellen, während sie gleichzeitig für Nichtraucher nur bedingt attraktiv sind. [Contrib. Tob. Nicotine Res. 30 (2021) 63-108]

\section{RESUME}

Sachant que le tabagisme demeure, au niveau mondial, une cause majeure de morbidité et de mortalité évitables, un point d'inflexion potentiel est atteint où il pourrait devenir possible pour des produits non combustibles contenant de la nicotine de supplanter la cigarette et de réduire le risque pour les fumeurs abandonnant complètement le tabac. Ces produits non combustibles apportent aux consommateurs

* Received: $9^{\text {th }}$ February 2021 - accepted: $4^{\text {th }}$ May 2021 
une satisfaction avérée et sont désormais de plus en plus aisément et largement disponibles dans le monde. Un des produits les plus en vue contenant de la nicotine est la cigarette électronique (e-cig), qui est utilisée, au quotidien, par des millions de fumeurs, anciens et encore adeptes du tabac. Cette catégorie de produits n'est pas sans susciter la controverse car ces produits ne sont pas dénués de risques et peuvent induire une dépendance à la nicotine. L'interprétation divergente de la science qui évalue les ecigs transparaît dans l'incohérence de la réglementation et des normes applicables aux produits et crée, pour la base fragmentée des fabricants, un environnement qui permet des variations de la qualité des produits, variations qui, à leur tour, influencent la perception des produits. Dans la présente étude, nous évaluons les preuves scientifiques publiées afin de juger si, tout bien considéré, les e-cigs jouent un rôle d'allègement de la nocivité du tabac en réduisant les risques pour la santé liés au tabagisme, en proposant une option alternative viable pour les fumeurs tout en exerçant un attrait limité pour les non-fumeurs [Contrib. Tob. Nicotine Res. 30 (2021) 63-108]

\section{INTRODUCTION}

Smoking remains an important cause of preventable morbidity and mortality (1). The World Health Organization (WHO) currently estimates that worldwide, around 1.3 billion adults smoke (2). The overwhelming majority of the disease risk is acknowledged to come from compounds formed during combustion of tobacco at very high temperatures $\left(\sim 950{ }^{\circ} \mathrm{C}\right)(3,4)$. Of roughly 6,500 compounds $(5)$, about 150 are known toxicants (6) that contribute to smoking-related diseases, such as cardiovascular and respiratory diseases, and cancers. These toxicants also increase the risk of disability and death by other diseases; risks rising with increasing duration of regular smoking. However, excess risks are substantially reversible with smoking cessation (7). Nevertheless, not all nicotine users want to quit, and others find it difficult to do so.

In 2010, the WHO published its Framework Convention on Tobacco Control (FCTC) treaty (8), creating aspirational policy goals for the 181 member states that ratified it. Traditionally, WHO has taken an absolute tobacco control approach to smoking, despite article 1(d) in the FCTC advocating for harm reduction strategies. Since its publication, many countries have implemented the associated guidelines to varying degrees. Since these goals were published, various alternative nicotine products have become commercially available (e.g., electronic cigarettes (ECs), tobacco-free nicotine pouches, and other vapour products), which has led to increasing consideration of the concept of tobacco harm reduction. Harm reduction initiatives involving alternatives to smoking must aim to protect youth and non-smokers from uptake, including by regulation of products, advertising, promotion, and sponsorship (9). This principle involves reducing the risk to smokers by offering satisfactory alternative products with lower risk profiles (10-13). For example, in Sweden, where there is high prevalence of snus use, daily smoking prevalence is one of the lowest in Europe. Only $7 \%$ of the adult population were daily smokers in 2020 (14). Snus is less harmful to health than smoking (15), and Swedish men, who are the predominant snus users, have among the lowest rates of lung cancer incidence and tobacco-related mortality worldwide (16). The potential role of snus in a tobacco harm reduction strategy has been recognised by the US Food and Drug Administration (FDA), granting modified risk orders for eight snus products in $2019(17,18)$.

A widely available alternative nicotine product is ECs. Use of ECs is commonly known as vaping and users are known as vapers. These products heat a liquid (termed e-liquid) containing ingredients that function as carriers (e.g., propylene glycol (PG) and vegetable glycerin (VG)) and may contain flavours and/or nicotine. Compared with tobacco combustion, e-liquids are heated to only around $250^{\circ} \mathrm{C}$ and release an aerosol that is much less complex than cigarette smoke, having substantially fewer and lower concentrations of compounds (19-22). Systematic reviews indicate substantially decreased disease risk compared with smoking through greatly reduced exposure to toxicants and carcinogens (23-28), although the risks are not wholly eliminated nor yet fully characterised. Several governments, including those in the UK $(24,29)$, Canada (30), and New Zealand (31) support use of ECs as reduced-risk alternatives to smoking.

Where manufacturing is actively regulated and monitoring systems are in place, EC quality tends to be high (32) and numbers of reported adverse and serious adverse events leading to morbidity or mortality are low (33). By contrast, if poorly made or illegal products are allowed to enter markets, they substantially increase the risks of adverse events. In the electronic vapour acute lung injury (EVALI) crisis in the USA in 2019, non-regulated e-liquid containing vitamin $\mathrm{E}$ acetate and medium-chain triglycerides that are often used in consumption of cannabis and tetrahydrocannabidiol were illegally used as additives, causing severe lung injury in some users $(34,35)$. This tragedy killed 68 people and injured over 2,000.

This review paper considers the role of ECs in tobacco harm reduction. It provides a high-level account of the evolution of EC design, safety and performance, and methods of testing. Scientific evidence is assessed in relation to acute and long-term health risks associated with EC use. Finally, it discusses how ECs perceptions and use behaviours could impact a harm reduction strategy as well as how available evidence can be used to evaluate health outcomes at population level.

\section{PRODUCT DESIGN AND REGULATION}

\subsection{EC design basics}

ECs were introduced to the market in 2004 and came to prominence around 2010. Despite this short period, the types of devices have cycled through several generations (Figure 1) (28), in each of which many different devices are available (36). From simple closed, low-power 'cig-a-like' devices (generation one), they transformed to refillable long-term use (generation two) and modifiable (generation three) systems, and further to discreet closed system devices with many safety features and improved nicotine delivery (generation four; Figure 1). 
(c)

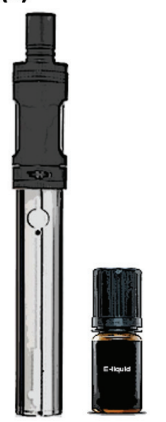

(a) Disposable \& (b) rechargeable e-cigarettes (a) (b)

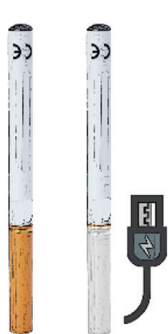
e-cigarettes with (c) Open mod system variable power (d)

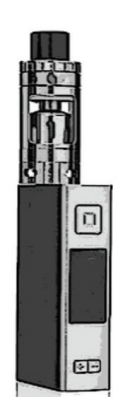

(d) Open mod system e-cigarettes with variable settings

(e)

$3^{\text {rd }}$ Generation

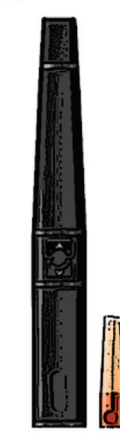

(e) Pod mod closed system e-cigarette
Innovation in:

- non-coil \& wick technology

- higher aerosol mass and nicotine delivery

- mobile Bluetooth connectivity

- usage monitoring

- overall device functionality

Figure 1. Schematic illustration of e-cigarette devices showing disposable $1^{\text {st }}$ generation (cig-a-like) e-cigarettes, $2^{\text {nd }}$ generation with refillable system, $3^{\text {rd }}$ generation customizable ECs, and $4^{\text {th }}$ generation e-cigarettes closed systems.

The basic elements of ECs are a battery connected to a heating element and an e-liquid reservoir. In first generation, single-piece cig-a-like products, all parts are encased into one (usually disposable) unit. The three-piece open systems of generations two and three consist of a separate battery, e-liquid cartridge, and atomizer (vaporizes the e-liquid), and parts and components may be swapped to customize the vaping experience (e.g., by increasing voltage, tank size, and/or e-liquid strength and flavour). Fourth-generation two-piece products consist of a battery and a cartomizer (a combined e-liquid cartridge and atomizer), which is the only exchangeable part. EC emissions may differ by product characteristics and operation and user behaviour (28). Many manufacturers' design changes have been based on feedback from users searching for products that can meet their nicotine preference with sufficient satisfaction to enable them to replace cigarettes while favouring safety and flexibility $(21,36)$. In most countries, cig-a-like devices account for only $15 \%$ of the EC market, except in the USA, where they are used by around $50 \%$ of vapers (37).

The most common reasons for smokers rejecting ECs relate to performance (mimicking smoking and effectiveness at lessening cravings for smoking), but other common reasons are ease of use. In a survey published by Action on Smoking and Health (ASH) (38), 7\% of users stopped using ECs because of difficulties in replacing components, refilling e-liquid, or due to leaking. WADSWORTH et al. (39) found that the ease of using cig-a-like ECs (confidence in nicotine dose, no refilling required, ease of availability compared with later-generation devices, etc.) made them a popular first device for vapers. By contrast, third-generation modifiable models were considered "bulky" or "scary". However, cig-a-likes (39) and e-cigarettes in general (40) were often found to be unsatisfactory.

An unpleasant problem is so-called dry wicking, more commonly known as "dry puff", which is caused when the wick in the atomizer is not saturated, leading to the coil be- coming overheated and thermal breakdown of solvents in e-liquid (41-47). The dry wick effect can occur when the e-liquid runs out and the user puffs deeply or if the voltage on modifiable devices is too high for the heating system. While this phenomenon is thought to increase the emission of toxicants (42), it causes a very unpleasant acrid taste (48) that is generally viewed as sufficiently arresting to prevent harm (24). In generation four products, some manufacturers have introduced pre-set power settings to help users to vary their vaping experience while avoiding dry wicking. For example, a distiller-plate heating system, which heats the e-liquid directly and replaces the coil and wick system, has increased nicotine delivery while minimizing the risk of dry puffs (21).

\subsection{Use of flavours}

Thousands of flavours are available for ECs, and even within individual flavours, many variations in formulations exist. Sensorial aspects, such as sweetness, coolness, and vapour visibility or smoothness, play important parts in product acceptability (49-51). A systematic review by ZARE et al. (52) found that all vapers preferred flavoured ECs, particularly sweet flavours, irrespective of age group. Adult consumers identify taste and variety of flavours as important characteristics of ECs (53). Most first-time purchases of ECs and e-liquids contain fruit flavours $(54,55)$. However, some studies suggest that flavours could be a determinant for adolescents trying ECs and, potentially, transitioning to smoking (56) or that flavours could reinforce the reward obtained from nicotine vaping products, increasing their potential for abuse liability $(57,58)$. An ASH survey (59) found that fruit flavours have overtaken both tobacco flavours and mint as the preferred e-liquid, accounting for nearly one-third of flavoured e-liquids used, and those using fruits or sweet flavours were more likely than tobacco flavour users to vape in order to quit smoking (60). 


\subsection{Product regulation}

In many countries, ECs are regulated (in around 100 countries) (61), but the regulations are inconsistent and generally cover marketing, labelling, ingredients, and/or taxation, leading to highly variable product standards globally. However, only six countries have no regulations beyond minimum age for purchase (61). Marketing authorizations or product notifications/marketing applications may be required before products can enter the market. Premarket authorizations involve the regulator giving permission for marketing after review of an application, placing some of the responsibility for a product on the regulator. By contrast, with product notifications/marketing applications, while the regulator may act on information provided, responsibility for the product remains with the submitter. The European Parliament, the US Food and Drug Administration (FDA), and various other national authorities request data on ingredients and various compounds in emissions, including types, quantities, and origins. Forty-two countries have banned ECs, most frequently based on the perceived risk of youth nicotine addiction or the potential that yet unknown long-term effects of vaping might outweigh any health benefits (61-64).

In the USA, regulation of ECs was introduced in 2016 (65). All new tobacco products, including ECs despite their lack of tobacco leaves, are subject to approval via Pre-Market Tobacco Product Applications (PMTA) (66). Manufacturers that wish to be able to claim that an individual tobacco product (but not a product class) reduces risk to health compared with smoking must also make a Modified Risk Tobacco Product Application (67, 68). Each submission requires a dossier with description and formulation of the product, description of non-clinical and clinical research findings relating to the effects of the product on tobaccorelated diseases and other health-related conditions, how it will be used, as well as, examples of labelling and a description of how the product would be marketed. So far, numerous Pre-Market Tobacco Product Applications have been made for ECs but no Modified Risk Tobacco Product Application submission for ECs has yet been approved by the FDA. Dossier review times are expected to run into several years, making it likely the market will not easily benefit from product improvements as the category develops.

In the EU, the Tobacco Products Directive 2014/40/EU (TPD2) regulates the manufacture, sale, and marketing of tobacco products (69). It incorporates a product notification system and aims "to facilitate the smooth functioning of the internal market for tobacco and related products, taking as a base a high level of health protection". The first factor requires an assessment of the product relative to the products already on the market, whereas the second focuses on the safety of the product itself. The TPD2 sets certain minimum safety and quality requirements, including, but not limited to, maximum nicotine concentration $(20 \mathrm{mg} / \mathrm{mL})$ and maximum volumes for cartridges, tanks, and nicotine liquid containers $(2 \mathrm{~mL})$, child-resistant and tamper proof features on devices and e-liquid bottles, and refilling systems that prevent leaking. These are, in addition to EU safety regulations on restriction of hazardous substances in electrical and electronic equipment products (70), the Registration, Evaluation, Authorisation and Restriction of Chemicals (REACH) regulation (71), testing requirements for electrical parts, and monitoring and reporting of adverse events (69). TPD2 is expected to be revised in the mid-2020s.

In most countries, advertising and marketing of ECs is highly controlled in terms of where and what information may be displayed and how. In the UK, the Committee of Advertising Practice does not allow advertising of ECs to make medicinal claims (e.g., can help with smoking cessation) unless they have marketing authorization from the Medicines and Healthcare Products Regulatory Agency, and messages must not appeal to youth or encourage nonsmokers or non-nicotine-users to use ECs (72). In the US, modified risk claims can be made only for products authorized by the FDA via the Modified Risk Tobacco Product Application process (73). A few countries, like Canada and New Zealand, allow promotion of the use of ECs as less harmful alternatives to tobacco smoking by providing balanced risk information for consumers $(74,31)$.

As well as top-line requirements, further detail on interpretation and compliance are provided by regulatory guidance documents, national, regional, and international technical product standards, and voluntary industry codes. Technical committees creating standardised safety and quality guidance for ECs have been set up at the International Organization for Standardization (ISO) and the European Committee for Standardization (CEN), involving experts from industry, regulators, consumers, and other relevant stakeholders. Each has published two technical standards on generating emissions for measurements, what to measure in emissions, device safety, and analytical methods for measuring the main components in e-liquids (75-78). Further guidelines are being developed on electrical safety, manufacturing, ingredients, additional emissions and e-liquid measurement methods, consumer information, and labelling. Adoption of product standards is important to consumers to inform them about the quality of ECs, and to regulators and industry to clarify methodologies and data generated for marketing applications. Specifically, a framework of testing standards for ECs has been proposed, as many methods used had simply been adapted from cigarette testing methods. This will enable clearer comparison of aerosol yields within and across different product categories, including cigarettes (79).

\section{PRODUCT SAFETY AND STEWARDSHIP}

When ECs were first introduced, concerns were expressed about e-liquid after the number of calls to poison centres reporting exposure and irritation of skin or eyes with contact rose (80-82), but the risk of incidents has been reduced by changes in product design and labelling, e.g., non-spill e-liquid cartridges in closed ECs, improved information for use of open, refillable ECs and measures to take when accidental spills do occur, and testing of appropriate concentration ranges for ingredients. Nevertheless, some of the measures that could increase the safety are, for example, by developing child-resistant mechanisms for puff-activated products. For open products, the tanks should be child resistant and refilling could be leak-free, such as with a dock-and-lock mechanism.

Exploding devices and batteries occur infrequently but have 
led to severe burns and projectile injuries. These events are generally related to use of inappropriate chargers not supplied with the product that deliver too much current to the battery, leading to thermal runaway and generation of flammable and explosive gases (83). Well-designed products should meet international standards for protection against overcharging (76) and ensure sufficient venting capacity of the battery compartment. Likewise, battery quality should comply with existing international standards. EC products in Europe are covered directly by Electromagnetic Compatibility (EMC) Directive (2014/30/EU) (84) and Restriction of the Use of Certain Hazardous Substances (RoHS) Directive (2011/65/EU) (85), as indicated by the CE marking. Additionally, aspects of the General Product Safety (GPS) Directive (2001/95/EC) apply (86). The GPS sets out safety requirements for all consumer products being placed on the European market (and allows the use of adjacent standards, such as within the low-voltage-device safety standards, to control failure modes and risks), but is not itself associated with CE marking. Occasionally, battery explosions have been caused by improper storage or modification by users (28), and this issue requires further user education.

The European Committee for Standardization provides practical and enforceable requirements related to electrical safety, leakage and breakage, child resistance and some high-level device material considerations (76). ECs continue to be a developing product category and best practice guidance will thus require regular updating.

Product stewardship for ECs has been developed by several EC manufacturers to address materials and ingredients, interactions of the e-liquid and the device (e.g., aerosol laboratory and clinical testing), and post-marketing surveillance (e.g., customer feedback or complaints, product sustainability, etc.). A potential approach for toxicological stewardship of ECs is summarised in Panel 1 (87-89). The need for purity requirements and exclusion of ingredients with certain toxicological properties has gained widespread recognition (90). However, the basic principle that the dose determines the level of toxicological risk seems often to be forgotten, leading to purported adverse effects in the literature based on in vitro cytotoxicity or other effects without human exposure contextualisation. (91).

\section{Panel 1. EC stewardship toxicological best practice.}

- Nicotine and humectants should be of pharmaceutical grade purity

- Flavourings should be food grade purity

- Protect consumers from ingredients identified as carcinogens, mutagens, reprotoxicants, and respiratory allergens

- Manufacturers should maintain an additional negative list of ingredients that have been proven to be unsuitable for use in vaping products (e.g., diacetyl, vitamin E acetate, triglycerides) and follow regulatory guidance about any other substance

- Toxicological risk assessments should be performed for each e-liquid to demonstrate ingredients and concentrations in e-liquid are supportable

- Conduct chemical and toxicological assessments of aerosol for every device and e-liquid variant (can benefit from a bridging approach)
Besides addressing ingredient selection, an e-liquid toxicological risk assessment should determine whether the levels of the ingredients are suitable for the intended use $(92,93)$. In vitro assessments, such as cytotoxicity tests, and comparison to reference materials enable quantitative translation of effects to real-life situations.

Additionally, a robust stewardship process should monitor consumer complaints and analyse them to ensure safety and engagement with the product continuous improvement process.

\section{INVESTIGATION OF ACUTE AND LONG-TERM HEALTH RISKS}

Multiple scientific frameworks for risk assessment have been presented that outline the approach for investigating the risk profile of non-combustible tobacco and nicotine products (13, 94-96). Broadly, all frameworks are underpinned by investigation of acute and long-term risk from using ECs in studies assessing chemistry, toxicology and clinical outcomes, and also by the perceptions and behaviours of users and nonusers of ECs. In this section, we present published data from multi-disciplinary scientific studies of ECs generated within product assessment frameworks and investigating acute and long-term risks from using ECs.

\subsection{Chemical and physical characterization}

Compounds of interest in ECs have often been based on smoking toxicant emissions (97) and many studies use smoking as a comparator, meaning that smoke toxicants have been the focus of most assessments so far (98-102). Investigational approaches are, therefore, evolving in response to emerging evidence and growing understanding of EC aerosol composition.

The EU TPD2 stipulates chemical emissions testing for multiple priority compounds, including acetaldehyde, acrolein, and formaldehyde (84). The US FDA has identified 92 harmful or potentially harmful constituents (HPHCs) in addition to nicotine (103) and public comment was recently sought on the proposal to add a further 19 compounds to the list (104). However, to our knowledge, only one study has investigated the emissions of these additional HPHCs (22). In practice, it has been suggested that Pre-Market Tobacco Product Applications should report at least 32 compounds (66). ECs generally do not reach temperatures higher than $250{ }^{\circ} \mathrm{C}$ during normal use or more than $350^{\circ} \mathrm{C}$ under dry wicking conditions (105). However, a huge variety of devices and e-liquids exist (106) and many different puffing conditions and analytical techniques have been used to assess them (42, 107-109), but, overall, results indicate significantly lower levels of toxicants in EC aerosols than in cigarette smoke $(20,22,43,44,102,110,111)$.

\subsubsection{Methodological considerations in vaping products analytical testing}

Despite the relative simplicity of EC aerosol, consideration must be given to aerosol collection methods and measurement of specific analytes. For example, a review of papers that measured carbonyl emissions from ECs showed many variations in the measurement techniques, including puffing 
regime, aerosol collection, and analytical methodology, making data comparisons difficult $(41,42)$. Reducing variability would maximize sensitivity of reported values (43). The CORESTA Recommended Method $\mathrm{N}^{\circ} 81$ (112) includes standardised puffing conditions for ECs that have now been used in multiple emissions testing studies (20-22, 113-115).

Potential contamination from the testing environment (e.g., the presence of volatile organic species in occupational and residential room air) is a well-documented phenomenon. Indoor air quality reference values have been established for several species (20). The presence of an analyte in a laboratory reagent used for testing, for example carbonyls in 2,4-dinitrophenylhydrazine, is also well recognized (43). Given the low levels of most compounds in EC emissions, use of air and blank controls and management of the chemical background of the testing environment are crucial to provide context (e.g., contribution of non-product-related compounds of interest) and minimize errors in the analytical data $(20,116)$. Reporting control data as standard will improve interpretability of results.

\subsubsection{Sources of toxicants in e-liquids and aerosol}

The number of components in e-liquids is estimated to be around 113 (28) compared with around 600 in tobacco cigarettes (109). In high-quality manufactured ECs, the main sources of toxicants in aerosol are attributed to impurities in liquid, degradation of the e-liquid ingredients, and device components. Most compounds associated with e-liquid formulation are either not detected or are very close to the limit of quantification $(113,117)$.

\subsubsection{Impurities and leaching}

Carbonyl compound levels can increase with increasing flavour content. Retail flavours were added to a $1: 1 \mathrm{PG}-\mathrm{VG}$ mixture at 5-50\% $(v / v)$ and carbonyl compound levels increased linearly by 1.3-10.5 times (118). However, these concentrations are not representative of commercial e-liquid formulations and were sampled in a non-standard puffing regime. In flavours derived from the extraction of cured tobacco leaf, major tobacco-derived toxicants (e.g., tobacco-specific nitrosamines and nitrates) were present at very low levels compared to those in tobacco products but whether these transferred to aerosol was not assessed (100). E-liquid components can cause unintended formation of toxicants, such as acetoin leading to formation of diacetyl (119). Reduction of toxicants in e-liquid, directly or by avoiding reactions with other components, may be achieved with good stewardship during product development (87). Metals in e-liquid are generally impurities or are leached from the cartomiser or device materials through contact (120-122), but this occurrence is generally restricted to earlier EC designs (123-126). A selection of results from studies investigating metals in different devices has been compiled in Table 1 . In a study of 15 trace elements in 27 different e-liquids from one manufacturer, samples contained fewer than $10 \mathrm{ppb}$ or concentrations below the lower level of quantification for all elements except aluminium, chromium, copper, antimony, and zinc (127).
KAMILARI et al. (128) found levels of metals below those defined by regulatory authorities for inhaled medicines in 22 e-liquids from various markets. NA et al. (129) reported that levels of some metals increased and transferred to aerosol after e-liquid was in contact with coils and opensystem atomizers for 7 days, but this circumstance would be unusual for most EC users. Ratios of metals before and after use differed, indicating transfer of metals into aerosol in six liquids (129). However, generally, heavy metals do not seem to transition to aerosol (44). BELUSHKIN et al. (116) found higher concentrations of heavy metals in aerosol than in air blanks in only two samples of e-liquid among a wide range of products from multiple manufacturers. Similarly, MARGHAM et al. (20), found that the measured metals in EC aerosol were not significantly different from those in air blanks. High-powered and open-system devices are likely to have higher metal content in aerosol than closed systems (130), but none of the metal content is likely to generate significant adverse health effects (131). FOWLES et al. (132) concluded in a review that metals in vapour could constitute a health risk to EC users but that high product standards can minimize exposure and reduced health risks associated with metals in EC aerosol.

\subsubsection{Thermal degradation}

Aldehyde formation may be influenced by e-liquid ingredients, overheating and dry wicking (41-47) and e-liquid oxidation through direct contact with the nickel-chromium heater coil (133-134) are the dominant causes. Improved coil designs and wicking materials that enhance e-liquid flow to the heaters can reduce the risk of these phenomena (135-137). In fourth-generation ECs, the levels of the key carbonyls of concern - formaldehyde, acetaldehyde, and acrolein - are greatly reduced compared to those in cigarette smoke (22). Table 2 illustrates the complexity of comparisons due to the differences in methodological and reporting approaches.

Nicotine salts in e-liquids have lower volatility than freebase nicotine, enabling enhanced nicotine delivery without increased irritation during vaping (138). Pharmacokinetic assessments indicate that the concentration of nicotine delivered is close to that in cigarette smoke, and the efficiency of delivery is improved compared with e-liquids containing free-base nicotine (139-141). At least six different acids have been identified in e-liquid formulations, alone or in combination, but the most common are lactic, benzoic, and levulinic acids (142). Nicotine benzoate is one of the most thermally stable organic acids but can decarboxylate under high temperatures to form benzene or phenol (143). Only one study has shown such degradation in ECs, and this effect was limited to high-powered open systems (144).

\subsubsection{Second-hand exposure to vaping aerosol}

Harmful health effects from secondhand smoke exposure have been widely reported (145). Although EC aerosol is much simpler than cigarette smoke and does not generate side-stream smoke, bystanders are still exposed to exhaled compounds, especially in indoor conditions. 


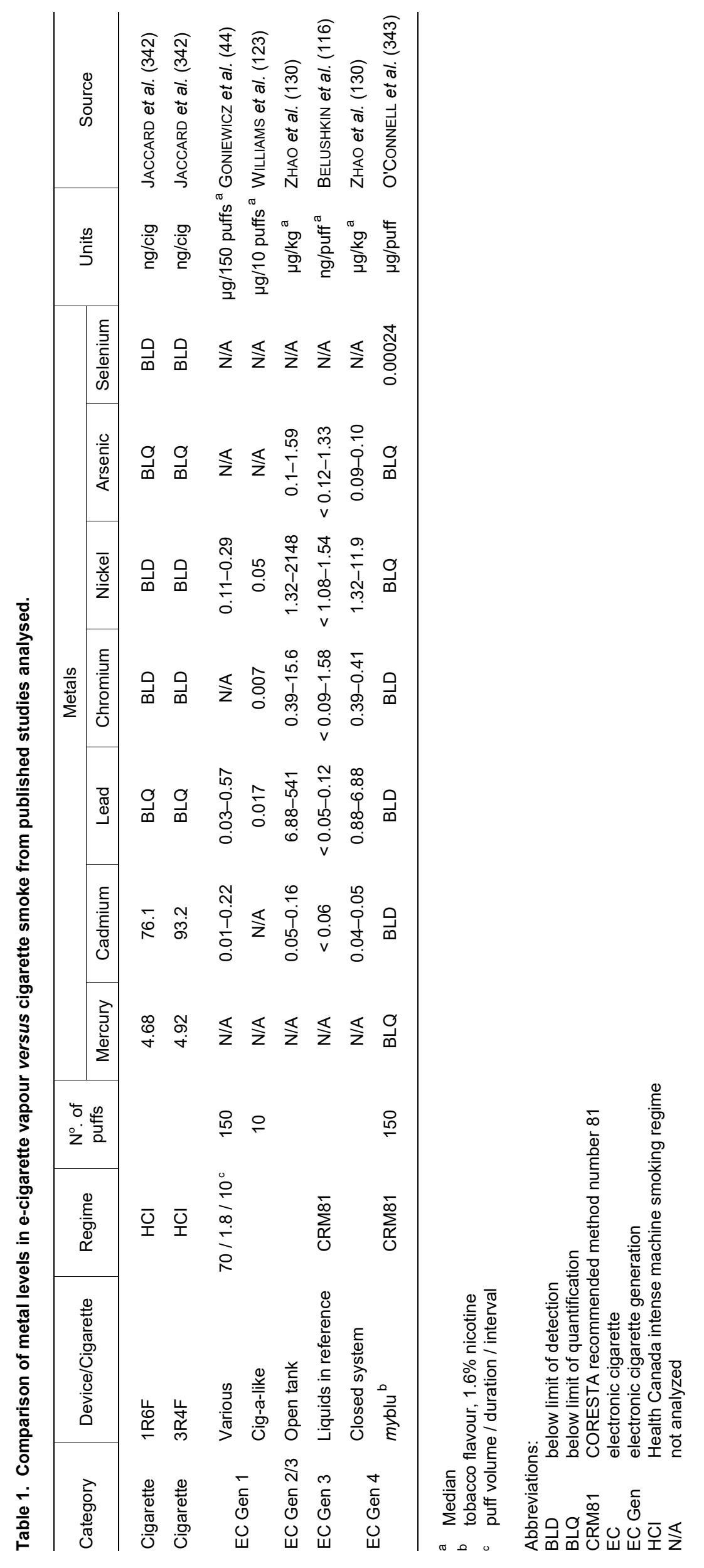




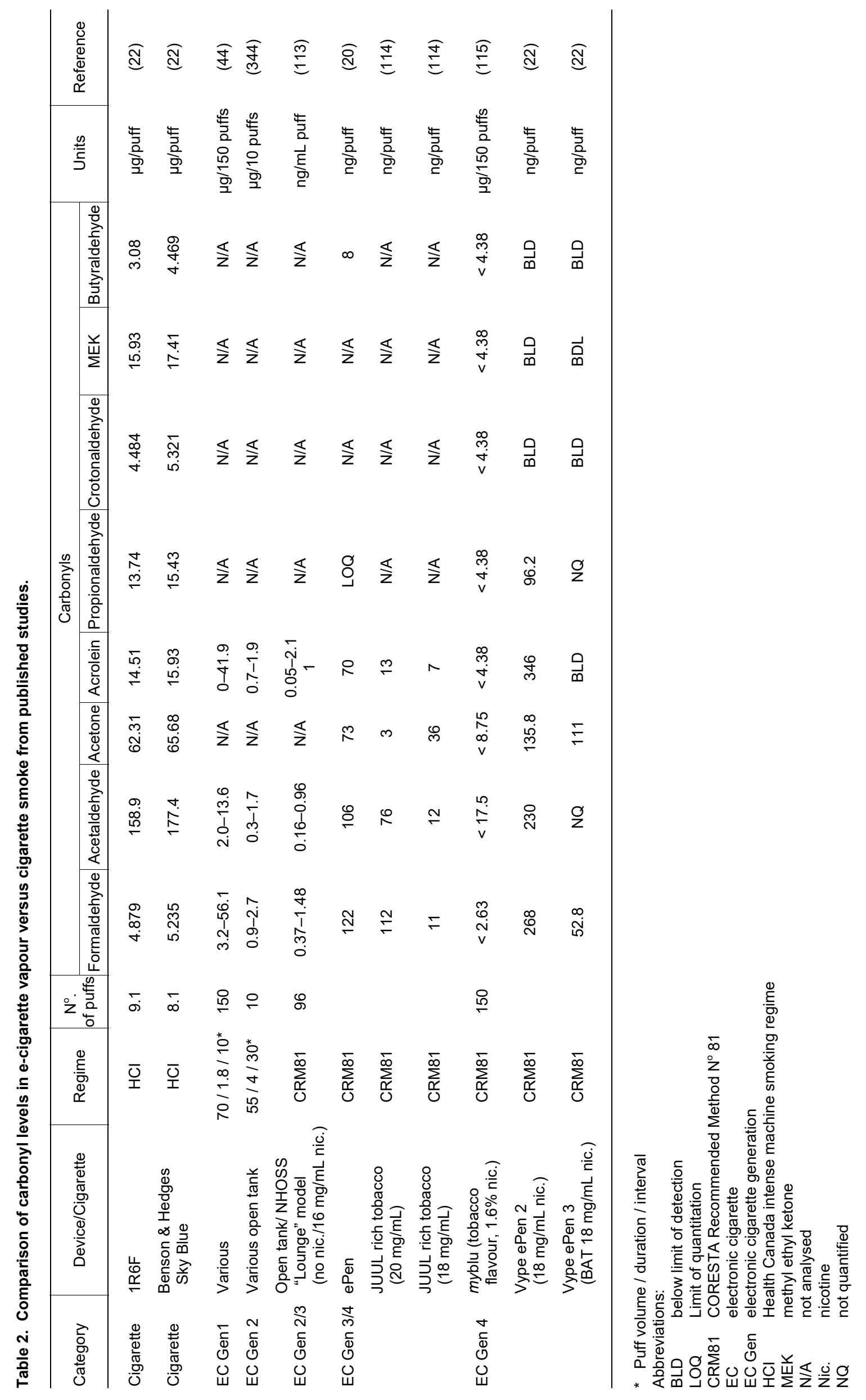


Studies investigating the extent and nature of this exposure have tended to measure volatile organic compounds, $\mathrm{CO}_{2}$, particulate matter (generally PM2.5 or PM10.0), ultrafine particles, and nicotine. Some studies have found increased concentrations of particulate matter after vaping in indoor settings (146-148), but generally conclude that exposure is lower compared to cigarette smoke $(149,150)$ and is less likely to be harmful to bystanders than second hand smoke $(28,29,151-153)$. The absolute risk from passive exposure to EC aerosol specially in vulnerable populations, like children, pregnant women and people with impaired respiratory and cardiovascular systems, requires further assessment (151).

\subsection{Toxicological assessment}

As explained in the product stewardship section (see p. 6667), robust toxicological approaches guided by regulation are essential to screen ingredients and complex mixtures $(92,154)$. In the screening phase, in silico approaches can be useful to identify hazards from known substances in e-liquids and to estimate toxicity of substances for which toxicological profiles are not well characterised (155). ZARINI et al. (156) used an in silico approach to develop quantitative structure-activity relationship models from data in the literature and toxicological databases in order to prioritize e-liquid ingredients according to potential acute toxicity. They used this approach to classify 264 e-liquid ingredients and flavours according to European classification labelling and packaging criteria and recommended this method to generate information for use in a weight-ofevidence approach (156).

Substances of potential concern identified through in silico toxicology should be investigated by in vitro and in vivo methods, including toxicological assays where appropriate, to calculate thresholds of concern (157). The US FDA still recommends in vivo studies when assessing acute effects in the respiratory system (158). THE EUROPEAN CHEMICALS AGENCY (ECHA) (159) favours a weight-of-evidence approach, reflecting changing attitudes and laws in multiple countries about moving toxicology analysis away from animal testing towards innovative high-throughput and cellculture platforms.

In vitro studies range from traditional toxicological models adapted from smoke exposure studies (160) to threedimensional cell-culture models that recreate organotypic tissue $(161,162)$. Multiple studies have investigated acute and chronic toxicological risk of ECs $(163,164)$, including testing for mutagenicity $(91,115,165-167)$, cytotoxicity (potency) (91, 115, 168-171), genotoxicity (91, 115, 172-174), oxidative stress $(175,176)$, and wound healing (177).

Traditional toxicological tests yield complex results and are affected by variability found between and within cell lines, limited translatability to the in vivo assays, and a lack of benchmarks to contextualize the findings $(171,178)$. Additionally, results might be affected by the diversity of EC designs, as found in a critical review of toxicological in vivo and in vitro studies by WANG et al. (164). Overall, though, the weight of evidence indicates that ECs present lower risks to users and bystanders than conventional cigarettes (179).
Broader toxicological approaches, such as systems toxicology, may be applied. Systems toxicology employs data from techniques like transcriptomics or proteomics from exposed cells to investigate pathways involved in oxidative stress, inflammation, cell proliferation, or DNA damage, and may highlight previously unidentified potential risks (180-183).

Computational risk assessment methodologies have been proposed to compare cancer potencies across tobacco products $(47,184)$. Cancer potency can be calculated from EC chemical emissions data and enable comparisons between products by factoring consumer exposure to different products. STEPHENS (47) suggested that ECs only have 0.004 times the carcinogenicity of cigarette smoke whilst still being 10.7 times more carcinogenic than nicotine inhalers.

\subsection{Assessment of clinical and health effects of vaping}

Smoking increases health risks to cardiovascular, respiratory, and other systems soon after the onset of smoking, with the risks of death, disease, and disability rising with increasing duration of use. However, these excess risks are largely reversible with smoking cessation (7). Acute measurements of circulation and lung function may improve within 3-9 months of quitting, and coronary heart disease excess risk due to smoking is halved after 1 year and completely reversed by around 15 years $(2,185)$. The aim of assessing clinical effects of smoking, therefore, is not only to investigate damage caused but also to assess whether changing behaviour can reduce these excess risks and/or lead to functional benefits.

\subsubsection{Nicotine pharmacokinetic studies}

Satisfactory nicotine delivery is critical to the acceptability of ECs. Despite the popularity of later-generation ECs, many users relapse to smoking alone or alongside EC use (dual use) raising concerns about the viability of ECs as a long-term alternative to cigarettes (186-189). Data from 1,489 current adult smokers reported they discontinued using ECs mostly because the experience was not close enough to smoking and cravings were not reduced (189). Later-generation EC designs have attempted to address these issues through use of higher power, improved coil heating elements, and nicotine delivery without irritation (190).

Pharmacokinetic clinical trials are often used to investigate safety, nicotine delivery, and acceptability of ECs. These studies assess the likelihood of product-related adverse effects, describe the concentration-time profile for nicotine, and provide insights into the relationship between nicotine concentration and specific responses (e.g., urge for product, craving, and product liking/satisfaction). Pharmacokinetic endpoints estimated from these studies can be used to make comparisons between different EC products and with other product classes (e.g., combustible cigarettes and nicotine replacement therapies (NRTs)).

The average maximum concentration $\left(\mathrm{C}_{\max }\right)$ of nicotine with smoking is $10-21 \mathrm{ng} / \mathrm{mL}$, depending on the "tar" and nicotine yield of the cigarette (191-197). For NRT, $\mathrm{C}_{\max }$ is generally in the range $2-18 \mathrm{ng} / \mathrm{mL}$, depending on the 
nicotine concentration, type of device, and usage (198-200). Early pharmacokinetic studies using first-generation (cig-a-like) ECs with similar nicotine concentrations to NRT and a fixed puffing protocol for 5 min reported $\mathrm{C}_{\max }$ of 1.3-17 ng/mL (201-203). Second- and third-generation ECs improved nicotine delivery under similar conditions $\left(\mathrm{C}_{\max } 4-12.8 \mathrm{ng} / \mathrm{mL}\right)(100,201,204-206)$. Fourth-generation ECs using protonated nicotine have substantially lessened or even closed the nicotine bioavailability gap between cigarette smoke and EC vapour $(139,207,208)$. For instance, EBAJEMITO et al. (139) assessed nicotine delivery in participants who switched from smoking to vaping at several nicotine concentrations and with and without nicotine salts. The $\mathrm{C}_{\max }$ for e-liquid $(30 \mathrm{mg} / \mathrm{mL}$ nicotine) containing nicotine salt reached $14.1 \mathrm{ng} / \mathrm{mL}$ compared with $14.5 \mathrm{ng} / \mathrm{mL}$ for a 7-mg ISO "tar" cigarette. Another study conducted by O'CONNELL et al. (140) found a similar delivery profile for an EC containing a 40-mg nicotine lactate e-liquid formulation.

Product use also has an impact on nicotine delivery, with more experienced users achieving greater nicotine concentrations $(209,210)$. Finally, satisfaction with e-liquid formulations containing nicotine might be limited by sensorial aspects, as nicotine content and flavour strength seem to correlate with harshness or throat irritation and perception of bitterness (51). Together, these findings could explain the results from some studies suggesting that ECs are more successful than NRT in providing smokers a satisfactory alternative to cigarettes $(211,212)$. Table 3 summarises some of the findings from Pharmacokinetic studies according to EC type/generation.

\subsubsection{Biomarkers of exposure}

Biomarkers of exposure (BoEs) to cigarette smoke have long been used to assess the effects of tobacco consumption. Exposure to nicotine and aerosol toxicants is assessed by measurement of nicotine metabolites and toxicant concentrations in biological samples, most often in urine. In most EC studies, reductions in toxicant exposure are benchmarked against cigarette smoke and, therefore, the panels of BoEs are based on compounds known to be present in cigarette smoke. The FDA workshop identified the measurement of BoE for nicotine and 19 HPHCs, including nicotine and tobacco alkaloids, carbon monoxide, tobacco-specific nitrosamines, polycyclic aromatic hydrocarbons, volatile organic compounds, carcinogenic aromatic amines, and metals (213).

Multiple studies have assessed changes in BoEs after study participants' exposure to EC aerosol (Table 4). In interventional studies, which are generally randomised studies, participants are assigned to use a small number of products or different categories of products (214-217). Observational studies are often larger and assess products chosen or already used by the consumers (218-221). Interpretation and extrapolation of results from some randomised studies has been hindered by lack of appropriate descriptions of products used in the study (222), exclusion of appropriate controls to provide context $(215,217)$, and small sample sizes that limit generalizability $(216,222)$.
Some of the larger and longer-term studies provide a clearer picture. In a switching study of 153 smokers who switched from cigarettes to a cig-a-like EC or nicotine gum, ROUND et al. (223) assessed a comprehensive panel of BoEs. They found significant reductions across all BoEs in the EC arm, while nicotine levels were higher than in those using nicotine gum. A cross-sectional study by SHAHAB et al. (221) compared exposure to carcinogens and toxicants in long-term smokers with those in former smokers who had used ECs or NRT exclusively for at least 6 months and in dual users who had smoked combustible cigarettes plus used ECs or NRT for at least 6 months. The sample size was 181 , with $36-37$ in each group. Nicotine intake was similar for all study groups, but BoE concentrations were significantly lower in the exclusive NRT and EC groups than in any group including smokers. NNAL, a BoE associated with lung cancer, was lower in the EC only group than in all other groups. WALELE et al. (224) performed a 2-year ambulatory study as continuation of a 12-week residential study in which smokers had switched to a cig-a-like EC or continued smoking (225). They compared changes in BoE to acrolein, benzene, and NNK over time in 209 participants. BoE concentrations among smokers who switched to the EC fell substantially within roughly 1 month and remained at similar levels over 2 years. A very large cross-sectional biomarker analysis based on the US PATH observational study, with biomarker data for more than 5,000 participants classified as smokers, EC users, dual users, and never tobacco users showed lower BoE levels of tobacco-specific nitrosamines in the EC users group than in smokers (219). Exposure to metals, such as beryllium, cadmium, and lead, were lower in EC users than in cigarette smokers but higher than in never tobacco users. There were no differences across groups for cobalt, manganese, or thallium. All seven BoEs for polycyclic aromatic hydrocarbons and 17 of 20 volatile organic compounds BoEs were significantly higher in smokers than in the other groups. In a comparison of exclusive smokers and exclusive EC users, levels of exposure to total NNAL and carbon monoxide were significantly lower in vapers, including below the level of detection in $30 \%$ of cases (206). There is also some evidence of reversibility of effects in ex-smokers who had switched entirely to ECs for at least 2 months (226). GONIEWICZ et al. (215) evaluated seven nicotine metabolites and 17 BoEs in urine samples of 20 cigarette smokers before and after switching exclusively to ECs for 2 weeks and found significantly reduced concentrations of 12 of the biomarkers following switching.

Large observational studies are more representative in terms of demographics and the EC category $(219,227)$. However, assessment of usage patterns can be complex in ambulatory studies yet not reflect real-world use in confinement settings where product use can be controlled. In all studies, especially large observational studies, the numbers of BoEs that may be assessed might be hampered by resource availability.

Overall, measurement of BoEs appears to reflect toxicant delivery differences observed in chemistry assessments. 


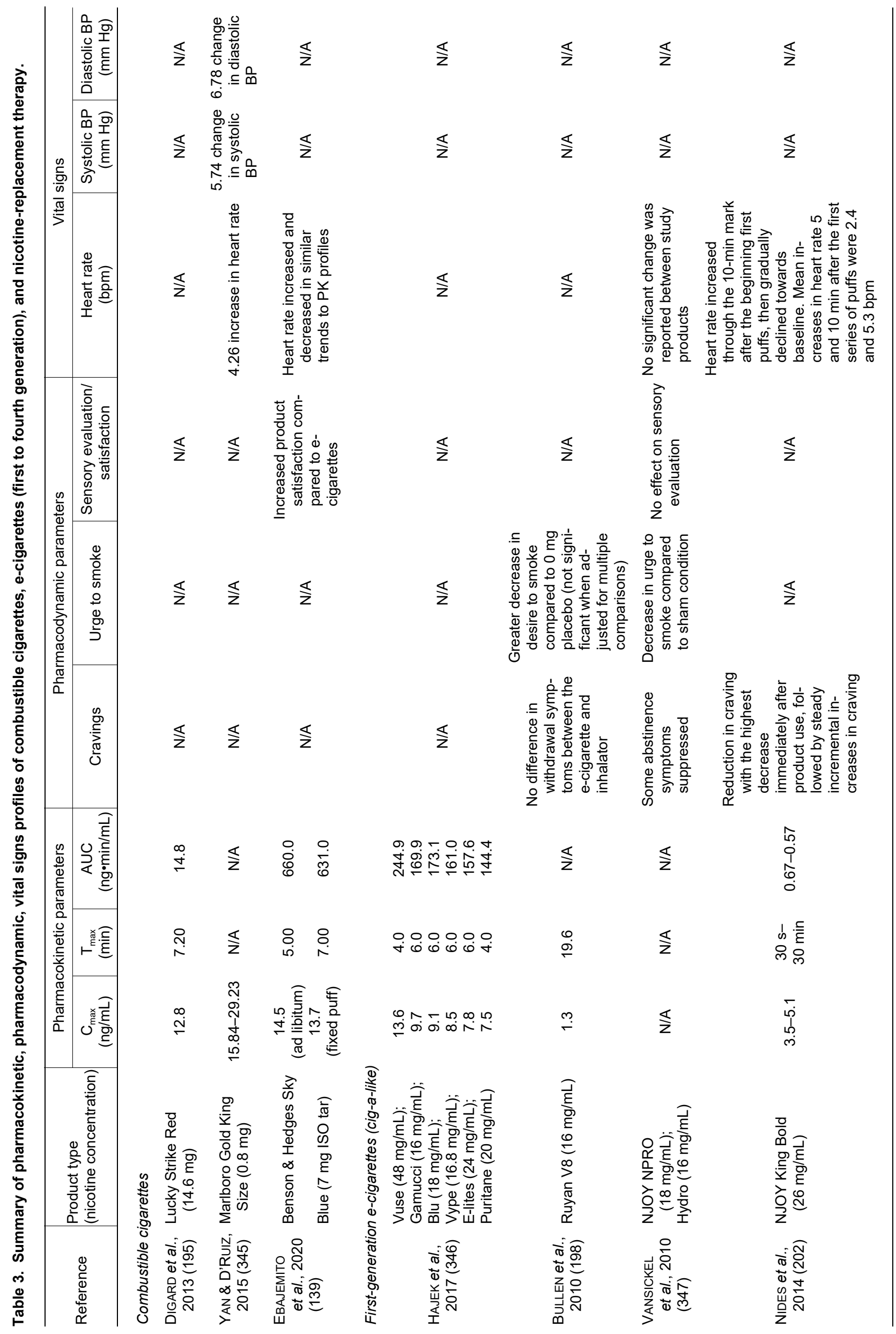




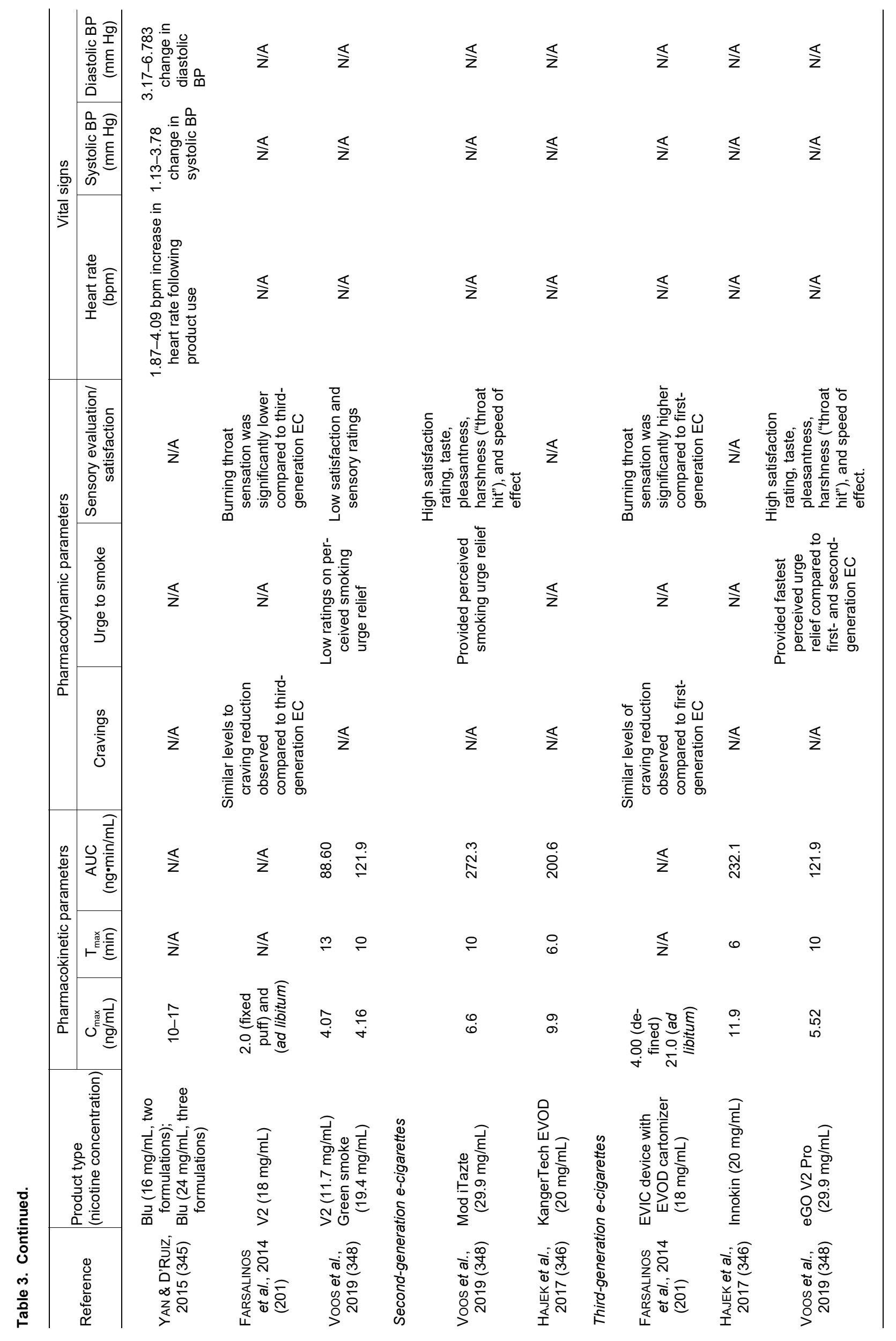




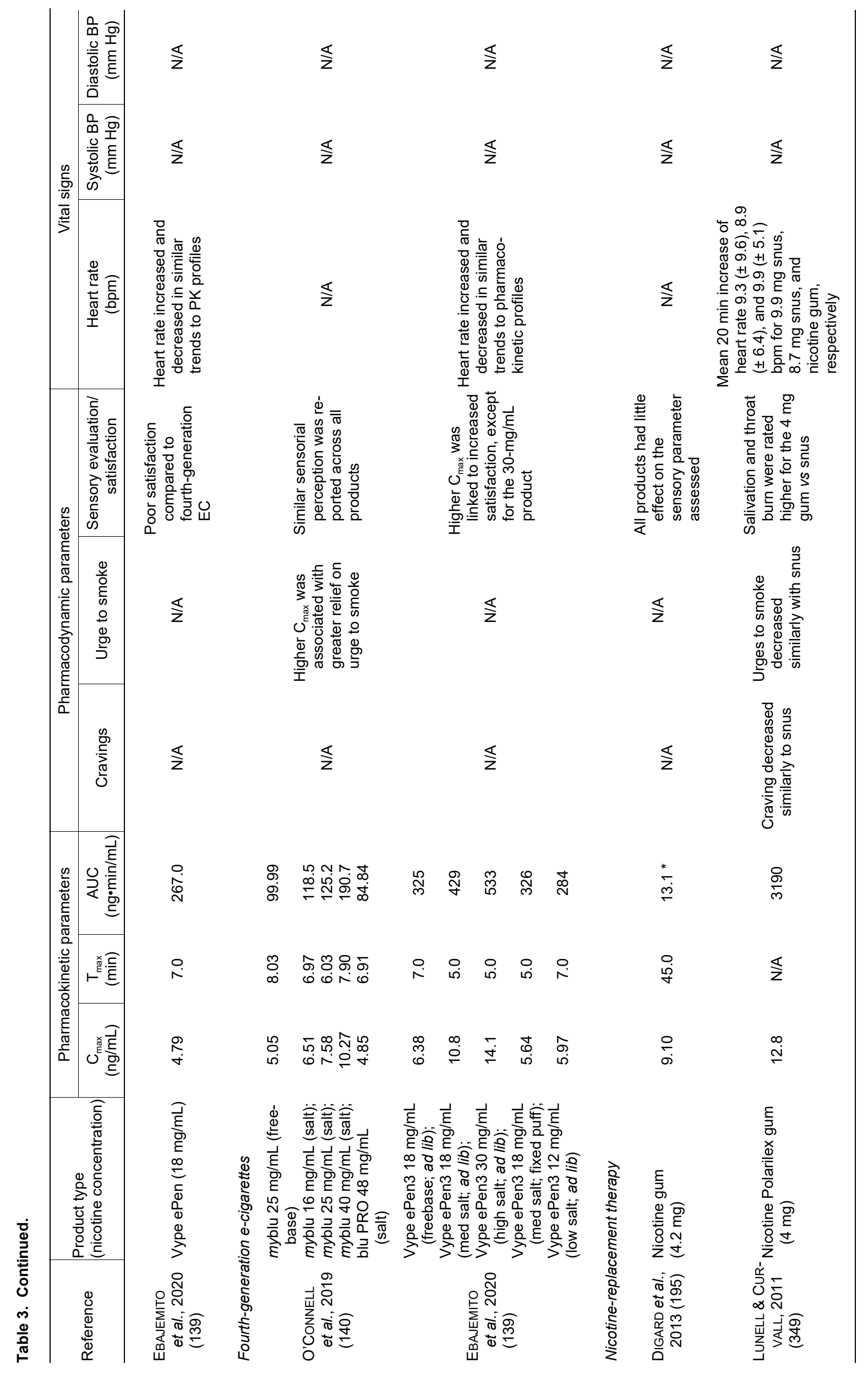




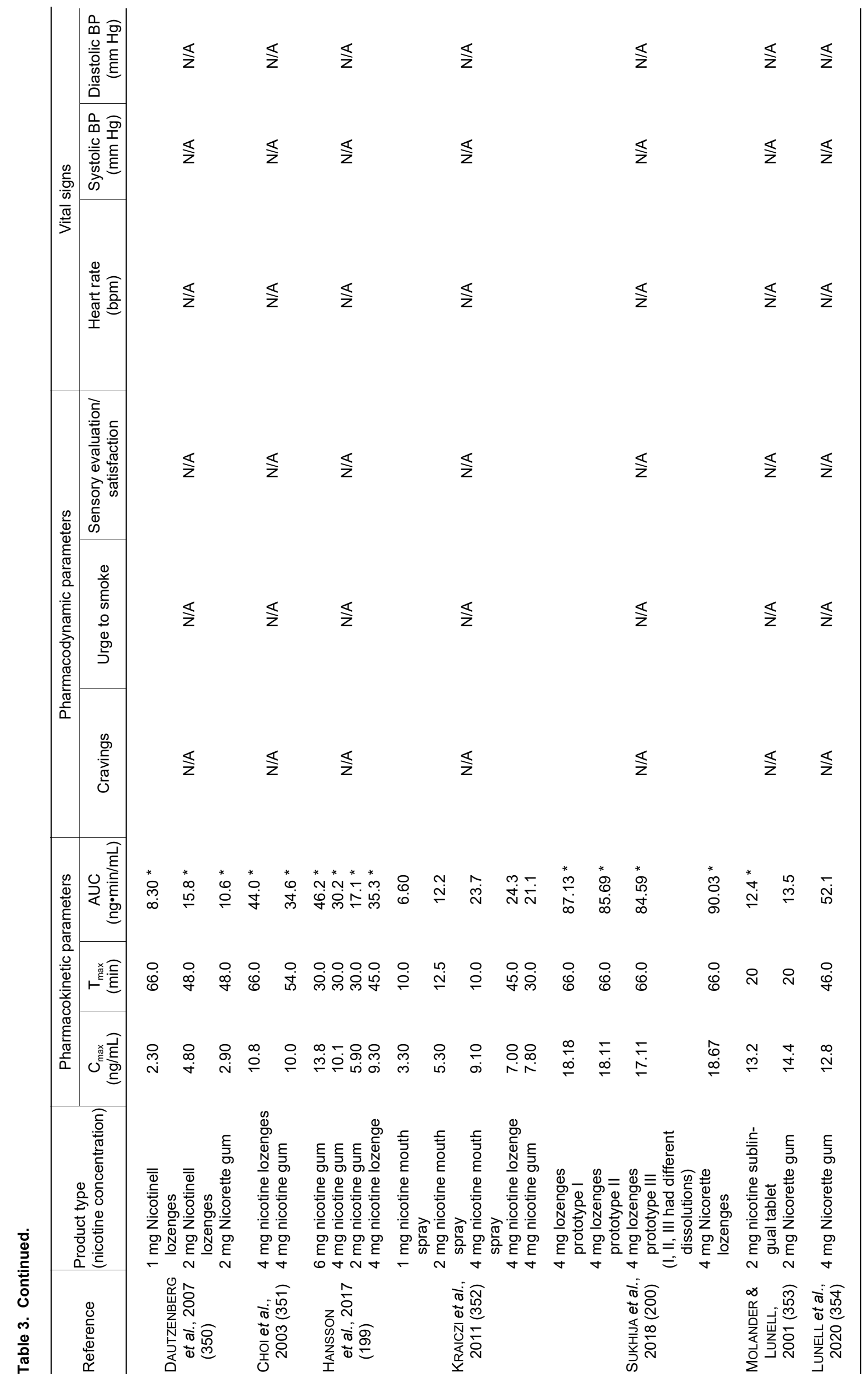




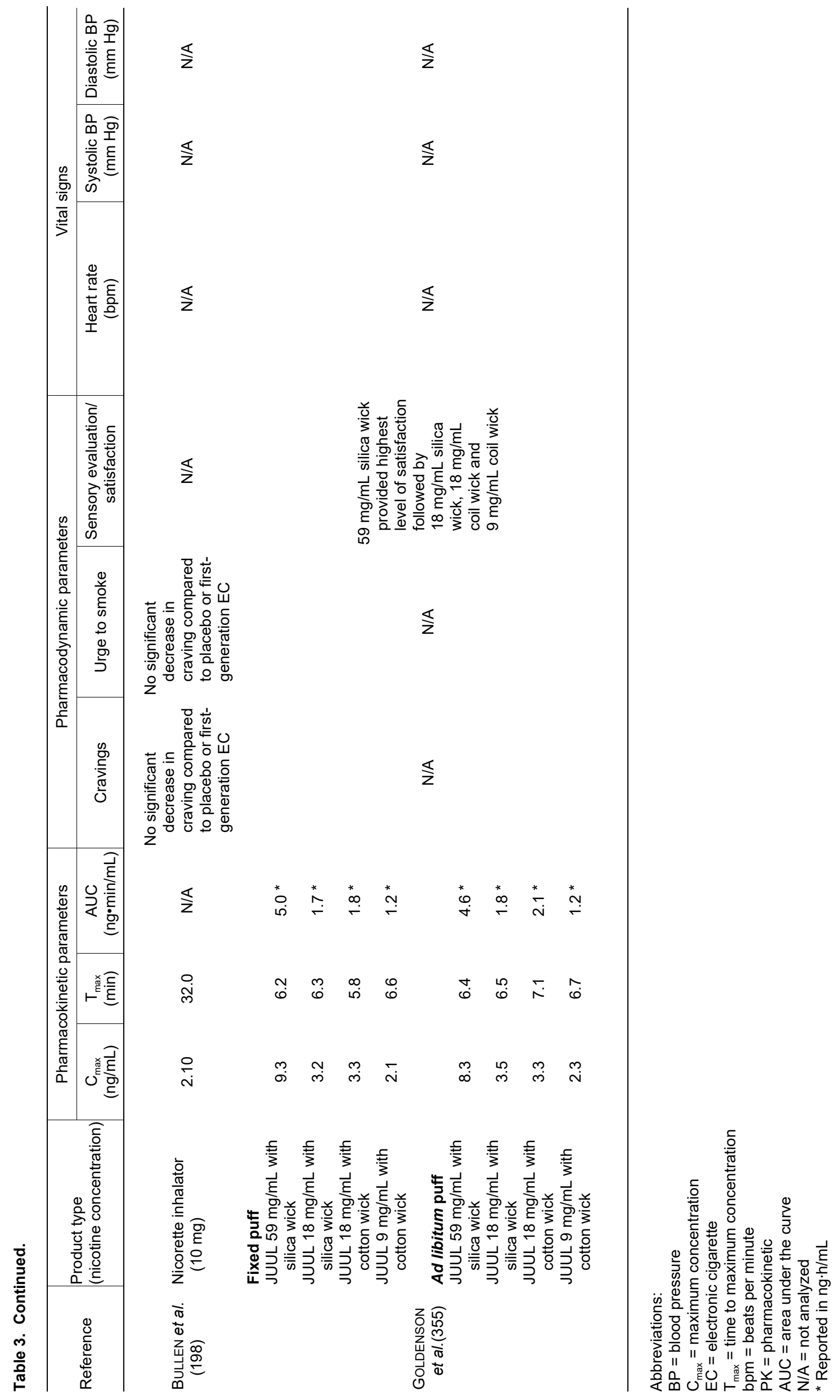




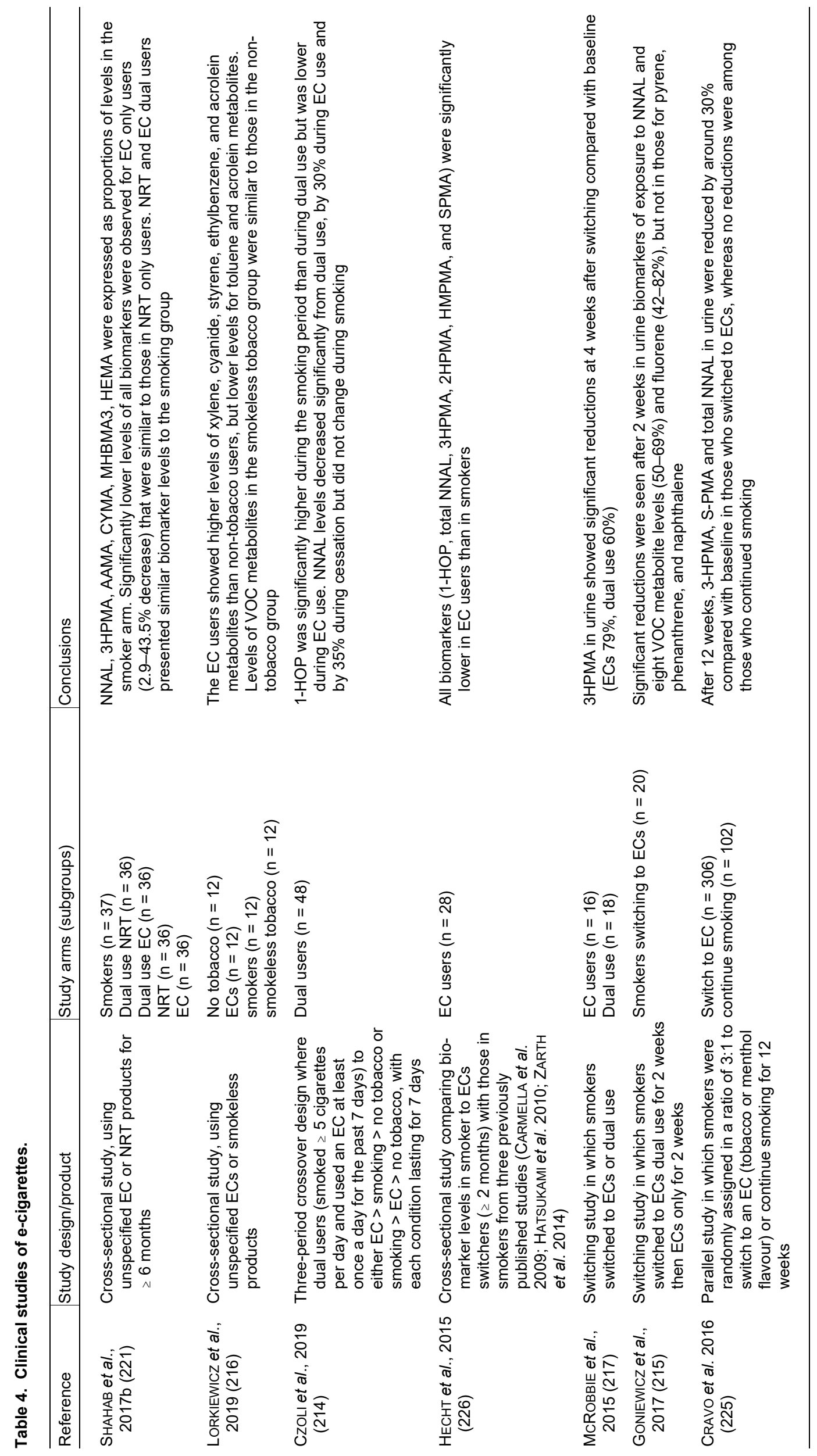




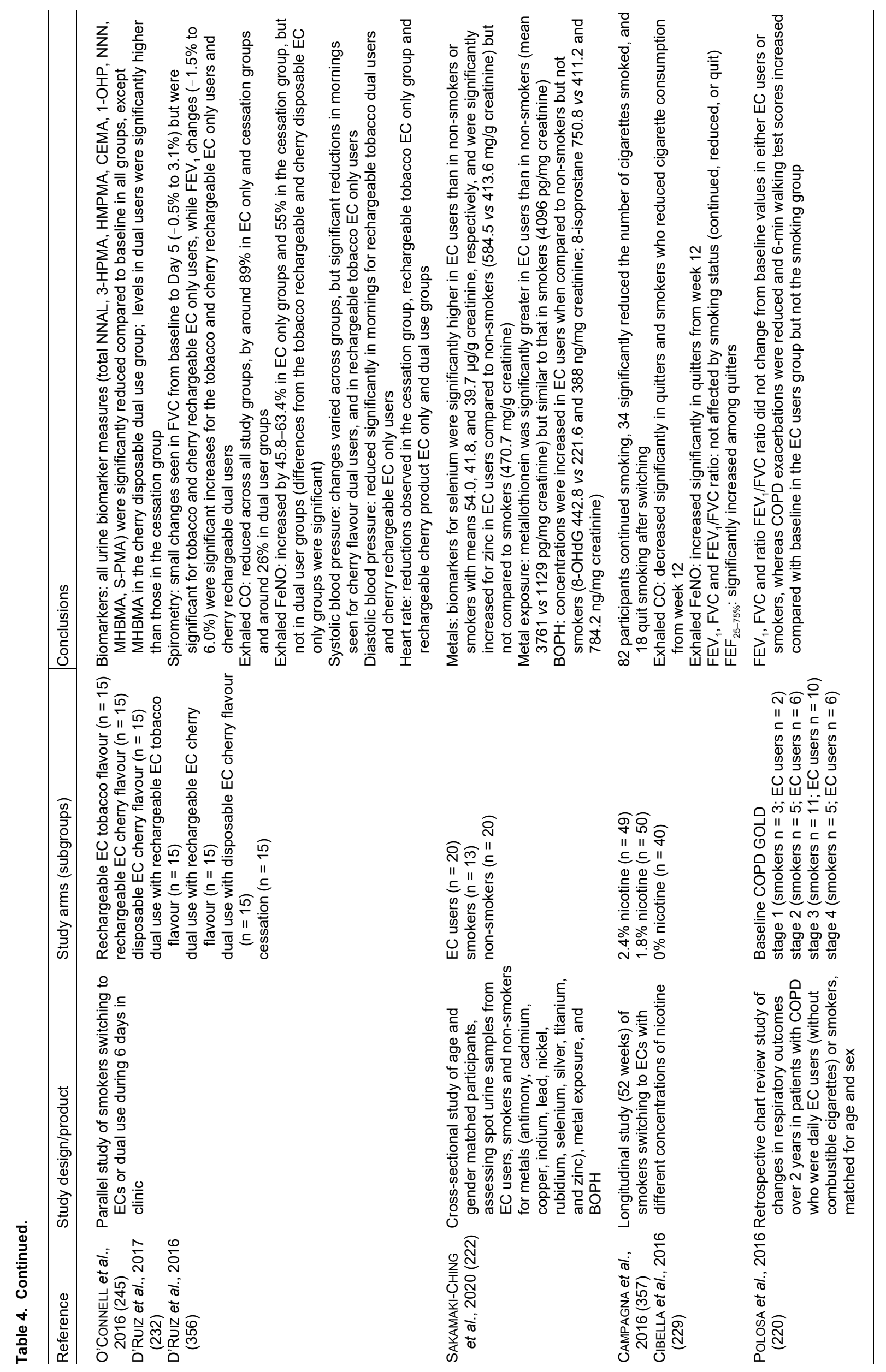




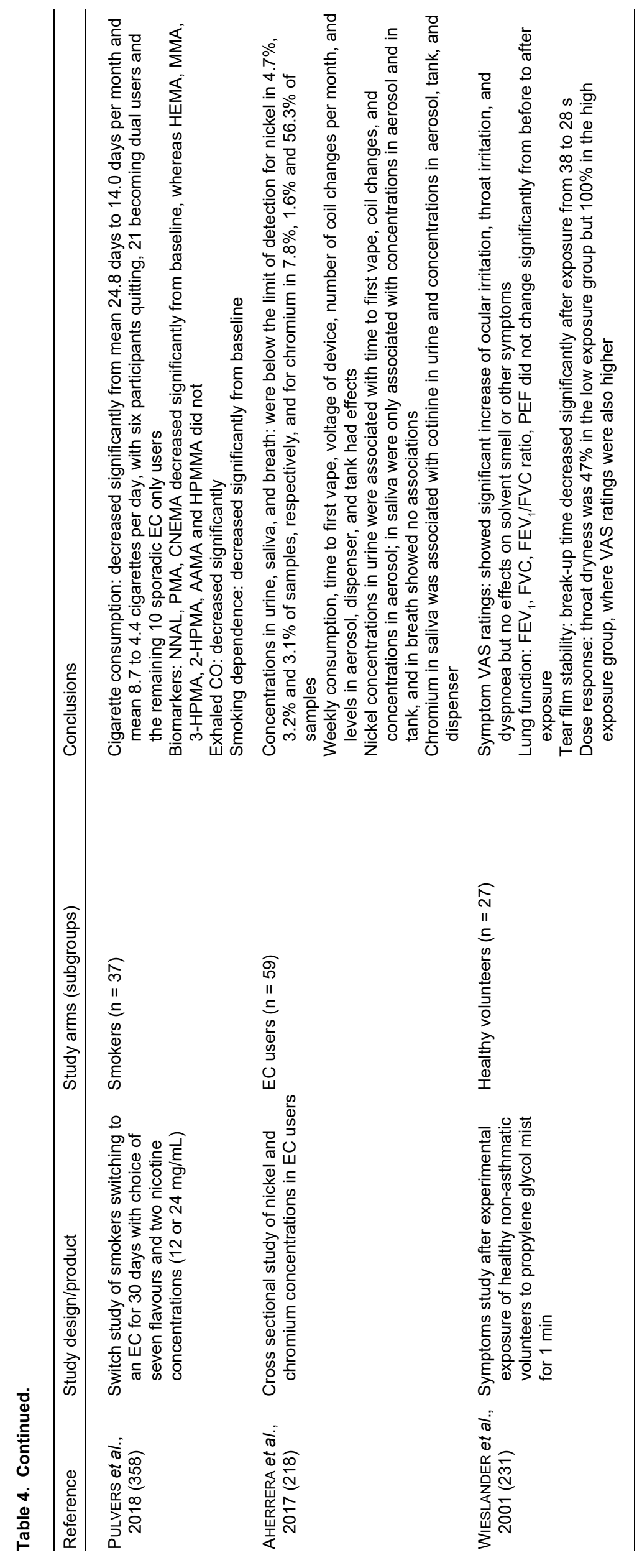




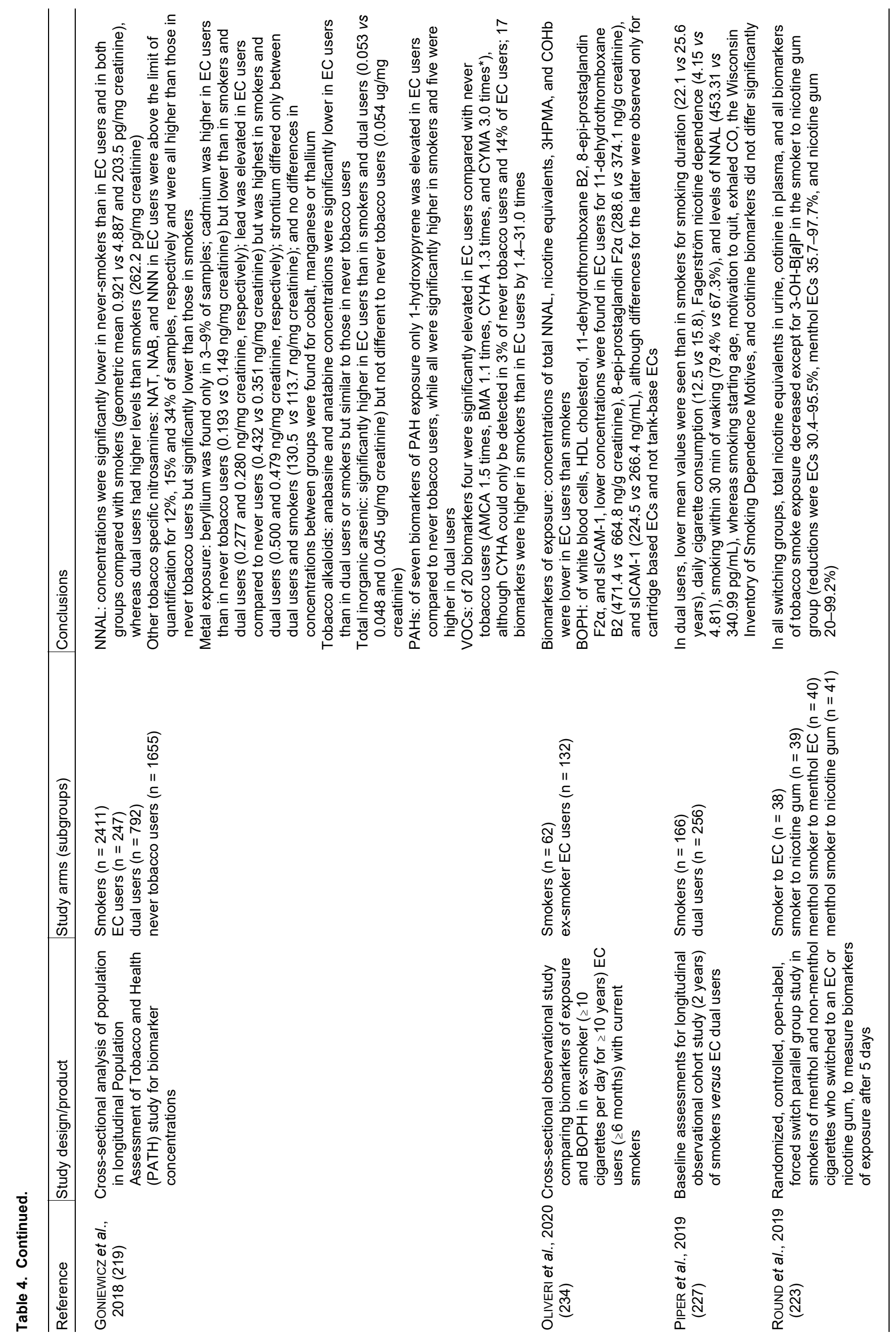




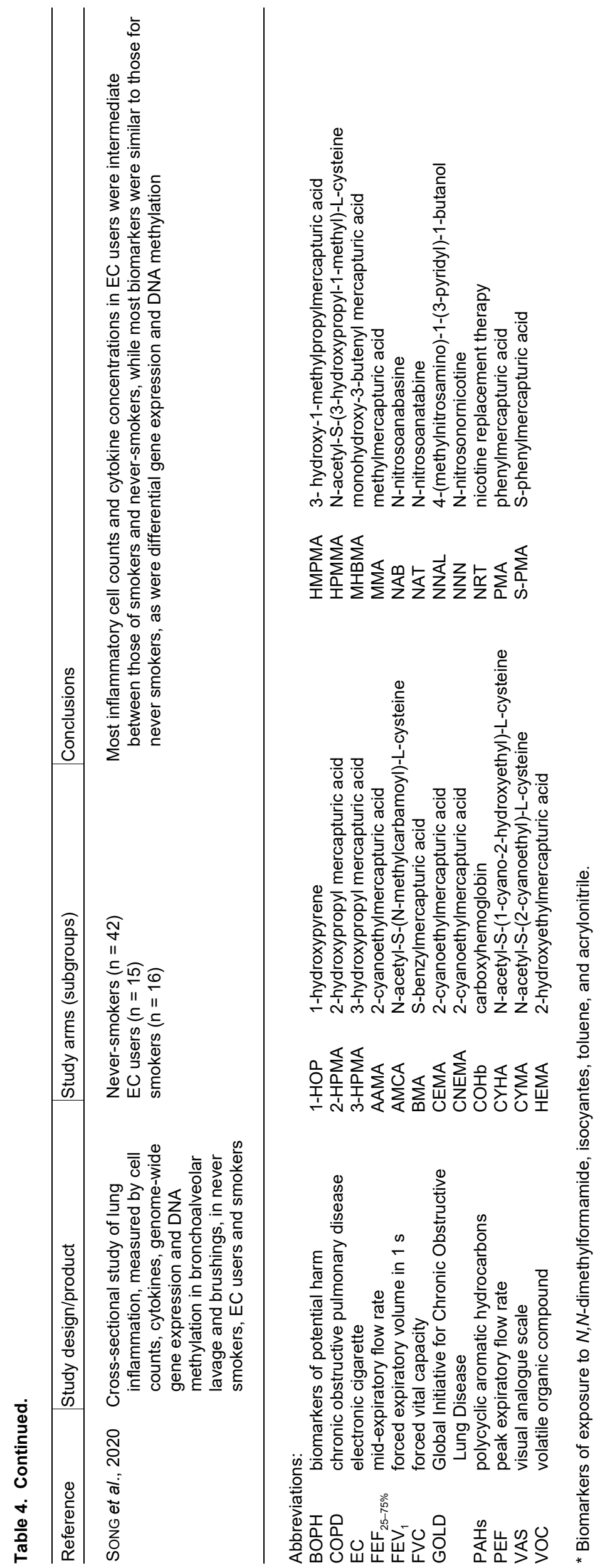




\subsubsection{Biomarkers of potential harm}

Disease-associated biomarkers known as biomarkers of potential harm (BoPHs) could provide valuable information characterising the risk of tobacco products. BoPHs were defined by the Institute of Medicine as the "measurement of an effect due to exposure; these include early biological effects, alterations in morphology, structure, or function, and clinical symptoms consistent with harm; also includes "preclinical changes" (11). CHANG et al. (228) describe in detail $\mathrm{BoPH}$ in the context of tobacco product assessment as well as the types of BoPHs identified during this FDA public workshop. Table 4 also summarizes results from studies evaluating biomarkers of potential harm.

Usability of BoPHs to characterize risk associated with ECs is underpinned by reversibility of smoking harm achieved through complete cessation of tobacco products. Most clinical studies compare disease-associated BoPHs in vapers against those in smokers and a cessation group used as a reference. Many BoPHs are not smoking specific or even disease specific, so contextualization against effects observed in cessation groups is crucial to evaluate validity and biological relevance.

The same shortcomings observed in BoE studies are often found in BoPH studies but are often accentuated due to the non-specific nature of the biomarkers, leading to smaller effect sizes, i.e. requiring larger sample sizes. Other important factors to consider when designing these types of studies is to ensure their time frame is long enough for assessment of biomarker reversibility, as many BoPHs may take months to reveal significant changes.

Few BoPH studies have been done in EC users, and most are cross-sectional and compare self-reported vapers with smokers. No standard panel of BoPHs has been established, but most studies focus on end points related to cancer, cardiovascular disease, the respiratory system, oxidative stress, and inflammation.

Spirometry measurements of lung function, like forced expiratory volume in $1 \mathrm{~s}\left(\mathrm{FEV}_{1}\right)$ and forced vital capacity (FVC), have been used as surrogate end points for COPD. Most studies comparing $\mathrm{FEV}_{1}, \mathrm{FVC}$, or ratio of $\mathrm{FEV}_{1}$ to FVC in healthy vapers and smokers have shown no significant differences (229-231). CiBELla et al. (229) did, however, report significant increases of forced expiratory flow at $25-75 \%$ of FVC as well as fractional exhaled nitric oxide. D'RuIZ et al. (232) observed some significant changes for $\mathrm{FEV}_{1}$ and FVC 5 days after smokers switched to an EC in a clinical setting, but, unexpectedly, saw no change in the cessation group.

For cancer, besides BoEs like NNAL and volatile organic compounds, studies overwhelmingly present lower levels of BoPHs in vapers than in smokers but higher than in cessation groups. Other BoPHs, such as the inflammation biomaker 8-epi-prostaglandin $\mathrm{F}_{2 \alpha}$, have also been associated with lung cancer (233), and levels are significantly lower in exclusive vapers than in smokers (234). Similarly, a crosssectional study by SoNG et al. (235) concluded that most inflammatory BoPHs and cytokine concentrations in EC users were intermediate between those of smokers and nonsmokers. In contrast, levels of 8-hydroxy-2'-deoxyguanosine, a biomarker for oxidative stress (236), have been reported to be higher in EC users than in non-smokers and not different to those in smokers (222).

Improvements in vascular health markers have been reported in smokers who switched to ECs for 1 month, particularly among women (237). Various BoPHs, such as 8-isoprostane (238) and 11-dehydro-thromboxane $\mathrm{B}_{2}$ (239), have been associated with cardiovascular disease. Differences have been reported between smokers and vapers for 11-dehydro-thromboxane $\mathrm{B}_{2}$ (234) but not for 8 -isoprostane (222). Some reports have pointed to EC use as a potential cause of endothelial dysfunction (240) and heart rate variability $(241,242)$. In the PATH study, the association between vaping and heart failure was investigated, and the researchers concluded that respondents suffering heart failure had higher odds of being dual users than exclusive EC users (243). A comparison of vapers and/or dual users' odds of suffering heart failure against those in smokers or never smokers would be of interest.

Most clinical studies assessing ECs have been small and with designs that limit interpretation and generalizability of conclusions. Studies should include appropriate controls, such as a cessation group (including people using NRT), as recommended by the Institute of Medicine (11), to provide context and determine the relevance of changes in relation to the time frame of the study. Much larger and longer-term studies assessing real-world behaviours are needed to fully understand the effects of switching to ECs, as the changes to health might take much longer to manifest than those traceable by other biomarkers in the short term (244).

\subsubsection{Dual use}

Whether dual use of combustible cigarettes and ECs provides beneficial changes to the harmful effects of smoking remains unclear. For instance, 5 days after switching half of cigarette consumption to ECs, slight decreases (7-38\%) were seen in eight of nine urinary BoE, but concentrations of nicotine equivalents increased by $1-20 \%$ (245). In a 7-day switching study, only small reductions in BoEs were found in dual users, with much more substantial reductions seen in exclusive vapers or non-users of any tobacco product (214). In long-term dual users, SHAHAB et al. (221) found a similar pattern of increased concentrations of nicotine and nicotine equivalent, with little to no reduction in biomarkers of exposure. In contrast, a large study in long-term users by GoNIEWICZ et al. (219), in which average cigarette consumption in a dual use group was 15.1 and in a smoking group was 15.4 , found BoEs in the group of dual users to be higher than in exclusive smokers, with NNAL on average $23 \%$ higher in dual users. However, this study showed a doseresponse relationship, with $\mathrm{BoE}$ levels being significantly higher in dual users who smoked daily than in those who smoked occasionally, independently of whether they vaped occasionally or daily.

\subsubsection{Pregnancy and reproductive toxicology}

Animal studies have suggested that nicotine has potential teratogenic effects, although the evidence for harmful effects on fetal development and birth outcomes in humans 
remains unclear (246). NRT is recommended for consideration in pregnant women who have been unable to quit smoking by behavioural changes $(247,248)$, but increased metabolism of nicotine during pregnancy might affect adherence to nicotine therapy $(246,249,250)$. The relative risks of vaping during pregnancy are untested in randomised trials (246), and most data are descriptive and derived from surveys.

Physicians are an important source of information about the risks of nicotine and pregnancy, and women are likely to view them as being able to provide similarly reliable information about vaping. However, without objective data and with developments in devices likely outstripping published evidence, providing objective advice can be difficult (251). Women who use ECs while pregnant seem most commonly to believe that they are less harmful to mothers and babies than combustible cigarettes (although not completely harmless) and that use will help with quitting smoking $(26,252,253)$. However, social stigma is viewed as a barrier to EC use in public (252).

Some argue that as the toxicology of ECs is similar to that of NRT $(223,254)$ it is likely to be a safer alternative to smoking in pregnant women. However, the amount of nicotine consumed via ECs could be as high as that consumed via combustible cigarettes $(139,207,208,255)$ and higher than received from NRT products and dose-effect data are unavailable.

Much more formal and standardised research is needed in this area, particularly on the safety of different nicotine levels, the risks of nicotine dependence among pregnant women who want to quit smoking but have been unable to, and adherence to prevent a return to smoking.

\subsubsection{Mental health}

Smoking prevalence is higher among people with mental health illnesses and conditions than in the general population, particularly those with severe mental illness or distress $(256,257)$. Rates of ever having tried vaping also seem to be higher (258), particularly among people with schizoaffective disorders and bipolar disorder (26). Among smokers with severe mental illness, strong associations were found with EC use, education level, and wish to quit smoking (quit attempt in the previous 6 months) (259).

Misconceptions among health professionals that smokers with severe mental illness are either not willing to quit or will suffer worsening symptoms as a result of doing so is hindering provision of adequate quitting options $(260,261)$. As well as NRT and supportive behavioural counselling, ASH (262) suggests that ECs could be considered for this subgroup of the population.

Formal studies are needed in this area to clarify the role that ECs could play in tobacco harm reduction.

\subsubsection{Oral health}

Tobacco consumption is associated with oral diseases (263), but whether ECs lessen or contribute to the burden is unclear. A study investigating numerous end points (plaque index, bleeding on probing, probing depth, clinical attachment loss, number of missing teeth, and gingival crevicular fluid levels of pro-inflammatory cytokine) found consistent significant differences between smokers and never-smokers, whereas there was no difference between the vapers and never smokers (264). However, in a pilot study, some biomarkers associated with antimicrobial activity and inflammation were increased in EC users compared with in never smokers (265). The findings from these two studies appear to synthesize the conclusion from a systematic review, in which 99 publications investigating ECs and oral health (mouth, throat, periodontal, dental, cytotoxic/genotoxic/oncological, oral microbiome, and traumatic/accidental injury) were assessed (266). Cosmetically, ECs lead to less tooth enamel staining than cigarette smoke. This difference might have social benefits to former smokers who have switched to ECs $(267,268)$.

Overall, the evidence suggested that while switching from smoking to ECs mitigates some smoking-induced symptoms, a wide range of oral issues could be associated with vaping. However, most of the evidence in the area is weak, with studies so far not specifically designed to assess oral health outcomes.

\section{PERCEPTIONS AND BEHAVIOURS - USER DEMO- GRAPHICS}

Perception of risks associated with ECs can be an important determinant of product use (269). Misconceptions about the harmfulness of ECs versus combustible cigarettes seems to be a growing reason among smokers to reject them $(38,59)$. In this section we review studies investigating perceptions about ECs and nicotine use behaviours associated with those perceptions.

\subsection{Consumer perception studies}

A survey conducted in six European countries suggested that among respondents who were aware of ECs in 2016, $58.5 \%$ perceived them to be as risky or of higher risk than cigarettes, increasing to $61.8 \%$ in 2018 (270). Only around a quarter of respondents perceived reduced risk with ECs (28.6\% and $28.4 \%$ in 2016 and 2018 , respectively). A similar increasing trend in perceived high risk of ECs was seen in a US survey, where $11.5 \%$ (95\% CI 10.0-13.2\%) of adults viewed them to be as harmful as smoking in 2012 but $36.4 \%$ (35.1-37.7\%) did so in 2017 (271). The importance of risk perception amongst vapers is clear, as shown in another study where dual users who perceived ECs as being less harmful than smoking were more likely to be exclusive vapers after 1 year than those who did not perceive them as less harmful $(7.5 \%$ vs $2.7 \%$, adjusted odds ratio $2.9,95 \%$ CI 1.7-4.8) (269). It is worth noting that, according to an analysis based on the PATH study, the proportion of US adults perceiving e-cigarettes as harmful or more than cigarettes steadily increased from $53.7 \%$ to $72.7 \%$ between 2014 and 2016 (272). Other perceptions, such as product addictiveness, social acceptability, potential to harm others, and environmental impact, may also affect product choice. The most common reasons to use ECs among adults and youth in one survey were smoking cessation and novelty, respectively (273). In another study, the two main reasons for using ECs by current and former smokers were perceptions that they could be helpful to quit 
and were less harmful than smoking (274). In a Europewide survey in 2014, the main reasons given for use of ECs were to stop or reduce smoking and being able to use them in places where smoking was banned (275), while in 2020, reducing tobacco consumption was still the main reason for using ECs followed by believing they were less harmful than cigarettes (14). In the UK, ASH (276) reported that the three main reasons for vaping were as an aid to quit smoking, remain abstinent from smoking, and save money.

\subsection{Switching to ECs and abuse liability}

One criticism of ECs is their inefficacy for sustaining exclusive vaping and propensity to facilitate dual usage (277). These views, in part at least, were based on early studies of products providing low nicotine delivery and hence low user satisfaction (278). While ECs are not marketed as smoking cessation products, a large 1-year study in the UK showed that the smoking abstinence rate among people who switched to later-generation ECs was roughly double that among those who switched completely to NRT (212).

For smokers attempting to quit smoking, higher reward from ECs could help them to completely transition away from combustible cigarettes, as frequency of use of vaping products has been positively associated with becoming a former smoker with quit durations of 2-6 years $(188,279)$. However, increases in nicotine exposure could raise concerns about the abuse liability of ECs.

Abuse liability is the likelihood of engaging in persistent and problematic use of a substance that will lead to undesirable consequences (280). High nicotine delivery via ECs could increase the risk of abuse liability. However, if ECs can provide a viable alternative to cigarettes, they might have a public health benefit $(24,281,282)$ and some degree of abuse liability might be acceptable $(283,284)$. A standard methodology has been established to assess the abuse liability of pharmaceuticals (285) and is largely adaptable for tobacco products $(280,286)$. This type of study is likely to be most relevant in countries where high concentrations of nicotine are allowed in e-liquids, such as the USA (287). In a prospective direct comparison of ECs with smoking and NRT (nicotine gum), STILES et al. (96) found that while their study showed ECs probably had some degree of abuse liability, it was much closer to that of NRT than to combustible cigarettes. This conclusion was reinforced at category level by the analyses of symptoms of dependence collected through national US surveys, the Population Assessment of Tobacco and Health (PATH) $(288,289)$ and the National Adult Tobacco Survey (290). Both identified dependence symptoms in EC users but to a substantially lesser degree than in smokers. Another retrospective study, based on the International Tobacco Control database, investigated differences in symptoms of dependence between vaping and non-vaping ex-smokers in four countries (USA, UK, Australia, and Canada) (291). Vapers were more likely to perceive themselves as very addicted to smoking, but at the same time to feel more confident about remaining abstinent from smoking and to experience fewer urges to smoke than non-vapers.

\subsection{Vapers demographics - uptake by young people and potential gateway effects}

Vaping products have experienced an increase in popularity all around the World. In Europe estimated vaping prevalence increased from $1.5 \%$ in 2014 to $1.8 \%$ in 2017 (292). Ever use ranged widely from $5.5 \%$ to $56.5 \%$ and was highest in younger age groups, with studies reporting consumption from respondents ranging from 10-24 years old. In the USA a larger study with 158,626 participants (293) reported ever use of vaping products of $14.8 \%$, $12.8 \%, 9.4 \%, 7.0 \%, 2.3 \%$ in the age groups $18-24,25-34$, $35-44,45-64, \geq 65$ years, respectively, while regular use (use in $\geq 20$ of the previous 30 days) was more comparable across the same age groups $(1.3 \%, 1.3 \%, 1.2 \%, 1.0 \%$, $0.4 \%$, respectively). In the UK, where uptake of ECs has been high, ever use in 2019 was estimated to be $16.5 \%$, $20.1 \%, 12.3 \%, 10.8 \%, 5.2 \%$ in the age groups $16-24$, $25-34,35-49,50-59, \geq 60$ years and $3.3 \%, 9.2 \%, 7.3 \%$, $7.1 \%, 3.0 \%$, respectively were regular users (294). Prevalence of vaping is generally lower among women than men, as for smoking $(292,295)$. Most vapers smoke or have smoked in the past. Vapers without smoking history account for a very small proportion of all vapers $(26,292$, 294, 296-298).

Youth EC initiation has taken centre stage in the EC scientific world since the US Surgeon General declared EC use among youth "an epidemic" (299). Public Health England's (PHE) annual review estimated that EC prevalence with use of once per week or less was around 5\% among 11-18-year olds, but varied by age. Prevalence among 11 -year olds was $1 \%$ up to $5 \%$ among 15 year olds (26). A large 2017 review of surveys involving 60,000 children aged 11-16 years in the UK suggested that the prevalence of more frequent regular use (at least weekly) was $3 \%$, even though proportions of $7-18 \%$ had ever tried ECs (300). Most young people regularly using ECs were already smokers, and among never smokers, only $0.1-0.5 \%$ regularly used ECs. In the US, uptake seems to be higher, with $13.1 \%$ of middle-school and high-school students nationally reported to be current EC users in 2015-2017, although most users $(76.7 \%)$ also used at least one other tobacco product (301). However, smoking initiation rates among youth in the US reached the lowest recorded rate of $2.29 \%$ in 2018 (302), and similar patterns have been observed across European countries where ECs are widely available (303). Friend or caregiver smoking seems to increase the likelihood of children trying ECs, as does lower socioeconomic status $(304,305)$. Differing perceptions of risks have been found across subgroups of young people (e.g., classified by ethnic origin or sexuality) (306), but little work has been done on social factors (307), and this area needs greater attention.

Gateway theory originates in the use of a psychoactive drug being viewed as increasing the likelihood of using further drugs. When applied to vaping, it describes changes in a biological and/or behavioural pathway seen with use of a lower-risk product, such as an EC, increasing the risk of smoking combustible cigarettes for a higher reward (308). This theory has been cited to support the banning or restriction of access to EC products and liquids containing nicotine, for instance in Australia (309), but it is not backed 
up by reliable evidence $(29,310,311)$. Application of such policies risk denying adult smokers the opportunity to switch to ECs and might increase relapse to smoking or smoking initiation (312). KASZA et al. (313) analysed the US PATH study database from 2013 to 2016 and found that ever users of ECs aged 12-17 years were more likely to have smoked in the previous 30 days at follow-up (adjusted odds ratio 3.4, 95\% CI 2.4-4.7\%). However, the likelihood of smoking was increased by use of any other tobacco product, including hookahs and smokeless tobacco. EC use was similarly increased by smoking (adjusted odds ratio $2.9,95 \%$ CI $2.1-4.0 \%$ ). Thus, changing to smoking could be explained by youth experimentation and propensity to risk $(314,315)$. Concurrent use of nicotine products has also been reported by AUF et al. (316). However, national surveys do not suggest any gateway effect. Studies from the USA $(288,302,317)$, UK, New Zealand (318) and Canada (319), have concluded that (i) smoking usually precedes vaping; (ii) regular vaping is rare amongst never smokers; (iii) not all adolescent vapers used nicotine and dependence was lower than for smokers; (iv) since vaping has been introduced, smoking rates have continued to decline. The Canadian study concluded, "when it comes to smoking cigarettes, very few smoked cigarettes in addition to vaping and fewer still believe they started smoking after they had started vaping" (319).

\subsection{Use behaviour studies}

Consumer use behaviour studies can provide an understanding of puffing topography, potential nicotine uptake, and variability in patterns of usage between different EC types and users $(37,320)$. The data are crucial for understanding how consumers use products and play a key part in setting the scientific framework for assessing risk potential. EC use differs significantly from cigarette smoking, although more information is needed on topography, perceptions, and behaviours. The US FDA recommends conducting "actual use" studies in "real-world conditions" within their Modified Risk Tobacco Product Application guidelines (73).

Consumer use behaviour studies should adhere to the principles of good clinical research practice, which aim to protect the wellbeing of participants and ensure appropriate study execution and data traceability. Attempts are being made to establish independent ethics committees that can weigh risks against (participant and society) benefits of use behaviour studies conducted with consumer products. Such committees would ensure that the rights, safety, and wellbeing of trial participants prevail over the interests of researchers, science, and society by providing participants with adequate information on study products; details of the study in a scientifically sound protocol; obtaining informed consent from every participant prior to participation; ensuring that the data generated are stored, recorded, handled, and accurately interpreted, verified, and reported by implementing quality systems and procedures.

In a typical EC use behaviour study, volunteers who have given informed consent are trained in the use of the products where necessary to ensure familiarity and are provided with the test product for use at home over a fixed period. Consumption patterns at home are self-reported while periodic attendance at a study site might also be required to assess puffing behaviour with a topography device $(320,321)$. Questionnaires might be used to obtain feedback about the sensory experience of vaping, satisfaction with selected attributes, and overall acceptability (322). Results from typical topography studies have been summarised in Table 5.

HAMMOND et al. (323) concluded that ECs topography studies "show a high degree of stability in puffing behaviour within the same subject over time, but considerable variability between e-cigarettes users". Thus, more-granular information is needed to improve the accuracy of topography data and how they relate to nicotine exposure in users' everyday environments. To enable the collection of real-life data over longer periods of time, attempts have been made to incorporate topography devices into ECs that record various attributes and transmit data via an internetenabled electronic device to cloud data platforms (Table 6). Further work is needed to validate the accuracy and reliability of the data generated by these connected ECs compared to traditional instruments, but they seem not to substantially affect puffing behaviour (324).

Topography data can be used to improve understanding of baseline characteristics related to EC use, which can then be used to establish representative vaping machine protocols. While standardization of regimes would be valuable to industry, academics, and regulators, no single regime is likely to represent true human behaviour or produce emissions linked closely enough to human exposure given the wide range of puffing behaviours. CORESTA Recommended Method $\mathrm{N}^{\circ} 81$ lays out the essential requirements necessary to generate and collect EC aerosol for analytical testing purposes (112), but the parameters do not reflect intense use.

Rather than using maximum settings for intense regimes, parameters for puff duration, volume, frequency, profile, and number, battery charge status, coil or atomiser age, voltage setting, ventilation setting, and device orientation should be based on representative human usage data. These parameters are not all independent and improved understanding of how different combinations affect the amount of aerosol generated will be central to defining protocols for testing and regulating ECs.

\section{BRIDGING STUDIES}

Given the pace of EC innovation, providing the amount of data required for regulatory decisions while a product remains relevant is not always possible. Borrowed from the pharmaceutical industry, the concept of bridging applies the best practice data from an existing product to the design of a similar product and updates only data pertinent to modifications (95). For example, for 'biosimilars' in Europe, data from a reference drug are supplied and the only new data are those which show that the new variant does not diverge in safety or efficacy from the reference (325). In ECs this can be translated to maintaining product safety while ensuring the new variant does not increase health risks to users and non-users. Regulatory bodies, such as the FDA, recognize the potential of this approach for ECs as long as it is supported by a rationale and justification (66). 


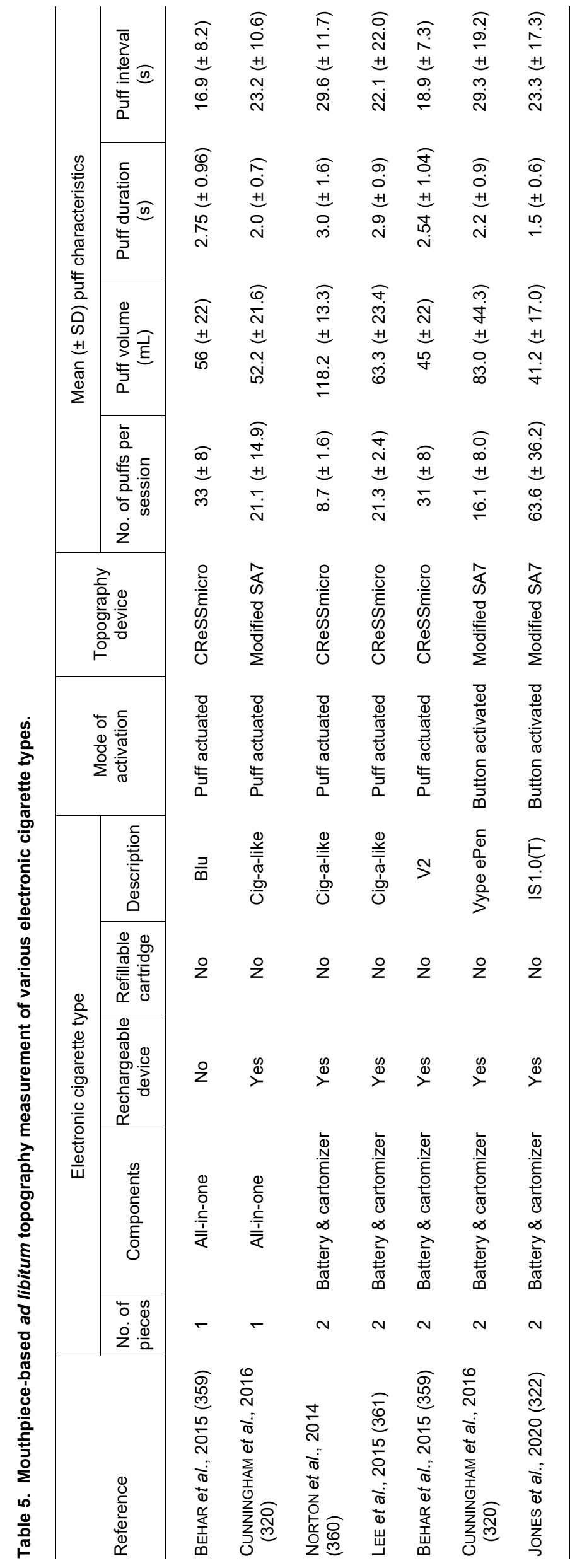




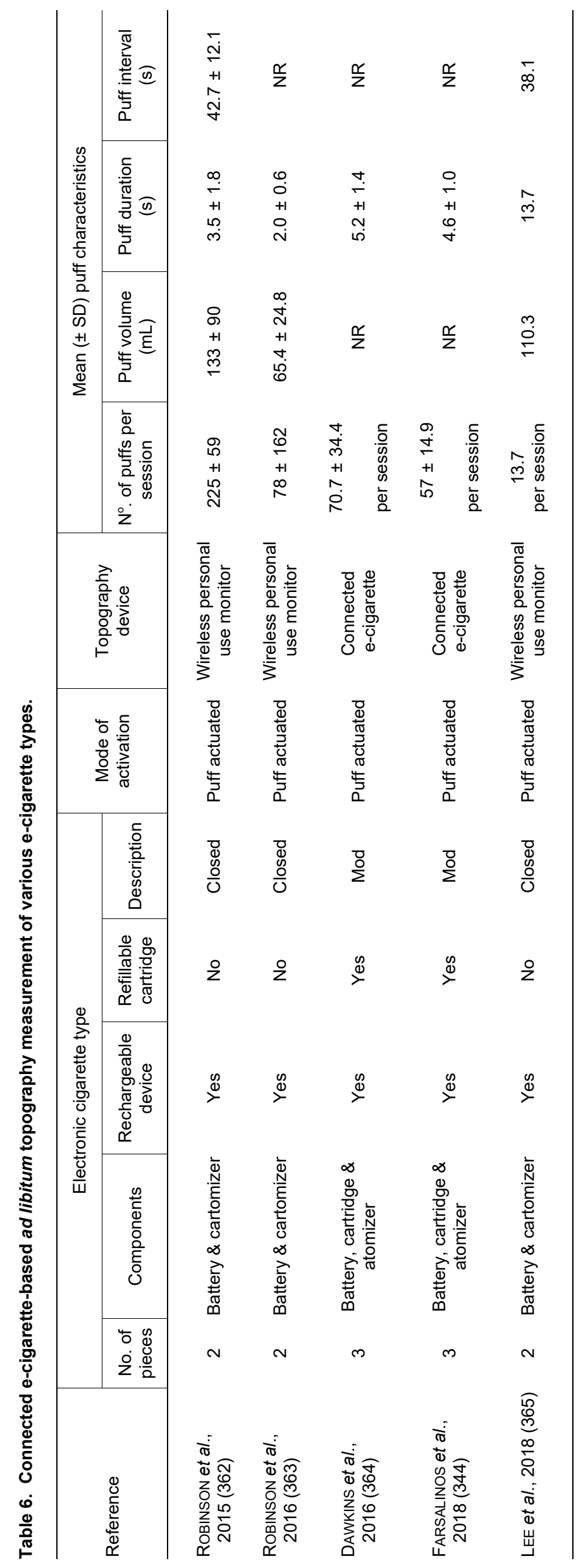


Thus, for an EC variant of an existing product, if the changes do not affect factors like age, gender, race of users or cultural environmental factors, data could be reused from studies using earlier models of the product and new bridging data should be only required only for those aspects which could potentially be affected by the changes.

\section{POPULATION MODELLING}

Modelling has become important to support risk-benefit assessments and policy decisions in tobacco control because it provides projections based on credible simplifications of complex mechanisms underlying nicotine use. The strength of modelling resides in the capability of processing many parameters with complex interactions rather than looking at one aspect of an issue at a time. Additionally, the impact of inputs' uncertainty may be assessed. A wide range of topics in relation to tobacco control and harm reduction has been assessed, from the impact of taxation of cigarettes (326) to banning menthol cigarettes in the USA (327). In assessment of potential health benefits or burdens from commercialization of ECs, models have been used to consider morbidity or mortality at the population level, including EC use versus smoking in adults and youth, possible effects of different proportions of dual use, and complete displacement of cigarettes by ECs.

There are two main types of nicotine population models. First, microsimulation models aggregate changes at the individual level (328). Various parameters can be set to reflect individual characteristics and interactions between the units (people). Macrosimulations involve groups of people considered to be homogenous individuals with respect to the main factors affecting the outcome (329). Macrosimulations can be further separated into two main categories: birth cohort models (330) and system models (331). In birth cohort models, a group of homogenous individuals born in a specific year (e.g., smokers born in 1960) is followed up until death or a timepoint. The potential impact of introducing different scenarios involving ECs is projected, and effects are compared to the counterfactual scenario of no change (i.e., the status quo, generally a scenario with cigarettes only). System models use information about past demographic and smoking patterns to generate projections of mortality or morbidity. As before, a status quo scenario in which ECs have never existed is compared to an alternative scenario in which they are commercialized. The most common outcome is the numbers of life-years lost or saved as a compound measure of prolonged life across the entire population. LEE et al. (332) have described various models used for modified tobacco product risk assessment, including strengths and weaknesses. Conclusions from some of these models have been summarised in Table 7 .

Most studies are based on data from the US adult population. WARNER and MENDEZ (333) used a system model representing this population, based on demographics and smoking status, and made projections to 2070. The status quo scenario was that ECs had never existed and was compared against three variants of an alternative scenario in which ECs were available, involving EC-associated changes in smoking initiation, smoking cessation, and health effects. In all three scenarios the model suggested positive gains ranging from nearly 583,000 to 3.3 million life-years saved based on the most optimistic and most conservative assumptions, respectively.

LEVY et al. (334) used two birth cohorts of smokers (1962 and 1982) to compare only cigarette smoking against replacement of cigarettes with ECs at different rates. In the status quo model, smoking was calculated to cause 390,632 cumulative premature deaths and 4,577,882 life-years lost in men and 135,468 premature deaths and 1,628,491 lifeyears lost in women. In the 1982 birth cohort, if only $5 \%$ of smokers transitioned to dual use or exclusive EC use per year and the risks associated with ECs were $5 \%$ of those associated with smoking, premature deaths and life-years lost would decrease by 69,585 and 1,048,763, respectively, in men and 26,104 and 433,872 in women. For the 1962 cohort under the same assumptions, the model also projects fewer premature deaths and fewer life-years lost. In another model using a 2001 birth cohort, LEVY et al. (334) assessed scenarios in which vaping would reduce smoking prevalence to $5 \%$ (optimistic) or $10 \%$ (pessimistic) by 2026 . In the pessimistic scenario, cumulative reductions of 19.5 million premature deaths and 161.9 million fewer life-years lost were projected with the introduction of ECs. In the optimistic scenario, the values would be 24.4 million and 227.8 million, respectively.

A model used by BACHAND et al. (335) suggested that if only $2 \%$ of smokers switched completely to a lower-risk product in all age-groups, population survival would be significantly enhanced by 3,127 lives. Survival would increase with the growing proportion of complete switchers. The gain would also offset unintended exposure patterns, such as use of lower-risk products leading to cigarette smoking initiation by never users or dual use by smokers. Credibility of these outcomes were reinforced by CHERNG et al. (336), who concluded that simulated effects of ECs on smoking cessation would generate substantially greater decreases in smoking prevalence than increases in smoking initiation.

Not all model projections based on US data have been favourable to ECs. SONEJI et al. (337) projected between 1.3 and 1.15 million life-years lost by introducing ECs. This opposition in directionality to most of the other modelling efforts could be due to over-pessimistic inputs with high gateway effects into smoking from vaping and low quitting rates from smoking to vaping. This study highlights the importance of using not only possible but credible inputs based on robust scientific data.

Beyond the USA, HILL and CAMACHO (338) used a system dynamics model to estimate differences in effects from 2000 to 2050 between the introduction and no introduction of ECs in the UK. It was assumed that there would be no reduction in risk for dual users and any benefit gained by switching would be lost for people who relapsed to smoking. The model still suggested a beneficial impact from introducing ECs, with smoking-related deaths in 2050 projected to fall to $8.4 \%$ in the status quo scenario compared with $8.1 \%$ in the vaping scenario, and to $11.2 \%$ versus $10.5 \%$ in people younger than 75 years. 


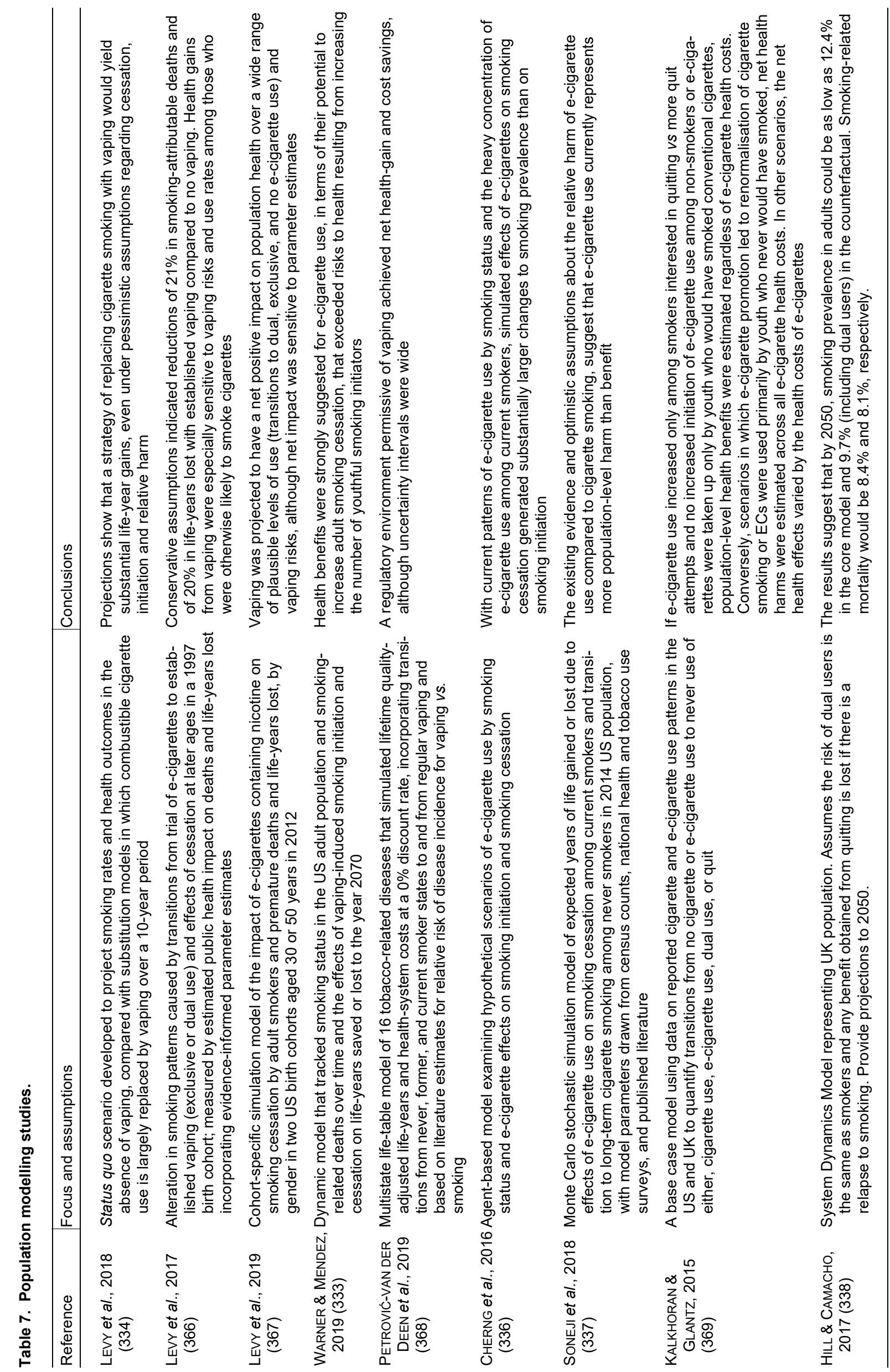


In summary, a wide range of models have been used to assess the potential impact of commercialization of ECs and, when credible inputs are considered, these models have pointed to an overall health benefit at the population level.

\section{DISCUSSION}

Despite extensive variation in EC devices and e-liquid formulations (106), in the absence of tobacco combustion, $\mathrm{EC}$ aerosol is much simpler than cigarette smoke and the numbers and concentrations of compounds present are substantially lower (19-22). To promote comparability and interpretability, testing of ECs should be performed using appropriate puffing parameters $(42,75-78,112)$ and always with the measurement of air blanks to contextualize contamination by laboratory-based toxicants (20).

Frequently, flavouring ingredients are not fully listed on packaging. To maximize safety, manufacturers should restrict flavours to ingredients that are food grade or generally recognised as safe (339), and perform appropriate testing when the toxicological profile is not well characterised (87). Of note, many ingredients have not been tested for safety when consumed by aerosolization and inhalation and/or when heated, and effects might not transfer reliably from ingestion. For example, diacetyl, which gives a butterscotch flavour, is safe to eat but when inhaled in large amounts in popcorn factories was associated with bronchiolitis obliterans, also known as popcorn lung. As a result, this flavouring is banned in ECs in many countries, although testing at the very low levels that would be required has not been performed (93). Such safety aspects of EC design and ingredients continue to evolve through manufacturers product stewardship, and are being reflected in regulatory guidance (106). A wide range of assessment methods, including toxicological assays (88), three-dimensional organotypic models $(161,169,181)$, and in silico risk assessments (47) can be useful to guide product design and standards. The consolidation and standardization of methods and endorsements of testing frameworks by regulators will be important next steps to increase product quality within the EC category.

The gold standard to investigate EC-associated health risks are clinical and epidemiological studies. However, clinical studies are expensive and, therefore, primarily conducted through sponsorship by large manufacturers, which could bias studies towards well-designed and highly stewarded products. While epidemiological outcomes can be difficult to unveil, as it might take many years to observe significant changes, reversibility of harm from smoking as well as epidemiological effects might be further complicated by the fluidity between products among nicotine users. For exposure to toxicants, reduced levels of BoEs in exclusive vapers have been confirmed at population level, even with heterogeneity in products and how they are used (219), and $\mathrm{BoPH}$ and biomarkers of biological effect studies suggest a reduction of risk of acute health effects caused by smoking (340). Further work is required, particularly on endothelial dysfunction, oxidative stress, and cancer.

In conclusion, the harm reduction potential of ECs will be maximized by complete displacement of cigarettes. Two aspects will have a critical impact on the effectiveness of ECs to displace smoking.

- $\quad$ First will be the manufacture of robust, high-quality products that compete with conventional cigarettes by satisfying consumers through product performance, sensorial characteristics, and nicotine delivery, while striking a balance against abuse liability. Manufacturers must use these and all other tools they have, including flavours, to make ECs a more attractive proposition to adults than smoking.

- Second, public health institutions must unambiguously and accurately inform smokers about the likely reduced risk character of ECs compared with cigarettes. The UK has seen some public health institutions openly supporting ECs as lower risk alternatives to smoking. In 2019 , more than $50 \%$ of all vapers in the UK used ECs exclusively (294) and smoking prevalence reached a record minimum of $15.8 \%$, down from $16.6 \%$ in 2018 (341). Consolidating this trend, the proportion of former smokers in 2019 was the highest recorded at $62.5 \%(341)$.

Despite all evidence supporting ECs as reduced risk products as part of a smoking harm reduction framework, outright bans and restrictions of ECs or flavoured e-liquids continue in many countries, and others are introducing restrictions, for example on flavours, that are not supported by scientific evidence. The main reasons being used to ban or legislate against ECs are underage usage and the hypothesis of a gateway effect. However, irresponsible marketing of vaping products has led to a situation of distrust between governments and the vaping industry and is an area that needs to be addressed. As this topic is highly controversial, it may deviate from the scientific focus of this review. It is mentioned as it clearly can have an impact on initiation, but it deserves a publication of its own.

At population level, national surveys do not suggest any gateway effect, and smoking initiation rates among youth in the US also indicate the absence of such an effect and the lowest rates of smoking initiation on record in 2018 (2.29\%) (302). Similar patterns have been observed across European countries where ECs are widely available (303) and are also suggested by a study commissioned by HeAlth CANADA (319). Regulation of all aspects limiting the efficacy of ECs as an alternative to smoking should be considered with caution, as such measures could reduce the attractiveness of ECs for smokers and reignite smoking initiation (312).

\section{CONCLUSIONS}

- Regulatory strategies must promote quality in product development led by robust stewardship which is essential to identify and eliminate, or minimize potential hazards

- Vapour products have been soundly demonstrated to be able to reduce exposure to toxicants found in conventional cigarette smoke among smokers who transition completely to vapour products

- Emerging evidence in biomarkers of effect point to lower risk for most smoking-related disease endpoints, with further research required particularly for cardio- 
vascular endpoints, where there are conflicting data.

- Vapour products must offer a compelling alternative to smoking to attract smokers, including flavours while mitigating products' youth appeal

- $\quad$ Research suggests lower abuse liability from vaping products in comparison with conventional cigarettes

- Gateway effect claims are generally not sustained by public data which show lowest levels of smoking initiation ever recorded in key markets such as the US and UK.

\section{ACKNOWLEDGMENTS}

We would like to thank internal and external reviewers for their guidance adding clarity to this paper.

\section{REFERENCES}

1. U.S. Department of Health and Human Services (HHS): Smoking Cessation: A Report of the Surgeon General; 2020. Available at: https://www.hhs.gov/ sites/default/files/2020-cessation-sgr-full-report.pdf (accessed July 6, 2020)

2. World Health Organization (WHO): Tobacco: Health Benefits of Smoking Cessation; 2020. Available at: https://www.who.int/tobacco/quitting/benefits/en/ (accessed April 29, 2020)

3. Baker, R.R. and L.J. Bishop: The Pyrolysis of Tobacco Ingredients; J. Anal. Appl. Pyrolysis 71 (2004) 223311. DOI: $10.1016 /$ j.jaap.2004.10.01

4. Gottlieb, S. and M. Zeller: A Nicotine-Focused Framework for Public Health; N. Engl. J. Med. 377 (2017) 1111-1114. DOI: 10.1056/NEJMp1707409

5. Rodgman, A. and T.A. Perfetti: The Chemical Components of Tobacco and Tobacco Smoke; CRC Press, Boca Raton, FL, USA, 2013.

6. Fowles, J. and E. Dybing: Application of Toxicological Risk Assessment Principles to the Chemical Constituents of Cigarette Smoke; Tob. Control 12 (2003) 424-430. DOI: 10.1136/tc.12.4.424

7. Fagerström, K.: The Epidemiology of Smoking: Health Consequences and Benefits of Cessation; Drugs 62, Suppl. 2 (2002) 1-9.

DOI: $10.2165 / 00003495-200262002-00001$

8. World Health Organization (WHO): Partial Guidelines for Implementation of Articles 9 and 10 of the WHO Framework Convention on Tobacco Control. Regulation of the Contents of Tobacco Products and of Tobacco Product Disclosures; 2010. Available at: https://www.who.int/fctc/guidelines/Guideliness Articles_9_10_rev_240613.pdf\#: :text=The\%20pur pose $\% 20$ of $\% 20$ the $\%$ 20guidelines $\% 20$ is $\% 20$ to $\% 20$ as sist,evidence $\% 20$ and $\% 20$ the $\% 20$ experience $\% 20$ of $\%$ 20Parties\%2C\%20propose $\% 20$ measures (accessed September 7, 2020)

9. World Health Organization Framework Convention on Tobacco Control (FCTC): Conference of the Parties to the WHO Framework Convention on Tobacco Control. Sixth Session; Moscow, Russian Federation, 13-18 October, 2014. Available at: https://apps.who.
int/gb/fctc/PDF/cop6/FCTC_COP6(9)-en.pdf?ua=1 (accessed April 29, 2020)

10. Bates, C.: Tobacco Harm Reduction - A Note to WHO's Expert Committee; 2013. Available at: https://www.clivebates.com/tobacco-harm-reductiona-note-to-whos-expert-commitee (accessed September 7, 2020)

11. Stratton, K., P. Shetty, R. Wallace, and S. Bondurant: Clearing the Smoke: The Science Base for Tobacco Harm Reduction - Executive Summary; Tob. Control 10 (2001) 189-195. DOI: 10.1136/tc.10.2.189

12. Rodu, B. and W.T. Godshall: Tobacco Harm Reduction: An Alternative Cessation Strategy for Inveterate Smokers; Harm Reduct. J. 3 (2006) 37. DOI: 10.1186/1477-7517-3-37

13. Institute of Medicine: Scientific Standards for Studies on Modified Risk Tobacco Products; The National Academies Press, Washington, DC, USA, 2012. DOI: $10.17226 / 13294$

14. European Commission: Special Eurobarometer 506. Attitudes of Europeans Towards Tobacco and Electronic Cigarettes; 2021. Available at https://ec.europa.eu/ commfrontoffice/publicopinion/index.cfm/survey/ getsurveydetail/instruments/special/surveyky/2240 (accessed April 11, 2021)

15. Clarke, E., K. Thompson, S. Weaver, J. Thompson, and G. O'Connell: Snus: A Compelling Harm Reduction Alternative to Cigarettes; Harm Reduct. J. 16 (2019) 62. DOI: 10.1186/s12954-019-0335-1

16. Ferlay, J., M. Ervik, F. Lam, M. Colombet, L. Mery, M. Piñeros, A. Znaor, I. Soerjomataram, and F. Bray: Cancer Today (Powered by GLOBCAN 2018). Available at: https://publications.iarc.fr/Databases/IarcCancerbases/Cancer-Today-Powered-By-GLOBOCAN2018--2018 (accessed September 7, 2020)

17. U.S. Food and Drug Administration (FDA): FDA Grants First-Ever Modified Risk Orders to Eight Smokeless Tobacco Products; FDA News relase, October 22, 2019. Available at: https://www.fda.gov/ news-events/press-announcements/fda-grants-firstever-modified-risk-orders-eight-smokeless-tobaccoproducts (accessed January 25, 2021)

18. U.S. Food and Drug Administration (FDA): FDA Authorizes Modified Risk Tobacco Products; 2019. Available at: https://www.fda.gov/tobacco-products/ advertising-and-promotion/fda-authorizes-modifiedrisk-tobacco-products (accessed January 25, 2021)

19. Marco, E. and J.O. Grimalt: A Rapid Method for the Chromatographic Analysis of Volatile Organic Compounds in Exhaled Breath of Tobacco Cigarette and Electronic Cigarette Smokers; J. Chromatogr. A 1410 (2015) 51-59. DOI: 10.1016/j.chroma.2015.07.094

20. Margham, J., K. McAdam, M. Forster, C. Liu, C. Wright, D. Mariner, and C. Proctor: Chemical Composition of Aerosol from an E-Cigarette: A Quantitative Comparison with Cigarette Smoke; Chem. Res. Toxicol. 29 (2016) 1662-1678.

DOI: 10.1021/acs.chemrestox.6b00188

21. Nicol, J., R. Fraser, L. Walker, C. Liu, J. Murphy, and C.J. Proctor: Comprehensive Chemical Characterization of the Aerosol Emissions of a Vaping Product Based on a New Technology; Chem. Res. Toxicol. 33 (2020) 789- 
799. DOI: 10.1021/acs.chemrestox.9b00442

22. Cunningham, A., K. McAdam, J. Thissen, and H. Digard: The Evolving E-cigarette: Comparative Chemical Analyses of E-Cigarette Vapor and Cigarette Smoke; Front. Toxicol. 2 (2020) 586674. DOI: $10.3389 /$ ftox. 2020.586674

23. Hartmann-Boyce, J., H. McRobbie, N. Lindson, C. Bullen, R. Begh, A. Theodoulou, C. Notley, N.A. Rigotti, T. Turner, A.R. Butler, T.R. Fanshawe, and P. Hajek: Electronic Cigarettes for Smoking Cessation; Cochrane Database Syst. Rev. 10 (2020) CD010216. DOI: 10.1002/14651858.CD010216.pub4

24. McNeill, A., L.S. Brose, R. Calder, S.C. Hitchman, P. Hajek, and H. McRobbie: E-Cigarettes: An Evidence Update. A Report Commissioned by Public Health England; 2015. Available at: https://assets.publishing. service.gov.uk/government/uploads/system/uploads/ attachment_data/file/733022/Ecigarettes_an_evidence update_A_report_commissioned_by_Public_Health England_FINAL.pdf (accessed April 15, 2021)

25. McNeill, A., L.S. Brose, R. Calder, L. Bauld, and D. Robson: Vaping in England: An Evidence Update. A Report Commissioned by Public Health England; 2019. Available at: https://assets.publishing.service. gov.uk/government/uploads/system/uploads/attachmen t_data/file/821179/Vaping_in_England an_evidence update_February_2019.pdf (accessed April 15, 2021)

26. McNeill, A., L.S. Brose, R. Calder, L. Bauld, and D. Robson: Vaping in England: An Evidence Update Including Mental Health and Pregnancy. A Report Commissioned by Public Health England; 2020. Available at: https://assets.publishing.service.gov.uk/ government/uploads/system/uploads/attachment_data/ file/869401/Vaping_in_England_evidence_update_Ma rch_2020.pdf (accessed April 15, 2021)

27. McRobbie, H., C. Bullen, J. Hartmann-Boyce, and P. Hajek: Electronic Cigarettes for Smoking Cessation and Reduction; Cochrane Database Syst. Rev. 12 (2014) CD010216.

DOI: $10.1002 / 14651858 . C D 010216 . p u b 2$

28. National Academies of Sciences Engineering and Medicine; Health and Medicine Division; Board on Population Health and Public Health Practice; Committee on the Review of the Health Effects of Electronic Nicotine Delivery Systems: Public Health Consequences of E-Cigarettes; edited by D.L. Eaton, L.Y. Kwan and K. Stratton, National Academies Press, Washington, DC, USA, 2018. DOI: $10.17226 / 24952$

29. McNeill, A., L.S. Brose, R. Calder, L. Bauld, and D. Robson: Evidence Review of E-Cigarettes and Heated Tobacco Products 2018. A Report Commissioned by Public Health England; 2018. Available at: https://assets.publishing.service.gov.uk/government/upl oads/system/uploads/attachment_data/file/684963/Evid ence_review_of_e-cigarettes_and_heated_tobacco prodūcts_2018.p.pdf (accessed April 15, 2021)

30. Government of Canada: Tobacco and Vaping Products Act (TVPA); 2018. Available at: https://www.canada. ca/en/health-canada/services/health-concerns/tobacco/ legislation/federal-laws/tobacco-act.html (accessed January 25, 2021)
31. New Zealand Ministry of Health: Vaping Facts; 2019. Available at: https://vapingfacts.health.nz (accessed August 13, 2020)

32. Girvalaki, C., A. Vardavas, M. Tzatzarakis, C.N. Kyriakos, K. Nikitara, A.M. Tsatsakis, and C.I. Vardavas: Compliance of E-Cigarette Refill Liquids with Regulations on Labelling, Packaging and Technical Design Characteristics in Nine European Member States; Tob. Control 29 (2020) 531-536. DOI: 10.1136/tobaccocontrol-2019-055061

33. Seitz, C.M. and Z. Kabir: Burn Injuries Caused by E-Cigarette Explosions: A Systematic Review of Published Cases; Tob. Prev. Cessat. 4 (2018) 32. DOI: $10.18332 / \mathrm{tpc} / 94664$

34. Blount, B.C., M.P. Karwowski, P.G. Shields, M. Morel-Espinosa, L. Valentin-Blasini, M. Gardner, M. Braselton, C.R. Brosius, K.T. Caron, D. Chambers, J. Corstvet, E. Cowan, V.R. De Jesús, P. Espinosa, C. Fernandez, C. Holder, Z. Kuklenyik, J.D. Kusovschi, C. Newman, G.B. Reis, J. Rees, C. Reese, L. Silva, T. Seyler, M.A. Song, C. Sosnoff, C.R. Spitzer, D. Tevis, L. Wang, C. Watson, M.D. Wewers, B. Xia, D.T. Heitkemper, I. Ghinai, J. Layden, P. Briss, B.A. King, L.J. Delaney, C.M. Jones, G.T. Baldwin, A. Patel, D. Meaney-Delman, D. Rose, V. Krishnasamy, J.R. Barr, J. Thomas, and J.L. Pirkle: Lung Injury Response Laboratory Working Group: Vitamin E Acetate in Bronchoalveolar-Lavage Fluid Associated with EVALI; N. Engl. J. Med. 382 (2020) 697-705. DOI: 10.1056/NEJMoa1916433

35. Centers for Disease Control and Prevention (CDC): Outbreak of Lung Injury Associated with the Use of E-Cigarette, or Vaping, Products; 2020. Available at: https://www.cdc.gov/tobacco/basic_information/ecigarettes/severe-lung-disease.html (accessed September 7, 2020)

36. Williams, M. and P. Talbot: Design Features in Multiple Generations of Electronic Cigarette Atomizers; Int. J. Environ. Res. Public Health 16 (2019) 2904. DOI: 10.3390/ijerph16162904

37. Cahours, X. and K. Prasad: A Review of Electronic Cigarette Use Behaviour Studies; Beitr. Tabakforsch. Int. 28 (2018) 81-92. DOI: 10.2478/cttr-2018-0009

38. Action on Smoking and Health (ASH): ASH Fact Sheet: Use of Electronic Cigarettes (Vapourisers) Among Adults in Great Britain; 2017. Available at: https://www.zougla.gr/file.ashx? fid=2207534 (accessed April 29, 2020)

39. Wadsworth, E., J. Neale, A. McNeill, and S.C. Hitchman: How and Why Do Smokers Start Using ECigarettes? Qualitative Study of Vapers in London, UK; Int. J. Environ. Res. Public Health 13 (2016) 661674. DOI: $10.3390 /$ ijerph13070661

40. Weaver, S.R., J.W. Health, D.L Ashley, J. Huang, T.F. Pechacek, and M.P. Erikson: What are the Reasons that Smokers Reject ENDS? A National Probability Survey of U.S. Adult Smokers, 2017-2018; Drug Alcohol Depend. 211 (2020) 107855. DOI: 10.1016/j.drugalcdep.2020.107855

41. Beauval, N., M. Verrièle, A. Garat, I. Fronval, R. Dusautoir, S. Anthérieu, G. Garçon, J.M. Lo-Guidice, D. Allorge, and N. Locoge: Influence of Puffing 
Conditions on the Carbonyl Composition of E-Cigarette Aerosols; Int. J. Hyg. Environ. Health 222 (2019) 136-146. DOI: 10.1016/j.ijheh.2018.08.015

42. Farsalinos, K.E. and G. Gillman: Carbonyl Emissions in E-Cigarette Aerosol: A Systematic Review and Methodological Considerations; Front. Physiol. 8 (2018) 1119. DOI: 10.3389/fphys.2017.01119

43. Flora, J.W., N. Meruva, C.B. Huang, C.T. Wilkinson, R. Ballentine, D.C. Smith, M.S. Werley, and W.J. McKinney: Characterization of Potential Impurities and Degradation Products in Electronic Cigarette Formulations and Aerosols; Regul. Toxicol. Pharmacol. 74 (2016) 1-11.

DOI: $10.1016 /$ j.yrtph.2015.11.009

44. Goniewicz, M.L., J. Knysak, M. Gawron, L. Kosmider, A. Sobczak, J. Kurek, A. Prokopowicz, M. Jablonska-Czapla, C. Rosik-Dulewska, C. Havel, P. Jacob III, and N. Benowitz: Levels of Selected Carcinogens and Toxicants in Vapour from Electronic Cigarettes; Tob. Control 23 (2014) 133-139. DOI: $10.1136 /$ tobaccocontrol-2012-050859

45. Jensen, R.P., R.M. Strongin, and D.H. Peyton: Solvent Chemistry in the Electronic Cigarette Reaction Vessel; Sci. Rep. 7 (2017) 42549. DOI: $10.1038 /$ srep42549

46. Ogunwale, M.A., M. Li, M.V. Ramakrishnam Raju, Y. Chen, M.H. Nantz, D.J. Conklin, and X.A. Fu: Aldehyde Detection in Electronic Cigarette Aerosols; ACS Omega 2 (2017) 1207-1214. DOI: $10.1021 /$ acsomega.6b00489

47. Stephens, W.E.: Comparing the Cancer Potencies of Emissions from Vapourised Nicotine Products Including E-Cigarettes with Those of Tobacco Smoke; Tob. Control 27 (2018) 10-17.

DOI: 10.1136/tobaccocontrol-2017-053808

48. Farsalinos, K.E., G. Romagna, D. Tsiapras, S. Kyrzopoulos, and V. Voudris: Evaluation of Electronic Cigarette Use (Vaping) Topography and Estimation of Liquid Consumption: Implications for Research Protocol Standards Definition and for Public Health Authorities' Regulation; Int. J. Environ. Res. Public Health 10 (2013) 2500-2514.

DOI: $10.3390 /$ ijerph10062500

49. Kim, H., J. Lim, S.S. Buehler, M.C. Brinkman, N.M. Johnson, L. Wilson, K.S. Cross, and P.I. Clark: Role of Sweet and Other Flavours in Liking and Disliking of Electronic Cigarettes; Tob. Control 25 (2016) ii55ii61. DOI: 10.1136/tobaccocontrol-2016-053221

50. Laverty, A.A., C.I. Vardavas, and F.T. Filippidis: Design and Marketing Features Influencing Choice of E-Cigarettes and Tobacco in the EU; Eur. J. Public Health 26 (2016) 838-841. DOI: $10.1093 /$ eurpub/ckw109

51. Pullicin, A.J., H. Kim, M.C. Brinkman, S.S. Buehler, P.I. Clark, and J. Lim: Impacts of Nicotine and Flavoring on the Sensory Perception of E-cigarette Aerosol; Nicotine Tob. Res. 22 (2020) 806-813. DOI: $10.1093 / \mathrm{ntr} / \mathrm{ntz} 058$

52. Zare, S., M. Nemati, and Y. Zheng: A Systematic Review of Consumer Preference for E-Cigarette Attributes: Flavor, Nicotine Strength, and Type; PLoS One 13 (2018) e0194145.
DOI: 10.1371/journal.pone.0194145

53. Baweja, R., K.M. Curci, J. Yingst, S. Veldheer, S. Hrabovsky, S.J. Wilson, T.T. Nichols, T. Eissenberg, and J. Foulds: Views of Experienced Electronic Cigarette Users; Addict. Res. Theory 24 (2016) 80-88. DOI: 10.3109/16066359.2015.1077947

54. Berg, C.J.: Preferred Flavors and Reasons for E-Cigarette Use and Discontinued Use Among Never, Current, and Former Smokers; Int. J. Public Health 61 (2016) 225-236. DOI: 10.1007/s00038-015-0764-x

55. Russell, C., N. McKeganey, T. Dickson, and M. Nides: Changing Patterns of First E-Cigarette Flavor Used and Current Flavors Used by 20,836 Adult Frequent ECigarette Users in the USA; Harm Reduct. J. 15 (2018) 33. DOI: $10.1186 / \mathrm{s} 12954-018-0238-6$

56. Chen, J.C., B. Das, E.L. Mead, and D.L.G. Borzekowski: Flavored E-cigarette Use and Cigarette Smoking Susceptibility Among Youth; Tob. Regul. Sci. 3 (2017) 68-80. DOI: 10.18001/TRS.3.1.7

57. Audrain-McGovern, J., A.A. Strasser, and E.P. Wileyto: The Impact of Flavoring on the Rewarding and Reinforcing Value of E-Cigarettes with Nicotine Among Young Adult Smokers; Drug Alcohol Depend. 166 (2016) 263-267. DOI: $10.1016 /$ j.drugalcdep.2016.06.030

58. Krishnan-Sarin S., B.G. Green, G. Kong, D.A. Cavallo, P. Jatlow, R. Gueorguieva, E. Buta, and S.S. O'Malley: Studying the Interactive Effects of Menthol and Nicotine Among Youth: An Examination Using E-Cigarettes; Drug Alcohol Depend. 180 (2017) 193-199. DOI: 10.1016/j.drugalcdep.2017.07.044

59. Action on Smoking and Health (ASH): Use of Electronic Cigarettes (Vapourisers) Among Adults in Great Britain; 2019. Available at: https://ash.org.uk/ information-and-resources/fact-sheets/statistical/use-of-ecigarettes-among-adults-in-great-britain-2019 (accessed April 29, 2020)

60. Gravely, S., K.M. Cummings, D. Hammond, E. Lindblom, D.M. Smith, N. Martin, R. Loewen, R. Borland, A. Hyland, M.E. Thompson, C. Boudreau, K. Kasza, J. Ouimet, A.C.K. Quah, R.J. O’Connor, and G.T. Fong: The Association of E-Cigarette Flavors with Satisfaction, Enjoyment, and Trying to Quit or Stay Abstinent from Smoking Among Regular Adult Vapers from Canada and the United States: Findings from the 2018 ITC Four Country Smoking and Vaping Survey; Nicotine Tob. Res. 22 (2020) 1831-1841. DOI: $10.1093 /$ ntr/ntaa095

61. Institute for Global Tobacco Control: Country Laws Regulating E-Cigarettes: A Policy Scan; 2020. Available at: https://www.globaltobaccocontrol.org/ecigarette_policyscan (accessed April 29, 2020)

62. Bond, C.M. and A.R. Barry: Do the Benefits of Electronic Cigarettes Outweigh the Risks?; Can. J. Hosp. Pharm. 71 (2018) 44-47.

63. Rambaran, K., S. Sakhamuri, and L. Pinto Pereira: E-Cigarettes: Banning Flavours is Better Than an Outright Ban; Lancet Respir. Med. 7 (2019) e37. DOI: $10.1016 / \mathrm{S} 2213-2600(19) 30359-5$

64. Strombotne, K., J. Buckell, and J.L. Sindelar: Do JUUL and E-Cigarette Flavours Change Risk Perceptions of Adolescents? Evidence from a National 
Survey; Tob. Control $30 \quad$ (2020) 199-205. DOI: 10.1136/tobaccocontrol-2019-055394

65. U.S. Food and Drug Administration (FDA) and Department of Health and Human Services (HHS): Deeming Tobacco Products to be Subject to the Federal Food, Drug, and Cosmetic Act, as Amended by the Family Smoking Prevention and Tobacco Control Act; Restrictions on the Sale and Distribution of Tobacco Products and Required Warning Statements for Tobacco Products; 2016. Available at: https:/www.federal register.gov/documents/2016/05/10/2016-10685/ deeming-tobacco-products-to-be-subject-to-thefederal-food-drug-and-cosmetic-act-as-amended-bythe (accessed January 62021 ).

66. U.S. Department of Health and Human Services (HHS), Food and Drug Administration (FDA) Center for Tobacco Products: Premarket Tobacco Product Applications for Electronic Nicotine Delivery Systems. Guidance for Industry; 2019. Available at: https://www.fda.gov/media/127853/download (accessed August 4, 2020)

67. U.S. Food and Drug Administration (FDA): Section 907 of the Federal Food, Drug, and Cosmetic Act Tobacco Product Standards; 2018. Available at: https://www.fda.gov/tobacco-products/rulesregulations-and-guidance/section-907-federal-fooddrug-and-cosmetic-act-tobacco-product-standards (accessed September 7, 2020)

68. U.S. Food and Drug Administration (FDA): Modified Risk Tobacco Products; 2020. Available at: https://www.fda.gov/tobacco-products/advertisingand-promotion/modified-risk-tobacco-products (accessed January 25, 2021).

69. The European Parliament and the Council of the European Union: Directive 2014/40/EU of the European Parliament and of the Council of 3 April 2014 on the Approximation of the Laws, Regulations and Administrative Provisions of the Member States Concerning the Manufacture, Presentation and Sale of Tobacco and Related Products and Repealing Directive 2001/37/EC; Official Journal of the European Union L127 (2014) 1-38.

70. European Commission: Restriction of Hazardous Substances in Electrical and Electronic Equipment (RoHS); 2017. Available at: https://ec.europa.eu/ environment/waste/rohs_eee/index_en.htm (accessed January 6, 2021)

71. European Agency for Safety and Health at Work (EUOSHA): Regulation (EC) No 1907/2006 - Registration, Evaluation, Authorisation and Restriction of Chemicals (REACH); 2006. Available at: https://osha.europa.eu/en/legislation/directives/regul ation-ec-no-1907-2006-of-the-european-parliamentand-of-the-council (accessed January 6 2021).

72. Committee of Advertising Practice (ASA-CAP): Can E-Cigarettes Claim to be Healthy?; 2018. Available at: https://www.asa.org.uk/news/can-e-cigarettes-claim-tobe-healthy.html (accessed September 7 2020).

73. U.S. Department of Health and Human Services (HHS), Food and Drug Administration (FDA) Center for Tobacco Products: Guidance for Industry Modified Risk Tobacco Product Applications. Draft Guidance; 2012.
74. Government of Canada: Vaping Product Regulations; 2018. Available at: https://www.canada.ca/en/healthcanada/services/smoking-tobacco/vaping/productsafety-regulation.html (accessed April 29, 2020)

75. European Committee for Standardization (CEN): CEN TR 17236:2018. Electronic Cigarettes and E-Liquids Constituents to be Measured in the Aerosol of Vaping Products; 2018. Available at: https://standards.cen.eu/ dyn/www/f?p=204:110:0::::FSP_PROJECT,FSP_ORG_ID: $66961,1958025 \& \mathrm{cs}=1 \mathrm{CB} 5 \mathrm{~A} 86 \mathrm{D} 99 \mathrm{D} 1 \overline{0} \mathrm{CD} \overline{6} \mathrm{~A} 3$ 2BE1C35C52F2D34 (accessed September 7, 2020)

76. European Committee for Standardization (CEN): CEN/TS 17287:2019. Requirements and Test Methods for Electronic Cigarette Devices; 2019. Available at: h t t p s:// s t a ndards.cen.e u/d y n/ww w / $\mathrm{f}$ ? $\mathrm{p}=204: 110: 0::::$ FSP_PROJECT:65461\&cs $=11304$ D006B6DAFFEE8110B2710FD7478A (accessed September 7, 2020)

77. International Organization for Standardization (ISO): ISO 20768:2018. Vapour Products - Routine Analytical Vaping Machine - Definitions and Standard Conditions; ISO, Geneva, Switzerland, 2018. Available at: https://www.iso.org/standard/69019.html (accessed September 7, 2020).

78. International Organization for Standardization (ISO): ISO 20714:2019. E-Liquid - Determination of Nicotine, Propylene Glycol and Glycerol in Liquids Used in Electronic Nicotine Delivery Devices - Gas Chromatographic Method; 2019. Available at: https://www.iso. org/standard/68905.html (accessed September 7, 2020).

79. Belushkin, M., M. Esposito, G. Jaccard, C. Jeannet, A. Korneliou, and D. Tafin Djoko: Role of Testing Standards in Smoke-Free Product Assessments; Regul. Toxicol. Pharmacol. 98 (2018) 1-8. DOI: 10.1016/j.yrtph.2018.06.021

80. Chatham-Stephens, K., R. Law, E. Taylor, P. Melstrom, R. Bunnell, B. Wang, B. Apelberg, and J.G. Schier: Notes from the Field: Calls to Poison Centers for Exposures to Electronic Cigarettes - United States, September 2010-February 2014; MMWR Morb. Mortal. Wkly. Rep. 63 (2014) 292-293.

81. McCague, Y.: Ocular Chemical Burns Secondary to Accidental Administration of E-Cigarette Liquid; Adv. Emerg. Nurs. J. 40 (2018) 104-109. DOI: 10.1097/TME.0000000000000183

82. Jamison, A. and D. Lockington: Ocular Chemical Injury Secondary to Electronic Cigarette Liquid Misuse; JAMA Ophthalmol. 134 (2016) 1443. DOI: 10.1001/jamaophthalmol.2016.3651

83. Brownson, E.G., C.M. Thompson, S. Goldsberry, H.J. Chong, J.B. Friedrich, T.N. Pham, S. Arbabi, G.J. Carrougher, and N.S. Gibran: Explosion Injuries from ECigarettes; N. Engl. J. Med. 375 (2016) 1400-1402. DOI: $10.1056 / \mathrm{NEJMc1608478}$

84. The European Parliament and the Council of the European Union: Directive 2014/30/EU of the European Parliament and of the Council of 26 February 2014 on the Harmonisation of the Laws of the Member States Relating to Electromagnetic Compatibility; Official Journal of the European Union L96 (2014) 79-106.

85. The European Parliament and the Council of the European Union: Directive 2011/65/EU of the European 
Parliament and of the Council of 8 June 2011 on the Restriction of the Use of Certain Hazardous Substances in Electrical and Electronic Equipment; Official Journal of the European Union L174 (2011) 88-110.

86. The European Parliament and the Council of the European Union: Directive 2001/95/EC of the European Parliament and of the Council of 3 December 2001 on General Product Safety; Official Journal of the European Union L0095 (2001) 1-23.

87. Costigan, S. and C. Meredith: An Approach to Ingredient Screening and Toxicological Risk Assessment of Flavours in E-Liquids; Regul. Toxicol. Pharmacol. 72 (2015) 361-369. DOI: 10.1016/j.yrtph.2015.05.018

88. Costigan, S. and J. Lopez-Belmonte: An Approach to Allergy Risk Assessments for E-Liquid Ingredients; Regul. Toxicol. Pharmacol. 87 (2017) 1-8. DOI: 10.1016/j.yrtph.2017.04.003

89. Iskandar, A.R., I. Gonzalez-Suarez, S. Majeed, D. Marescotti, S. Sewer, Y. Xiang, P. Leroy, E. Guedj, C. Mathis, J.P. Schaller, P. Vanscheeuwijck, S. Frentzel, F. Martin, N.V. Ivanov, M.C. Peitsch, and J. Hoeng: A Framework for In Vitro Systems Toxicology Assessment of E-Liquids; Toxicol. Mech. Methods 26 (2016) 392416. DOI: $10.3109 / 15376516.2016 .1170251$

90. American E-Liquid Manufacturing Standards Association: E-Liquid Manufacturing Standards; 2014. Available at: http://www.aemsa.org/wp-content/uploads/ 2014/02/AEMSA-Standards_Version-1-8.pdf(accessed September 7, 2020)

91. Go, Y.Y., J.Y. Mun, S.-W. Chae, J. Chang, and J.-J. Song: Comparison Between In Vitro Toxicities of Tobacco- and Menthol-Flavored Electronic Cigarette Liquids on Human Middle Ear Epithelial Cells; Sci. Rep. 10 (2020) 2544. DOI: 10.1038/s41598-020-59290-y

92. Committee on Toxicity of Chemicals in Food, Consumer Products and the Environment (COT): Framework for Risk Assessment of Flavouring Compounds in Electronic Nicotine (and Non-Nicotine) Delivery Systems $(\mathrm{E}(\mathrm{N}) \mathrm{NDS}$ - E-Cigarettes); 2020. Available at: https://cot.food.gov.uk/sites/default/files/framework forriskassessingflavourings $0 . p d f$ (accessed January 26, 2021)

93. Farsalinos, K. and G. Lagoumintzis: Toxicity Classification of E-Cigarette Flavouring Compounds Based on European Union Regulation: Analysis of Findings from a Recent Study; Harm Reduct. J. 16 (2019) 48. DOI: 10.1186/s12954-019-0318-2

94. Berman, M.S., G. Connolly, M.K. Cummings, M.V. Djordjevic, D.K. Hatsukami, J.E. Henningfield, M. Myers, R.J. O’Connor, M. Parascandola, V. Rees, J.M. Rice, and P.G. Shields: Providing a Science Base for the Evaluation of Tobacco Products; Tob. Regul. Sci. 1 (2015) 76-93. DOI: 10.18001/TRS.1.1.8

95. Murphy, J., M. Gaça, F. Lowe, E. Minet, D. Breheny, K. Prasad, O. Camacho, I.M. Fearon, C. Liu, C. Wright, K. McAdam, and C. Proctor: Assessing Modified Risk Tobacco and Nicotine Products: Description of the Scientific Framework and Assessment of a Closed Modular Electronic Cigarette; Regul. Toxicol. Pharmacol. 90 (2017) 342-357.

DOI: 10.1016/j.yrtph.2017.09.008

96. Smith, M.R., B. Clark, F. Lüdicke, J.P. Schaller, P.
Vanscheeuwijck, J. Hoeng, and M.C. Peitsch: Evaluation of the Tobacco Heating System 2.2. Part 1: Description of the System and the Scientific Assessment Program; Regul. Toxicol. Pharmacol. 81, Suppl. 2(2016) S17-S26. DOI: 10.1016/j.yrtph.2016.07.006

97. Geiss, O., I. Bianchi, and J. Barerro-Morena: Correlation of Volatile Carbonyl Yields Emitted by E-Cigarettes with the Temperature of the Heating Coil and the Perceived Sensorial Quality of the Generated Vapours; Int. J. Hyg. Environ. Health 219 (2016) 268-277. DOI: $10.1016 /$ j.ijheh.2016.01.004

98. Etter, J.-F., E. Zäther, and S. Svensson: Analysis of Refill Liquids for Electronic Cigarettes; Addiction 108 (2013) 1671-1679. DOI: 10.1111/add.12235

99. Kim, H.-J. and H.-S. Shin: Determination of TobaccoSpecific Nitrosamines in Replacement Liquids of Electronic Cigarettes by Liquid Chromatography-Tandem Mass Spectrometry; J. Chromatogr. A 1291 (2013) 4855. DOI: 10.1016/j.chroma.2013.03.035

100. Farsalinos, K.E., I.G. Gillman, M.S. Melvin, A.R. Paolantonio, W.J. Gardow, K.E. Humphries, S.E. Brown, K. Poulas, and V. Voudris: Nicotine Levels and Presence of Selected Tobacco-Derived Toxins in Tobacco Flavoured Electronic Cigarette Refill Liquids; Int. J. Environ. Res. Public Health 12 (2015) 3439-3452. DOI: $10.3390 /$ ijerph120403439

101. Lisko, J.G., H. Tran, S.B. Stanfill, B.C. Blount, and C.H. Watson: Chemical Composition and Evaluation of Nicotine, Tobacco Alkaloids, $\mathrm{pH}$, and Selected Flavors in E-Eigarette Cartridges and Refill Solutions; Nicotine Tob. Res. 17 (2015) 1270-1278. DOI: $10.1093 /$ ntr/ntu279

102. Tayyarah, R. and G.A. Long: Comparison of Select Analytes in Aerosol from E-Cigarettes with Smoke from Conventional Cigarettes and with Ambient Air; Regul. Toxicol. Pharmacol. 70 (2014) 704-710. DOI: 10.1016/j.yrtph.2014.10.010

103. U.S. Food and Drug Administration (FDA): Harmful and Potentially Harmful Constituents (HPHCs); Available at https://www.fda.gov/tobacco-products/ products-ingredients-components/harmful-andpotentially-harmful-constituents-hphcs (accessed April 11, 2021)

104. U.S. Federal Register: A Notice by the U.S. Food and Drug Administration (FDA): Harmful and Potentially Harmful Constituents in Tobacco Products; Established List, Proposed Additions; Request for Comments; Federal Register (2019) 84 FR 38032. Available at: https:/www.federalregister.gov/documents/2019/ 08/05/2019-16658/harmful-and-potentially-harmfulconstituents-in-tobacco-products-established-listproposed-additions (accessed May 10, 2021)

105. Zhao, T., S. Shu, Q. Guo, and Y. Zhu: Effects of Design Parameters and Puff Topography on Heating Coil Temperature and Mainstream Aerosols in Electronic Cigarettes; Atmos. Environ. 134 (2016) 61-69. DOI: 10.1016/j.atmosenv.2016.03.027

106. Ward, A.M., R. Yaman, and J.O. Ebbert: Electronic Nicotine Delivery System Design and Aerosol Toxicants: A Systematic Review; PLoS One 15 (2020) e0234189. DOI: 10.1371/journal.pone.0234189

107. Bansal, V. and K.H. Kim: Review on Quantitation 
Methods for Hazardous Pollutants Released by E-Cigarette (EC) Smoking; Trends Analyt. Chem. 78 (2016) 120-133. DOI: $10.1016 /$ j.trac.2016.02.015

108. Cheng, T.: Chemical Evaluation of Electronic Cigarettes; Tob. Control 23, Suppl. 2 (2014) ii11-ii17. DOI: $10.1136 /$ tobaccocontrol-2013-051482

109. Strongin, R.M.: E-Cigarette Chemistry and Analytical Detection; Annu. Rev. Anal. Chem. 12 (2019) 23-39. DOI: 10.1146/annurev-anchem-061318-115329

110. Lauterbach, J.H. and M. Laugesen: Comparison of Toxicant Levels in Mainstream Aerosols Generated by Ruyan ${ }^{\circledR}$ Electronic Nicotine Delivery Systems (ENDS) and Conventional Cigarette Products; Poster \#1861 presented at the Society of Toxicology $51^{\text {st }}$ Annual Meeting \& ToxExpo, San Francisco, CA, USA, March 2012.

111. Lauterbach, J.H., M. Laugesen, and J.D. Ross: Suggested Protocol for Estimation of Harmful and Potentially Harmful Constituents in Mainstream Aerosols Generated by Electronic Nicotine Delivery Systems (ENDS); Poster \#1860 presented at the Society of Toxicology $51^{\text {st }}$ Annual Meeting \& ToxExpo, San Francisco, CA, USA, March 2012.

112. Cooperation Centre for Scientific Research Relative to Tobacco (CORESTA): CORESTA Recommended Method $\mathrm{N}^{\circ}$ 81. Routine Analytical Machine for E-Cigarette Aerosol Generation and Collection - Definitions and Standard Conditions; 2015. Available at: https://www.coresta.org/sites/default/files/technical documents/main/CRM 81.pdf (accessed April 29, 2020)

113. Beauval, N., S. Antherieu, M. Soyez, N. Gengler, N. Grova, M. Howsam, E.M. Hardy, M. Fischer, B.M.R. Appenzeller, J.F. Goossens, D. Allorge, G. Garçon, J.M. Lo-Guidice, and A. Garat: Chemical Evaluation of Electronic Cigarettes: Multicomponent Analysis of Liquid Refills and Their Corresponding Aerosols; J. Anal. Toxicol. 41 (2017) 670-678.

DOI: $10.1093 /$ jat/bkx054

114. Mallock, N., H.L. Trieu, M. Macziol, S. Malke, A. Katz, P. Laux, F. Henkler-Stephani, J. Hahn, C. Hutzler, and A. Luch: Trendy E-Cigarettes Enter Europe: Chemical Characterization of JUUL Pods and its Aerosols; Arch. Toxicol. 94 (2020) 1985-1994. DOI: 10.1007/s00204020-02716-3

115. Rudd, K., M. Stevenson, R. Wieczorek, J. Pani, E. Trelles-Sticken, O. Dethloff, L. Czekala, L. Simms, F. Buchanan, G. O'Connell, and T. Walele: Chemical Composition and In Vitro Toxicity Profile of a PodBased E-Cigarette Aerosol Compared to Cigarette Smoke; Appl. In Vitro Toxicol. 6 (2020) 11-41. DOI: 10.1089/aivt.2019.0015

116. Belushkin, M., D. Tafin Djoko, M. Esposito, A. Korneliou, C. Jeannet, M. Lazzerini, and G. Jaccard: Selected Harmful and Potentially Harmful Constituents Levels in Commercial E-Cigarettes; Chem. Res. Toxicol. 33 (2020) 657-668. DOI: 10.1021 acs.chemrestox.9b00470

117. Wagner, K.A., J.W. Flora, M.S. Melvin, K.C. Avery, R.M. Ballentine, A.P. Brown, and W.J. McKinney: An Evaluation of Electronic Cigarette Formulations and Aerosols for Harmful and Potentially Harmful Constituents (HPHCs) Typically Derived from
Combustion; Regul. Toxicol. Pharmacol. 95 (2018) 153160. DOI: 10.1016/j.yrtph.2018.03.012

118. Qu, Y., K.-H. Kim, and J.-E. Szulejko: The Effect of Flavor Content in E-Liquids on E-Cigarette Emissions of Carbonyl Compounds; Environ. Res. 166 (2018) 324333. DOI: 10.1016/j.envres.2018.06.013

119. Vas, C.A., A. Porter, and K. McAdam: Acetoin is a Precursor to Diacetyl in E-Cigarette Liquids; Food Chem. Toxicol. 133 (2019) 110727. DOI: $10.1016 /$ j.fct.2019.110727

120. Olmedo, P., W. Goessler, S. Tanda, M. Grau-Perez, S. Jarmul, A. Aherrera, R. Chen, M. Hilpert, J.E. Cohen, A. Navas-Acien, and A.M. Rule: Metal Concentrations in E-Cigarette Liquid and Aerosol Samples: The Contribution of Metallic Coils; Environ. Health Perspect. 126 (2018) 027010. DOI: 10.1289/EHP2175

121. Palazzolo, D.L., A.P. Crow, J.M. Nelson, and R.A. Johnson: Trace Metals Derived from Electronic Cigarette (ECIG) Generated Aerosol: Potential Problem of ECIG Devices That Contain Nickel; Front. Physiol. 7 (2017) 663. DOI: 10.3389/fphys.2016.00663

122. Zervas, E., H. Matsouki, G. Kyriakopoulos, S. Poulopoulos, T. Ioannides, and P. Katsaounou: Transfer of Metals in the Liquids of Electronic Cigarettes; Inhal. Toxicol. 32 (2020) 240-248. DOI: $10.1080 / 08958378.2020 .1776801$

123. Williams, M., A. Villarreal, K. Bozhilov, S. Lin, and P. Talbot: Metal and Silicate Particles Including Nanoparticles Are Present in Electronic Cigarette Cartomizer Fluid and Aerosol; PLoS One 8 (2013) e57987. DOI: 10.1371/journal.pone.0057987

124. Williams, M., A. To, K. Bozhilov and, P. Talbot: Strategies to Reduce Tin and Other Metals in Electronic Cigarette Aerosol; PLoS One 10 (2015) e0138933. DOI: 10.1371/journal.pone.0138933

125. Williams, M., K. Bozhilov, S. Ghai and P. Talbot: Elements Including Metals in the Atomizer and Aerosol of Disposable Electronic Cigarettes and Electronic Hookahs; PLoS One 12 (2017) e0175430. DOI: 10.1371/journal.pone.0175430

126. Williams, M., K.N. Bozhilov, and P. Talbot: Analysis of the Elements and Metals in Multiple Generations of Electronic Cigarette Atomizers; Environ. Res. 175 (2019) 156-166. DOI: 10.1016/j.envres.2019.05.014

127. Beauval, N., M. Howsam, S. Antherieu, D. Allorge, M. Soyez, G. Garçon, J.F. Goossens, J.M. Lo-Guidice and, A. Garat: Trace Elements in E-Liquids - Development and Validation of an ICP-MS Method for the Analysis of Electronic Cigarette Refills; Regul. Toxicol. Pharmacol. 79 (2016) 144-148.

DOI: $10.1016 /$ j.yrtph.2016.03.024

128. Kamilari, E., K. Farsalinos, K. Poulas, C.G. Kontoyannis, and M.G. Orkoula: Detection and Quantitative Determination of Heavy Metals in Electronic Cigarette Refill Liquids Using Total Reflection X-Ray Fluorescence Spectrometry; Food Chem. Toxicol. 116(2018) 233-237. DOI: 10.1016/j.fct.2018.04.035

129. Na, C.-J., S.-H. Jo, K.-H. Kim, J.-R. Sohn, and Y.-S. Son: The Transfer Characteristics of Heavy Metals in Electronic Cigarette Liquid; Environ. Res. 174 (2019) 152-159. DOI: 10.1016/j.envres.2019.04.025

130. Zhao, D., A. Navas-Acien, V. Ilievski, V. Slavkovich, P. 
Olmedo, B. Adria-Mora, A. Domingo-Relloso, A. Aherrera, N.J. Kleiman, A.M. Rule, and M. Hilpert: Metal Concentrations in Electronic Cigarette Aerosol: Effect of Open-System and Closed-System Devices and Power Settings; Environ. Res. 174 (2019) 125-134. DOI: 10.1016/j.envres.2019.04.003

131. Farsalinos, K.E., V. Voudris, and K. Poulas: Are Metals Emitted from Electronic Cigarettes a Reason for Health Concern? A Risk-Assessment Analysis of Currently Available Literature; Int. J. Environ. Res. Public Health 12 (2015) 5215-5232.

DOI: $10.3390 /$ ijerph120505215

132. Fowles, J., T. Barreau, and N. Wu: Cancer and NonCancer Risk Concerns from Metals in Electronic Cigarette Liquids and Aerosols; Int. J. Environ. Res. Public Health 17 (2020) 2146. DOI: 10.3390/ijerph17062146

133. Saliba, N.A., A. El Hellani, E. Honein, R. Salman, S. Talih, J. Zeaiter, and A. Shihadeh: Surface Chemistry of Electronic Cigarette Electrical Heating Coils: Effects of Metal Type on Propylene Glycol Thermal Decomposition; J. Anal. Appl. Pyrolysis 134 (2018) 520-525. DOI: $10.1016 /$ j.jaap.2018.07.019

134. Uchiyama, S., K. Ohta, Y. Inaba, and N. Kunugita: Determination of Carbonyl Compounds Generated from the E-Cigarette Using Coupled Silica Cartridges Impregnated with Hydroquinone and 2,4-Dinitrophenylhydrazine, Followed by High-Performance Liquid Chromatography; Anal. Sci. 29 (2013) 1219-1222. DOI: 10.2116/analsci.29.1219

135. Farsalinos, K.E., K.A. Kistler, A. Pennington, A. Spyrou, D. Kouretas, and G. Gillman: Aldehyde Levels in E-Cigarette Aerosol: Findings from a Replication Study and from Use of a New-Generation Device; Food Chem. Toxicol. 111 (2018) 64-70. DOI: $10.1016 /$ j.fct.2017.11.002

136. Gillman, I.G., K. Kistler, E. Stewart, and A.R. Paolantonio: Effect of Variable Power Levels on the Yield of Total Aerosol Mass and Formation of Aldehydes in E-Cigarette Aerosols; Regul. Toxicol. Pharmacol. 75 (2016) 58-65. DOI: 10.1016/j.yrtph.2015.12.019

137. Kosmider, L., C.F. Kimber, J. Kurek, O. Corcoran, and L.E. Dawkins: Compensatory Puffing with Lower Nicotine Concentration E-Liquids Increases Carbonyl Exposure in E-Cigarette Aerosols; Nicotine Tob. Res. 20 (2018) 998-1003. DOI: 10.1093/ntr/ntx162

138. Leventhal, A.M., D.R. Madden, N. Peraza, S.J. Schiff, L. Lebovitz, L. Whitted, J. Barrington-Trimis, T.B. Mason, M.K. Anderson, and A.P. Tackett: Effect of Exposure to E-Cigarettes with Salt vs Free-Base Nicotine on the Appeal and Sensory Experience of Vaping: A Randomized Clinical Trial; JAMA Netw. Open. 4 (2021) e2032757.

DOI: 10.1001/jamanetworkopen.2020.32757

139. Ebajemito, J.K., M. McEwan, N. Gale, O.M. Camacho, G. Hardie, and C.J. Proctor: A Randomised Controlled Single-Centre Open-Label Pharmacokinetic Study to Examine Various Approaches of Nicotine Delivery Using Electronic Cigarettes; Sci. Rep. 10 (2020) 19980. DOI: $10.1038 / \mathrm{s} 41598-020-76610-4$

140. O'Connell, G., J.D. Pritchard, C. Prue, J. Thompson, T. Verron, D. Graff, and T.A. Walele: A Randomised, Open-Label, Cross-Over Clinical Study to Evaluate the
Pharmacokinetic Profiles of Cigarettes and E-Cigarettes with Nicotine Salt Formulations in US Adult Smokers; Intern. Emerg. Med. 14 (2019) 853-861.

DOI: $10.1007 / \mathrm{s} 11739-019-02025-3$

141. Talih, S., R. Salman, R. El-Hage, N. Karaoghlanian, A. El-Hellani, N. Saliba, and A. Shihadeh: Effect of FreeBase and Protonated Nicotine on Nicotine Yield from Electronic Cigarettes with Varying Power and Liquid Vehicle; Sci. Rep. 10 (2020) 16263. DOI: $10.1038 / \mathrm{s} 41598-020-73385-6$

142. Harvanko, A.M., C.M. Havel, P. Jacob III, and N.L. Benowitz: Characterization of Nicotine Salts in 23 Electronic Cigarette Refill Liquids; Nicotine Tob. Res. 22 (2020) 1239-1243. DOI: 10.1093/ntr/ntz232

143. Moldoveanu, S.C.: Pyrolysis of Organic Molecules with Applications to Health and Environmental Issues; in: Techniques and Instrumentation in Analytical Chemistry, Vol 28, Elsevier Science, Amsterdam, The Netherlands, 2010, pp. 471-526.

144. Pankow, J.F., K. Kim, K.J. McWhirter, W. Luo, J.O. Escobedo, R.M. Strongin, A.K. Duell, and D.H. Peyton: Benzene Formation in Electronic Cigarettes; PLoS One 12 (2017) e0173055.

DOI: 10.1371/journal.pone.0173055

145. Cao, S., C. Yang, Y. Gan, and Z. Lu: The Health Effects of Passive Smoking: An Overview of Systematic Reviews Based on Observational Epidemiological Evidence; PLoS One 10 (2015) e0139907. DOI: 10.1371/journal.pone.0139907

146. Li, L., Y. Lin, T. Xia, and Y. Zhu: Effects of Electronic Cigarettes on Indoor Air Quality and Health; Ann. Rev. Public Health 41 (2020) 363-380. DOI: 10.1146/annurev-publhealth-040119-094043

147. Chen, R., A. Aherrera, C. Isichei, P. Olmedo, S. Jarmul, J.E. Cohen, A. Navas-Acien, and A.M. Rule: Assessment of Indoor Air Quality at an Electronic Cigarette (Vaping) Convention; J. Expo. Sci. Environ. Epidemiol. 28 (2018) 522-529.

DOI: $10.1038 / \mathrm{s} 41370-017-0005-\mathrm{x}$

148. Martuzevicius, D., T. Prasauskas, A. Setyan, G. O'Connell, X. Cahours, R. Julien, and S. Colard: Characterization of the Spatial and Temporal Dispersion Differences Between Exhaled E-Cigarette Mist and Cigarette Smoke; Nicotine Tob. Res. 21 (2019) 13711377. DOI: $10.1093 /$ ntr/nty121

149. Czogala, J., M.L. Goniewicz, B. Fidelus, W. ZielinskaDanch, M.J. Travers, and A. Sobczak: Secondhand Exposure to Vapors from Electronic Cigarettes; Nicotine Tob. Res. 16 (2014) 655-662. DOI: 10.1093/ntr/ntt203

150. Klepeis, N.E., J. Bellettiere, S.C. Hughes, B. Nguyen, V. Berardi, S. Liles, S. Obayashi, C.R. Hofstetter, E. Blumberg, and M.F. Hovell: Fine Particles in Homes of Predominantly Low-Income Families with Children and Smokers: Key Physical and Behavioral Determinants to Inform Indoor-Air-Quality Interventions; PLoS One 12 (2017) e0177718. DOI: 10.1371/journal.pone.0177718

151. Bals, R., J. Boyd, S. Esposito, R. Foronjy, P.S. Hiemstra, C.A. Jiménez-Ruiz, P. Katsaounou, A. Lindberg, C. Metz, W. Schober, A. Spira, and F. Blasi: Electronic Cigarettes: A Task Force Report from the European Respiratory Society; Eur. Respir. J. 53 (2019) 
1801151. DOI: $10.1183 / 13993003.01151-2018$

152. Cancer Research UK: Cancer Research UK Briefing: Electronic Cigarettes; 2016. Available at: https:/www.cancer researchuk.org/sites/default/files/e-cigarette_briefing nov_2016_final.pdf (accessed January 26, 2021)

153. Public Health England: Use of E-Cigarettes in Public Places and Workplaces. Advice to Inform Evidencebased Policy Making; 2016. Available at: https://assets. publishing.service.gov.uk/government/uploads/system/ uploads/attachment_data/file/768952/PHE-advice-on-use-ofe-cigarettes-in-public-places-and-workplaces.PDF (accessed January 26, 2021)

154. Committee on Toxicity of Chemicals in Food, Consumer Products and the Environment (COT): Statement on the Potential Toxicological Risks from Electronic Nicotine (and Non-Nicotine) Delivery Systems (E(N)NDS - ECigarettes); 2020. Available at: https://cot.food.gov.uk/ sites/default/files/2020-09/COT E(N)NDS statement 2020-04.pdf (accessed January 26, 2021)

155. Raunio, H.: In Silico Toxicology - Non-Testing Methods; Front. Pharmacol. 2 (2011) 33. DOI: $10.3389 /$ fphar.2011.00033

156. Zarini, D., A. Sangion, E. Ferri, E. Caruso, S. Zucchi, A. Orro, and E. Papa: Are In Silico Approaches Applicable as a First Step for the Prediction of E-Liquid Toxicity in ECigarettes?; Chem. Res. Toxicol. 33 (2020) 2381-2389. DOI: 10.1021/acs.chemrestox.0c00136

157. Merecz-Sadowska, A., P. Sitarek, H. Zielinska-Blizniewska, K. Malinowska, K. Zajdel, L. Zakonnik, and R. Zajdel: A Summary of In Vitro and In Vivo Studies Evaluating the Impact of E-Cigarette Exposure on Living Organisms and the Environment; Int. J. Mol. Sci. 21 (2020) 652. DOI: 10.3390/ijms21020652

158. Avila, A.M., I. Bebenek, J.A. Bonzo, T. Bourcier, K.L. Davis Bruno, D.B. Carlson, J. Dubinion, I. Elayan, W. Harrouk, S.L. Lee, D.L. Mendrick, J.C. Merrill, J. Peretz, E. Place, M. Saulnier, R.L. Wange, J. Yao, D. Zhao, and P.C. Brown: An FDA/CDER Perspective on Nonclinical Testing Strategies: Classical Toxicology Approaches and New Approach Methodologies (NAMs); Regul. Toxicol. Pharmacol. 114 (2020) 104662. DOI: 10.1016/j.yrtph.2020.104662

159. European Chemicals Agency: In Vitro Methods; 2020. Available at: https://echa.europa.eu/support/registration/ how-to-avoid-unnecessary-testing-on-animals/in-vitromethods (accessed January 6, 2021).

160. Wan, J., M.D. Johnson, J. Schilz, M.V. Djordjevic, J.R. Rice, and P.G. Shields: Evaluation of In Vitro Assays for Assessing the Toxicity of Cigarette Smoke and Smokeless Tobacco; Cancer Epidemiol. Biomarkers Prev. 18 (2009) 3263-3304.

DOI: 10.1158/1055-9965.EPI-09-0965

161. Czekala, L., L. Simms, M. Stevenson, N. Tschierske, A.G. Maione, and T. Walele: Toxicological Comparison of Cigarette Smoke and E-Cigarette Aerosol Using a 3D In Vitro Human Respiratory Model; Regul. Toxicol. Pharmacol. 103 (2019) 314-324.

DOI: 10.1016/j.yrtph.2019.01.036

162. Iskandar, A.R., C. Mathis, F. Martin, P. Leroy, A. Sewer, S. Majeed, D. Kuehn, K. Trivedi, D. Grandolfo, M. Cabanski, E. Guedj, C. Merg, S. Frentzel, N.V. Ivanov, M.C. Peitsch and J. Hoeng: 3-D Nasal Cultures:
Systems Toxicological Assessment of a Candidate Modified-Risk Tobacco Product; ALTEX 34 (2017) 2348. DOI: 10.14573/altex.1605041

163. Breheny, D., D. Thorne, A. Baxter, S. Bozhilova, T. Jaunky, S. Santopietro, M. Taylor, A. Terry, and M. Gaça: The In Vitro Assessment of a Novel Vaping Technology; Toxicol. Rep. 7 (2020) 1145-1156. DOI: $10.1016 /$ j.toxrep.2020.08.016

164. Wang, G., W. Liu, and W. Song: Toxicity Assessment of Electronic Cigarettes; Inhal. Toxicol. 31 (2019) 259273. DOI: $10.1080 / 08958378.2019 .1671558$

165. Breheny, D., O. Oke, K. Pant, and M. Gaça: Comparative Tumour Promotion Assessment of E-Cigarette and Cigarettes Using the In Vitro Bhas 42 Cell Transformation Assay; Environ. Mol. Mutagen. 58 (2017) 190-198. DOI: 10.1002/em.22091

166. Thorne, D., I. Crooks, M. Hollings, A. Seymour, C. Meredith, and M. Gaça: The Mutagenic Assessment of an Electronic-Cigarette and Reference Cigarette Smoke Using the Ames Assay in Strains TA98 and TA100; Mutat. Res. 812 (2016) 29-38. DOI: 10.1016/j.mrgentox.2016.10.005

167. Thorne, D., M. Hollings, A. Seymour, J. Adamson, A. Dalrymple, M. Ballantyne, and M. Gaca: Extreme Testing of Undiluted E-Cigarette Aerosol In Vitro Using an Ames Air-Agar-Interface Technique; Mutat. Res. Genet. Toxicol. Environ. Mutagen. 828 (2018) 46-54. DOI: 10.1016/j.mrgentox.2018.01.008

168. Azzopardi, D., K. Patel, T. Jaunky, S. Santopietro, O.M. Camacho, J. McAughey, and M. Gaça: Electronic Cigarette Aerosol Induces Significantly Less Cytotoxicity Than Tobacco Smoke; Toxicol. Mech. Methods 26 (2016) 477-491.

DOI: $10.1080 / 15376516.2016 .1217112$

169. Bishop, E., L. Haswell, J. Adamson, S. Costigan, D. Thorne, and M. Gaça: An Approach to Testing Undiluted E-Cigarette Aerosol In Vitro Using 3D Reconstituted Human Airway Epithelium; Toxicol. In Vitro 54 (2019) 391-401. DOI: $10.1016 /$ j.tiv.2018.01.010

170. Makwana, O., H. Flockton, G.A. Smith, G.P. Watters, R. Nisar, and W. Fields: Mechanisms of Whole Smoke Conditioned Media Induced Cytotoxicity to Human Aortic Endothelial Cells; Toxicol. In Vitro 58 (2019) 239-244. DOI: 10.1016/j.tiv.2019.03.011

171. Neilson, L., C. Mankus, D. Thorne, G. Jackson, J. DeBay, and C. Meredith: Development of an In Vitro Cytotoxicity Model for Aerosol Exposure Using 3D Reconstructed Human Airway Tissue; Application for Assessment of E-Cigarette Aerosol; Toxicol. In Vitro 29 (2015) 1952-1962. DOI: 10.1016/j.tiv.2015.05.018

172. Thorne, D., S. Larard, A. Baxter, C. Meredith, and M. Gaça: The Comparative In Vitro Assessment of E-Cigarette and Cigarette Smoke Aerosols Using the $\gamma \mathrm{H} 2 \mathrm{AX}$ Assay and Applied Dose Measurements; Toxicol. Lett. 265 (2017) 170-178.

DOI: 10.1016/j.toxlet.2016.12.006

173. Thorne, D., R. Leverette, D. Breheny, M. Lloyd, S. McEnaney, J. Whitwell, J. Clements, B. Bombick, and M. Gaça: Genotoxicity Evaluation of Tobacco and Nicotine Delivery Products: Part One. Mouse Lymphoma Assay; Food Chem. Toxicol. 132 (2019) 110584. 
DOI: 10.1016/j.fct.2019.110584

174. Thorne, D., R. Leverette, D. Breheny, M. Lloyd, S. McEnaney, J. Whitwell, J. Clements, B. Bombick, and M. Gaça: Genotoxicity Evaluation of Tobacco and Nicotine Delivery Products: Part Two. In Vitro Micronucleus Assay; Food Chem. Toxicol. 132 (2019) 110546. DOI: 10.1016/j.fct.2019.05.054

175. Ito, S., M. Taylor, S. Mori, D. Thorne, T. Nishino, D. Breheny, M. Gaça, K. Yoshino, and C. Proctor: An Inter-Laboratory In Vitro Assessment of Cigarettes and Next Generation Nicotine Delivery Products; Toxicol. Lett. 315 (2019) 14-22.

DOI: 10.1016/j.toxlet.2019.08.004

176. Taylor, M., T. Carr, O. Oke, T. Jaunky, D. Breheny, and F. Lowe: E-Cigarette Aerosols Induce Lower Oxidative Stress In Vitro When Compared to Tobacco Smoke; Toxicol. Mech. Methods 6 (2016) 445-467. DOI: $10.1080 / 15376516.2016 .1222473$

177. Taylor, M., T. Jaunky, K. Hewitt, D. Breheny, F. Lowe, I.M. Fearon, and M. Gaça: A Comparative Assessment of E-Cigarette Aerosols and Cigarette Smoke on In Vitro Endothelial Cell Migration; Toxicol. Lett. 277 (2017) 123-128. DOI: 10.1016/j.toxlet.2017.06.001

178. Farsalinos, K.E. and R. Polosa: Safety Evaluation and Risk Assessment of Electronic Cigarettes as Tobacco Cigarette Substitutes: A Systematic Review; Ther. Adv. Drug Saf. 5 (2014) 67-86.

DOI: $10.1177 / 2042098614524430$

179. Public Health England - Committee on Toxicity (COT): E-Cigarettes Likely to Reduce Harm to Health for Smokers but are not Entirely Risk-Free; 2020. Available at: https://phe-newsroom.prgloo.com/news/e-cigaretteslikely-to-reduce-harm-to-health-for-smokers-but-are-notentirely-risk-free (accessed January 26, 2021)

180. Banerjee, A., L.E. Haswell, A. Baxter, A. Parmar, D. Azzopardi, S. Corke, D. Thorne, J. Adamson, J. Mushonganono, M.D. Gaça, and E. Minet: Differential Gene Expression Using RNA Sequencing Profiling in a Reconstituted Airway Epithelium Exposed to Conventional Cigarette Smoke or Electronic Cigarette Aerosols; Appl. In Vitro Toxicol. 3 (2017) 84-98. DOI: 10.1089/aivt.2016.0024

181. Haswell, L.D., A. Baxter, A. Banerjee, I. Verrastro, J. Mushonganono, J. Adamson, D. Thorne, M. Gaça, and E. Minet: Reduced Biological Effect of E-Cigarette Aerosol Compared to Cigarette Smoke Evaluated In Vitro Using Normalized Nicotine Dose and RNA-SeqBased Toxicogenomics; Sci. Rep. 7 (2017) 888. DOI: 10.1038/s41598-017-00852-y

182. Marescotti, D., C. Mathis, V. Belcastro, P. Leroy, S. Acali, F. Martin, R. Dulize, D. Bornand, D. Peric, E. Guedj, L. Ortega Torres, M. Biasioli, M. Fuhrimann, E. Fernandes, F. Frauendorfer, I. Gonzalez Suarez, D. Sciuscio, N.V. Ivanov, M.C. Peitsch, and J. Hoeng: Systems Toxicology Assessment of a Representative ELiquid Formulation Using Human Primary Bronchial Epithelial Cells; Toxicol. Rep. 7 (2019) 67-80. DOI: 10.1016/j.toxrep.2019.11.016

183. Titz, B., J. Szostak, A. Sewer, B. Phillips, C. Nury, T. Schneider, S. Dijon, O. Lavrynenko, A. Elamin, E. Guedj, E. Tsin Wong, S. Lebrun, G. Vuillaume, A. Kondylis, S. Gubian, S. Cano, P. Leroy, B. Keppler,
N.V. Ivanov, P. Vanscheeuwijck, F. Martin, M.C. Peitsch, and J. Hoeng: Multi-Omics Systems Toxicology Study of Mouse Lung Assessing the Effects of Aerosols from Two Heat-Not-Burn Tobacco Products and Cigarette Smoke; Comput. Struct. Biotechnol. J. 18 (2020) 1056-1073. DOI: 10.1016/j.csbj.2020.04.011

184. Slob, W., L.G. Soeteman-Hernández, W. Bil, Y.C.M. Staal, W.E. Stephens, and R. Talhout: A Method for Comparing the Impact on Carcinogenicity of Tobacco Products: A Case Study on Heated Tobacco Versus Cigarettes; Risk Anal. 40 (2020) 1355-1366.

DOI: $10.1111 /$ risa. 13482

185. U.S. Department of Health and Human Services (DHHS): The Health Consequences of Smoking: A Report of the Surgeon General; Centers for Disease Control and Prevention, Atlanta, GA, USA, 2004. Available at: https://www.ncbi.nlm.nih.gov/books/ NBK44695/ (accessed May 12, 2021)

186. El Dib, R., E.A. Suzumura, E.A. Akl, H. Gomaa, A. Agarwal, Y. Chang, M. Prasad, V. Ashoorion, D. HeelsAnsdell, W. Maziak, and G. Guyatt: Electronic Nicotine Delivery Systems and/or Electronic Non-nicotine Delivery Systems for Tobacco Smoking Cessation or Reduction: A Systematic Review and Meta-Analysis; BMJ Open 7 (2017) e012680.

DOI: 10.1136/bmjopen-2016-012680

187. Hartmann-Boyce, J., H. McRobbie, C. Bullen, R. Begh, L.F. Stead, and P. Hajek: Electronic Cigarettes for Smoking Cessation; Cochrane Database Syst. Rev. 9 (2016) CD010216.

DOI: 10.1002/14651858.CD010216.pub3

188. Kalkhoran, S. and S.A. Glantz: E-Cigarettes and Smoking Cessation in Real-World and Clinical Settings: A Systematic Review and Meta-Analysis; Lancet Respir. Med. 4 (2016) 116-128. DOI: 10.1016/S2213-2600(15)00521-4

189. Simonavicius, E., A. McNeil, D. Arnott, and L.S. Brose: What Factors are Associated with Current Smokers Using or Stopping E-Cigarette Use?; Drug Alcohol Depend. 173 (2017) 139-143.

DOI: 10.1016/j.drugalcdep.2017.01.002

190. Fearon, I.M., A.C. Eldridge, N. Gale, M. McEwan, M.F. Stiles, and E.K. Round: Nicotine Pharmacokinetics of Electronic Cigarettes: A Review of the Literature; Regul. Toxicol. Pharmacol. 100 (2018) 25-34. DOI: 10.1016/j.yrtph.2018.09.004

191. Armitage, A., C. Dollery, T. Houseman, E. Kohner, P. Lewis, and D. Turner: Absorption of Nicotine from Small Cigars; Clin. Pharmacol. Ther. 23 (1978) 143-151. DOI: $10.1002 / \mathrm{cpt} 1978232143$

192. Armitage, A.K., J. Alexander, R. Hopkins, and C. Ward: Evaluation of a Low to Middle Tar/Medium Nicotine Cigarette Designed to Maintain Nicotine Delivery to the Smoker; Psychopharmacology 96 (1988) 447-453. DOI: 10.1007/BF02180022

193. Armitage, A. and D. Turner: Absorption of Nicotine in Cigarette and Cigar Smoke Through the Oral Mucosa; Nature 226 (1970) 1231-1232.

DOI: $10.1038 / 2261231 \mathrm{a} 0$

194. Benowitz, N. and P. Jacob III: Daily Intake of Nicotine During Cigarette Smoking; Clin. Pharmacol. Ther. 35 (1984) 499-504. DOI: 10.1038/clpt.1984.67

195. Digard, H., C. Proctor, A. Kulasekaran, U. Malmqvist, 
and A. Richter: Determination of Nicotine Absorption from Multiple Tobacco Products and Nicotine Gum; Nicotine Tob. Res. 15 (2013) 255-261.

DOI: $10.1093 / \mathrm{ntr} / \mathrm{nts} 123$

196. Stiles, M.F., L.R. Campbell, D.W. Graff, B.A. Jones, R.V. Fant, and J.E. Henningfield: Pharmacodynamic and Pharmacokinetic Assessment of Electronic Cigarettes, Combustible Cigarettes, and Nicotine Gum: Implications for Abuse Liability; Psychopharmacology 234 (2017) 2643-2655. DOI: 10.1007/s00213-017-4665-y

197. Stiles, M.F., L.R. Campbell, T. Jin, D.W. Graff, R.V. Fant, and J.E. Henningfield: Assessment of the Abuse Liability of Three Menthol Vuse Solo Electronic Cigarettes Relative to Combustible Cigarettes and Nicotine Gum; Psychopharmacology 235 (2018) 2077-2086. DOI: $10.1007 / \mathrm{s} 00213-018-4904-\mathrm{x}$

198. Bullen, C., H. McRobbie, S. Thornley, M. Glover, R. Lin, and M. Laugesen: Effect of an Electronic Nicotine Delivery Device (E Cigarette) on Desire to Smoke and Withdrawal, User Preferences and Nicotine Delivery: Randomised Cross-Over Trial; Tob. Control 19 (2010) 98-103. DOI: 10.1136/tc.2009.031567

199. Hansson, A., T. Rasmussen, and H. Kraiczi: Single-Dose and Multiple-Dose Pharmacokinetics of Nicotine $6 \mathrm{mg}$ Gum; Nicotine Tob. Res. 19 (2017) 477-483. DOI: $10.1093 /$ ntr/ntw211

200. Sukhija, M., R. Srivastava and A. Kaushik: Pharmacokinetic Characterization of Three Novel 4-mg Nicotine Lozenges; Int. J. Clin. Pharmacol. Ther. 56 (2018) 113 119. DOI: $10.5414 / \mathrm{CP} 203097$

201. Farsalinos K.E., A. Spyrou, K. Tsimopoulou, C. Stefopoulos, G. Romagna, and V. Voudris: Nicotine Absorption from Electronic Cigarette Use: Comparison Between First and New-Generation Devices; Sci. Rep. 4 (2014) 4133. DOI: 10.1038/srep04133

202. Nides, M.N., S.J. Leischow, M. Bhatter, and M. Simmons: Nicotine Blood Levels and Short-Term Smoking Reduction with an Electronic Nicotine Delivery System; Am. J. Health Behav. 38 (2014) 265 274. DOI: 10.5993/AJHB.38.2.12

203. Walele, T., T. Sharma, R. Savioz, C. Martin, and J. Williams: A Randomised, Crossover Study on an Electronic Vapour Product, a Nicotine Inhalator and a Conventional Cigarette. Part A: Pharmacokinetics; Regul. Toxicol. Pharmacol. 74 (2016) 187-192. DOI: 10.1016/j.yrtph.2015.12.003

204. St. Helen, G., C. Havel, D.A. Dempsey, P. Jacob III, and N.L. Benowitz: Nicotine Delivery, Retention and Pharmacokinetics From Various Electronic Cigarettes; Addiction 111 (2016) 535-544.

DOI: $10.1111 /$ add. 13183

205. Vansickel, A.R. and T. Eissenberg: Electronic Cigarettes: Effective Nicotine Delivery After Acute Administration; Nicotine Tob. Res. 15 (2013) 267-270. DOI: $10.1093 / \mathrm{ntr} / \mathrm{ntr} 316$

206. Wagener, T.L., E.L. Floyd, I. Stepanov, L.M. Driskill, S.G. Frank, E. Meier, E.L. Leavens, A.P. Tackett, N. Molina, and L. Queimado: Have Combustible Cigarettes Met Their Match? The Nicotine Delivery Profiles and Harmful Constituent Exposures of Second-Generation and Third-Generation Electronic Cigarette Users; Tob. Control 26 (2017) e23-e28.
DOI: 10.1136/tobaccocontrol-2016-053041

207. Hajek, P., K. Pittaccio, F. Pesola, K. Myers Smith, A. Phillips-Waller, and D. Przulj: Nicotine Delivery and Users' Reactions to Juul Compared with Cigarettes and Other E-Cigarette Products; Addiction 115 (2020) 11411148. DOI: $10.1111 /$ add.14936

208. Ramôa, C.P., M.M. Hiler, T.R. Spindle, A.A. Lopez, N. Karaoghlanian, T. Lipato, A.B. Breland, A. Shihadeh, and T. Eissenberg: Electronic Cigarette Nicotine Delivery Can Exceed That of Combustible Cigarettes: A Preliminary Report; Tob. Control 25 (2016) e6-9. DOI: 10.1136/tobaccocontrol-2015-052447

209. Fearon, I.M., A. Eldridge, N. Gale, C.J. Shepperd, M. McEwan, O.M. Camacho, M. Nides, K. McAdam, and C.J. Proctor: E-Cigarette Nicotine Delivery: Data and Learnings From Pharmacokinetic Studies; Am. J. Health Behav. 41 (2017) 16-32. DOI: $10.5993 / a j h b .41 .1 .2$

210. Hajek, P., M.L. Goniewicz, A. Phillips, K. Myers Smith, O. West, and H. McRobbie: Nicotine Intake from Electronic Cigarettes on Initial Use and After 4 Weeks of Regular Use; Nicotine Tob. Res. 17 (2015) 175-179. DOI: $10.1093 /$ ntr/ntu153

211. Cox, S., L. Dawkins, J. Doshi, and J. Cameron: Effects of E-Cigarettes Versus Nicotine Replacement Therapy on Short-Term Smoking Abstinence When Delivered at a Community Pharmacy; Addict. Behav. Rep. 10 (2019) 100202. DOI: 10.1016/j.abrep.2019.100202

212. Hajek, P., A. Phillips-Waller, D. Przulj, F. Pesola, K. Myers Smith, N. Bisal, J. Li, S. Parrott, P. Sasieni, L. Dawkins, L. Ross, M. Goniewicz, Q. Wu, and H.J. McRobbie: A Randomized Trial of E-Cigarettes Versus Nicotine-Replacement Therapy; N. Engl. J. Med. 380 (2019) 629-637.

DOI: 10.1056/NEJMoa1808779

213. Chang, C.M., S.H. Edwards, A. Arab, A.Y. Del VallePinero, L. Yang, and D.K. Hatsukami: Biomarkers of Tobacco Exposure: Summary of an FDA-Sponsored Public Workshop; Cancer Epidemiol. Biomarkers Prev. 26 (2017) 291-302. DOI: 10.1158/1055-9965.EPI-16-0675

214. Czoli, C.D., G.T. Fong, M.J. Goniewicz, and D. Hammond: Biomarkers of Exposure Among "Dual Users" of Tobacco Cigarettes and Electronic Cigarettes in Canada; Nicotine Tob. Res. 21 (2019) 1259-1266. DOI: $10.1093 /$ ntr/nty174

215. Goniewicz, M.L., M. Gawron, D.M. Smith, M. Peng, P. Jacob III, and N.L. Benowitz: Exposure to Nicotine and Selected Toxicants in Cigarette Smokers Who Switched to Electronic Cigarettes: A Longitudinal Within-Subjects Observational Study; Nicotine Tob. Res. 19 (2017) 160167. DOI: $10.1093 /$ ntr/ntw160

216. Lorkiewicz, P., D.W. Riggs, R.J. Keith, D.J. Conklin, Z. Xie, S. Sutaria, B. Lynch, S. Srivastava, and A. Bhatnagar: Comparison of Urinary Biomarkers of Exposure in Humans Using Electronic Cigarettes, Combustible Cigarettes, and Smokeless Tobacco; Nicotine Tob. Res. 21 (2019) 12281238. DOI: $10.1093 /$ ntr/nty089

217. McRobbie, H., A. Phillips, M.L. Goniewicz, K.M. Smith, O. Knight-West, D. Przulj, and P. Hajek: Effects of Switching to Electronic Cigarettes With and Without Concurrent Smoking on Exposure to Nicotine, Carbon Monoxide, and Acrolein; Cancer Prev. Res. 8 (2015) 
873-878. DOI: 10.1158/1940-6207.CAPR-15-0058

218. Aherrera, A., P. Olmedo, M. Grau-Perez, S. Tanda, W. Goessler, S. Jarmul, R. Chen, J.E. Cohen, A.M. Rule, and A. Navas-Acien: The Association of E-Cigarette Use with Exposure to Nickel and Chromium: A Preliminary Study of Non-Invasive Biomarkers; Environ. Res. 159 (2017) 313-320.

DOI: 10.1016/j.envres.2017.08.014

219. Goniewicz, M.L., D.M. Smith, K.C. Edwards, B.C. Blount, K.L. Caldwell, J. Feng, L. Wang, C. Christensen, B. Ambrose, N. Borek, D. van Bemmel, K. Konkel, G. Erives, C.A. Stanton, E. Lambert, H.L. Kimmel, D. Hatsukami, S.S. Hecht, R.S. Niaura, M. Travers, C. Lawrence, and A.J. Hyland: Comparison of Nicotine and Toxicant Exposure in Users of Electronic Cigarettes and Combustible Cigarettes; JAMA Netw. Open 1 (2018) e 185937. DOI: 10.1001/jamanetworkopen.2018.5937

220. Polosa, R., J.B. Morjaria, P. Caponnetto, U. Prosperini, C. Russo, A. Pennisi, and C.M. Bruno: Evidence for Harm Reduction in COPD Smokers Who Switch to Electronic Cigarettes; Respir. Res. 17 (2016) 166. DOI: 10.1186/s12931-016-0481-x

221. Shahab, L., M.L. Goniewicz, B.C. Blount, J. Brown, A. McNeill, K.U. Alwis, J. Feng, L. Wang, and R. West: Nicotine, Carcinogen, and Toxin Exposure in LongTerm E-Cigarette and Nicotine Replacement Therapy Users: A Cross-Sectional Study; Ann. Intern. Med.166 (2017) 390-400. DOI: 10.7326/M16-1107

222. Sakamaki-Ching, S., M. Williams, M. Hua, J. Li, S.M. Bates, A.N. Robinson, T.W. Lyons, M.L. Goniewicz, and P. Talbot: Correlation Between Biomarkers of Exposure, Effect and Potential Harm in the Urine of Electronic Cigarette Users; BMJ Open Respir. Res. 7 (2020) e000452. DOI: 10.1136/bmjresp-2019-000452

223. Round, E.K., P. Chen, A.K. Taylor, and E. Schmidt: Biomarkers of Tobacco Exposure Decrease After Smokers Switch to an E-Cigarette or Nicotine Gum; Nicotine Tob. Res. 21 (2019) 1239-1247.

DOI: $10.1093 /$ ntr/nty140

224. Walele, T., J. Bush, A. Koch, R. Savioz, C. Martin, and G. O'Connell: Evaluation of the Safety Profile of an Electronic Vapour Product Used for Two Years by Smokers in a Real-life Setting; Regul. Toxicol. Pharmacol. 92 (2018) 226-238.

DOI: $10.1016 /$ j.yrtph.2017.12.010

225. Cravo, A.S., J. Bush, G. Sharma, R. Savioz, C. Martin, S. Craige, and T.A. Walele: A Randomized, Parallel Group Study to Evaluate the Safety Profile of an Electronic Vapour Product Over 12 Weeks; Regul. Toxicol. Pharmacol. 81 (2016) S1-S14.

DOI: 10.1016/j.yrtph.2016.10.003

226. Hecht, S.S., S.G. Carmella, D. Kotandeniya, M.E. Pillsbury, M. Chen, B.W. Ransom, R.I. Vogel, E. Thompson, S.E. Murphy, and D.K. Hatsukami: Evaluation of Toxicant and Carcinogen Metabolites in the Urine of E-Cigarette Users Versus Cigarette Smokers; Nicotine Tob. Res. 17 (2015) 704-709.

DOI: $10.1093 /$ ntr/ntu218

227. Piper, M.E., T.B. Baker, N.L. Benowitz, K.H. Kobinsky, and D.E. Jorenby: Dual Users Compared to Smokers: Demographics, Dependence, and Biomarkers; Nicotine Tob. Res. 21 (2019) 1279-1284.
DOI: 10.1093/ntr/nty231

228. Chang, C.M., Y.-C. Cheng, T.M. Cho, E.V. Mishina, A.Y. Del Valle-Pinero, D.M. van Bemmel, and D.K. Hatsukami: Biomarkers of Potential Harm: Summary of an FDA-Sponsored Public Workshop; Nicotine Tob. Res. 21 (2019) 3-13. DOI: 10.1093/ntr/ntx273

229. Cibella, F., D. Campagna, P. Caponnetto, M.D. Amaradio, M. Caruso, C. Russo, D.W. Cockcroft, and R. Polosa: Lung Function and Respiratory Symptoms in a Randomized Smoking Cessation Trial of Electronic Cigarettes; Clin. Sci. 130 (2016) 1929-1937.

DOI: $10.1042 / \mathrm{CS} 20160268$

230. Polosa, R., J.B. Morjaria, P. Caponnetto, M. Caruso, D. Campagna, M.D. Amaradio, G. Ciampi, C. Russo, and A. Fisichella: Persisting Long Term Benefits of Smoking Abstinence and Reduction in Asthmatic Smokers Who Have Switched to Electronic Cigarettes; Discov. Med. 21 (2016) 99-108.

231. Wieslander, G., D. Norbäck, and T. Lindgren: Experimental Exposure to Propylene Glycol Mist in Aviation Emergency Training: Acute Ocular and Respiratory Effects; Occup. Environ. Med. 58 (2001) 649-655. DOI: $10.1136 /$ oem.58.10.649

232. D’Ruiz, C.D., G. O’Connell, D.W. Graff, and X.S. Yan: Measurement of Cardiovascular and Pulmonary Function Endpoints and Other Physiological Effects Following Partial or Complete Substitution of Cigarettes with Electronic Cigarettes in Adult Smokers; Regul. Toxicol. Pharmacol. 87 (2017) 36-53. DOI: 10.1016/j.yrtph.2017.05.002

233. Yuan, J.-M., S.G. Carmella, R. Wang, Y.T. Tan, J. Adams-Haduch, Y.T. Gao, and S.S. Hecht: Relationship of the Oxidative Damage Biomarker 8-epi-Prostaglandin $\mathrm{F}_{2 \alpha}$ to Risk of Lung Cancer Development in the Shanghai Cohort Study; Carcinogenesis 39 (2018) 948954. DOI: 10.1093/carcin/bgy060

234. Oliveri, D., Q. Liang, and M. Sarkar: Real-World Evidence of Differences in Biomarkers of Exposure to Select Harmful and Potentially Harmful Constituents and Biomarkers of Potential Harm Between Adult E-Vapor Users and Adult Cigarette Smokers; Nicotine Tob. Res. 22 (2020) 1114-1122.

DOI: $10.1093 /$ ntr/ntz185

235. Song, M.-A., J.L. Freidenheim, T.M. Brasky, E.A. Mathe, J.P. McElroy, Q.A. Nickerson, S.A. Reisinger, D.J. Smiraglia, D.Y. Weng, K.L. Ying, M.D. Wewers, and P.G. Shields: Biomarkers of Exposure and Effect in the Lungs of Smokers, Nonsmokers, and Electronic Cigarette Users; Cancer Epidemiol. Biomarkers Prev. 29 (2020) 443-451. DOI: 10.1158/1055-9965.EPI-19-1245

236. Valavanidis, A., T. Vlachogianni, and C. Fiotakis: 8Hydroxy-2'-deoxyguanosine (8-OHdG): A Critical Biomarker of Oxidative Stress and Carcinogenesis; J. Environ. Sci. Health C Environ. Carcinog. Ecotoxicol. Rev. 27 (2009) 120-139. DOI: $10.1080 / 10590500902885684$

237. George, J., M. Hussain, T. Vadiveloo, S. Ireland, P. Hopkinson, A.D. Struthers, P.T. Donnan, F. Khan, and C.C. Lang: Cardiovascular Effects of Switching from Tobacco Cigarettes to Electronic Cigarettes; J. Am. Coll. Cardiol. 74 (2019) 3112-3120.

DOI: $10.1016 /$ j.jacc.2019.09.067 
238. de Faria, A.P., R. Modolo, and H. Moreno: Plasma 8Isoprostane as a Biomarker and Applications to Cardiovascular Disease; in: Biomarkers in Cardiovascular Disease, edited by V. Patel and V. Preedy, Springer, Dordrecht, The Netherlands, 2016.

DOI: $10.1007 / 978-94-007-7741-5$ 31-1

239. Wang, N., K.C. Vendrov, B.P. Simmons, R.N. Schuck, G.A. Stouffer, and C.R. Lee: Urinary 11-Dehydrothromboxane B2 Levels are Associated with Vascular Inflammation and Prognosis in Atherosclerotic Cardiovascular Disease; Prostaglandins Other Lipid Mediat. 134 (2018) 24-31.

DOI: 10.1016/j.prostaglandins.2017.11.003

240. Kuntic, M., M. Oelze, S. Steven, S. Kröller-Schön, P. Stamm, S. Kalinovic, K. Frenis, K. Vujacic-Mirski, M.T. Bayo Jimenez, M. Kvandova, K. Filippou, A. Al Zuabi, V. Brückl, O. Hahad, S. Daub, F. Varveri, T. Gori, R. Huesmann, T. Hoffmann, F.P. Schmidt, J.F. Keaney, A. Daiber, and T. Münzel: Short-Term E-Cigarette Vapour Exposure Causes Vascular Oxidative Stress and Dysfunction: Evidence for a Close Connection to Brain Damage and a Key Role of the Phagocytic NADPH Oxidase (NOX-2); Eur. Heart J. 41 (2020) 2472-2483. DOI: $10.1093 /$ eurheartj/ehz772

241. Kerr, D.M.I., K.J.M. Brooksbank, R.G. Taylor, K. Pinel, F.J. Rios, R.M. Touyz, and C. Delles; Acute Effects of Electronic and Tobacco Cigarettes on Vascular and Respiratory Function in Healthy Volunteers: A CrossOver Study; J. Hypertens. 37 (2019) 154-166. DOI: 10.1097/HJH.0000000000001890

242. Moheimani, R.S., M. Bhetraratana, K.M. Peters, B.K. Yang, F. Yin, J. Gornbein, J.A. Araujo, and H.R. Middlekauff: Sympathomimetic Effects of Acute E-Cigarette Use: Role of Nicotine and Non-Nicotine Constituents; J. Am. Heart Assoc. 6 (2017) e006579. DOI: 10.1161/JAHA.117.006579

243. Gathright, E.C., W.-C. Wu, and L.A.J. Scott-Sheldon: Electronic Cigarette Use Among Heart Failure Patients: Findings from the Population Assessment of Tobacco and Health Study (Wave 1: 2013-2014); Heart Lung 9 (2020) 229-232. DOI: 10.1016/j.hrtlng.2019.11.006

244. Flacco, M.E., M. Ferrante, M. Fiore, C. Marzuillo, C. La Vecchia, M.R. Gualano, G. Liguori, G. Fragassi, T. Carradori, F. Bravi, R. Siliquini, W. Ricciardi, P. Villari, and L. Manzoli: Cohort Study of Electronic Cigarette Use: Safety and Effectiveness After 4 Years of Followup; Eur. Rev. Med. Pharmacol. Sci. 23 (2019) 402-412. DOI: $10.26355 /$ eurrev 20190116789

245. O'Connell, G., D.W. Graff, and C.D. D'Ruiz: Reductions in Biomarkers of Exposure (BoE) to Harmful or Potentially Harmful Constituents (HPHCs) Following Partial or Complete Substitution of Cigarettes with Electronic Cigarettes in Adult Smokers; Toxicol. Mech. Methods 26 (2016) 443-454.

DOI: $10.1080 / 15376516.2016 .1196282$

246. Claire, R., C. Chamberlain, M.-A. Davey, S.E. Cooper, I. Berlin, J. Leonardi-Bee, and T. Coleman: Pharmacological Interventions for Promoting Smoking Cessation During Pregnancy; Cochrane Database Syst. Rev. 3 (2020) CD010078.

DOI: $10.1002 / 14651858 . C D 010078 . p u b 3$

247. The American College of Obstetricians and Gynecologists
(ACOG): Committee Opinion No. 807: Smoking Cessation During Pregnancy; 2020. Available at: https://www.acog.org/clinical/clinical-guidance/committeeopinion/articles/2020/05/tobacco-and-nicotine-cessationduring-pregnancy (accessed September 7, 2020)

248. National Institute for Health and Care Excellence (NICE): Smoking: Harm Reduction; Public Health Guideline [PH 45] 2013. Available at: https://www.nice. org.uk/guidance/PH45 (accessed April 29, 2020)

249. Berlin, I., G. Grangé, N. Jacob, and M.-L. Tanguy: Nicotine Patches in Pregnant Smokers: Randomised, Placebo Controlled, Multicentre Trial of Efficacy; BMJ 348 (2014) g1622. DOI: 10.1136/bmj.g1622

250. Bowker, K., S. Lewis, T. Coleman, and S. Cooper: Changes in the Rate of Nicotine Metabolism Across Pregnancy: A Longitudinal Study; Addiction 110 (2015) 1827-1832. DOI: 10.1111/add.13029

251. Singh, B., M. Hrywna, O.A. Wackowski, C.D. Delnevo, M. Jane Lewis, and M.B. Steinberg: Knowledge, Recommendation, and Beliefs of E-Cigarettes Among Physicians Involved in Tobacco Cessation: A Qualitative Study; Prev. Med. Rep. 8 (2017) 25-29.

DOI: 10.1016/j.pmedr.2017.07.012

252. Bowker, K., S. Orton, S. Cooper, F. Naughton, R. Whitemore, S. Lewis, L. Bauld, L. Sinclair, T. Coleman, A. Dickinson, and M. Ussher: Views on and Experiences of Electronic Cigarettes: A Qualitative Study of Women Who Are Pregnant or Have Recently Given Birth; BMC Pregnancy Childbirth 18 (2018) 233. DOI: $10.1186 / \mathrm{s} 12884-018-1856-4$

253. McCubbin, A., A. Fallin-Bennet, J. Barnett, and K. Ashford: Perceptions and Use of Electronic Cigarettes in Pregnancy; Health Educ. Res. 32 (2017) 22-32. DOI: 10.1093/her/cyw059

254. Shahab, L., F. Dobbie, R. Hiscock, A. McNeill, and L. Bauld: Prevalence and Impact of Long-Term Use of Nicotine Replacement Therapy in UK Stop-Smoking Services: Finding from the ELONS Study; Nicotine Tob. Res. 20 (2017) 81-88. DOI: 10.1093/ntr/ntw258

255. Whittington J.R., P.M. Simmons, A.M. Phillips, S.K. Gammill, R. Cen, E.F. Magann, and V.M. Cardenas: The Use of Electronic Cigarettes in Pregnancy: A Review of the Literature; Obstet. Gynecol. Surv. 73 (2018) 544-549. DOI: $10.1097 / O G X .0000000000000595$

256. Prochaska, J.J., S. Das, and K.C. Young-Wolff: Smoking, Mental Illness, and Public Health; Annu. Rev. Public Health 38 (2017) 165-185. DOI: 10.1146/annurev-publhealth-031816-044618

257. Weinberger, A.H., J. Zhu, J.L. Barrington-Trimis, K. Wyka, and R.D. Goodwin: Cigarette Use, E-Cigarette Use, and Dual Product Use is Higher Among Adults with Serious Psychological Distress in the United States: 2014-2017; Nicotine Tob. Res. 22 (2020) 1875-1882. DOI: $10.1093 /$ ntr/ntaa061

258. Cummins, S.E., S.H. Zhu, G.J. Tedeschi, A.C. Gamst, and M.G. Myers: Use of E-Cigarettes by Individuals with Mental Health Conditions; Tob. Control 23 (2014) iii48-iii53. DOI: 10.1136/tobaccocontrol-2013-051511

259. Peckham, E., M. Mishu, C. Fairhurst, D. Robson, T. Bradshaw, C. Arundel, D. Bailey, P. Heron, S. Ker, and S. Gilbody: E-Cigarette Use and Associated Factors 
Among Smokers with Severe Mental Illness; Addict. Behav. 108 (2020) 106456. DOI: 10.1016/j.addbeh.2020.106456

260. Sheals, K., I. Tombor, A. McNeill, and L. Shahab: A Mixed-Method Systematic Review and Meta-Analysis of Mental Health Professionals' Attitudes Toward Smoking and Smoking Cessation Among People with Mental Illnesses; Addiction 111 (2016) 1536-1553. DOI: 10.1111 /add.13387

261. Siru, R., G.K. Hulse, and R.J. Tait: Assessing Motivation to Quit Smoking in People with Mental Illness: A Review; Addiction 104 (2009) 719-733. DOI: $10.1111 / \mathrm{j} .1360-0443.2009 .02545 . \mathrm{x}$

262. Action on Smoking and Health (ASH): Fact Sheet No. 12: Smoking and Mental Health; 2019. Available at: https://ash.org.uk/wp-content/uploads/2019/08/ASHFactsheet_Mental-Health_v3-2019-27-August-1.pdf (accessed April 29, 2020)

263. Reibel, J.: Tobacco and Oral Diseases. Update on the Evidence with Recommendations; Med. Princ. Pract. 12 (2003) 22-32. DOI: 10.1159/000069845

264. BinShabaib, M., S.S. ALHarthi, Z. Akram, J. Khan, I. Rahman, G.E. Romanos, and F. Javed: Clinical Periodontal Status and Gingival Crevicular Fluid Cytokine Profile Among Cigarette-Smokers, ElectronicCigarette Users and Never-Smokers; Arch. Oral Biol. 102 (2019) 212-217.

DOI: $10.1016 /$ j.archoralbio.2019.05.001

265. Ye, D., S. Gajendra, G. Lawyer, N. Jadeja, D. Pishey, S. Pathagunti, J. Lyons, P. Veazie, G. Watson, S. McIntosh, and I. Rahman: Inflammatory Biomarkers and Growth Factors in Saliva and Gingival Crevicular Fluid of E-cigarette Users, Cigarette Smokers, and Dual Smokers: A Pilot Study; J. Periodontol. 91 (2020) 12741283. DOI: 10.1002/JPER.19-0457

266. Yang, I., S. Sandeep, and J. Rodriguez: The Oral Health Impact of Electronic Cigarette Use: A Systematic Review; Crit. Rev. Toxicol. 50 (2020) 97-127. DOI: $10.1080 / 10408444.2020 .1713726$

267. Dalrymple, A., T.C. Badrock, A. Terry, M. Barber, P.J. Hall, D. Thorne, M.D. Gaça, S. Coburn, and C. Proctor: Assessment of Enamel Discoloration In Vitro Following Exposure to Cigarette Smoke and Emissions from Novel Vapor and Tobacco Heating Products; Am. J. Dent. 31 (2018) 227-233.

268. Dalrymple, A., T.C. Badrock, A. Terry, E.J. Bean, M. Barber, P.J. Hall, S. Coburn, J. McAughey, and J. Murphy: Development of a Novel Method to Measure Material Surface Staining by Cigarette, E-Cigarette or Tobacco Heating Product Aerosols; Heliyon 6 (2020) e05012. DOI: 10.1016/j.heliyon.2020.e05012

269. Persoskie, A., E.K. O'Brien, and K. Poonai: Perceived Relative Harm of Using E-Cigarettes Predicts Future Product Switching Among US Adult Cigarette and ECigarette Dual Users; Addiction 114 (2019) 2197-2205. DOI: 10.1111 /add. 14730

270. Gravely, S., P. Driezen, C.N. Kyriakos, M.E. Thompson, J. Balmford, T. Demjén, E. Fernández, U. Mons, Y. Tountas, K. Janik-Koncewicz, W. Zatoński, A.C. Trofor, C.I. Vardavas, G.T. Fong, and the EUREST-PLUS Consortium: European Adult Smokers' Perceptions of the Harmfulness of E-Cigarettes Relative to Combustible
Cigarettes: Cohort Findings from the 2016 and 2018 EUREST-PLUS ITC Europe Surveys; Eur. J. Public Health. 30 (2020) iii38-iii45.

DOI: 10.1093/eurpub/ckz215

271. Huang, J., B. Feng, S.R. Weaver, T.F. Pechacek, P. Slovic, and M.P. Eriksen: Changing Perceptions of Harm of E-Cigarette $v s$ Cigarette Use Among Adults in 2 US National Surveys from 2012 to 2017; JAMA Netw. Open 2 (2019) e191047.

DOI: 10.1001/jamanetworkopen.2019.1047

272. Malt, L., T. Verron, X. Cahours, M. Guo, S. Weaver, T. Walele, and G. O'Connell: Perception of the Relative Harm of Electronic Cigarettes Compared to Cigarettes Amongst US Adults from 2013 to 2016: Analysis of the Population Assessment of Tobacco and Health (PATH) Study Data; Harm Reduct. J. 17 (2020) 65. DOI: 10.1186/s12954-020-00410-2

273. Romijnders, K.A.G.J., L. van Osch, H. de Vries, and R. Talhout: Perceptions and Reasons Regarding E-Cigarette Use Among Users and Non-Users: A Narrative Literature Review; Int. J. Environ. Res. Public Health 15 (2018) 1190.

DOI: $10.3390 /$ ijerph15061190

274. Sussan, T.E., F.G. Shahzad, E. Tabassum, J.E. Cohen, R.A. Wise, M.J. Blaha, J.T. Holbrook, and S. Biswal: Electronic Cigarette Use Behaviors and Motivations Among Smokers and Non-Smokers; BMC Public Health 17 (2017) 686. DOI: 10.1186/s12889-017-4671-3

275. European Commission: Special Eurobarometer 429. Attitudes of Europeans Towards Tobacco and Electronic Cigarettes; 2015. Available at: https:/ec.europa. eu/commfrontoffice/publicopinion/archives/ebs/ ebs_429_en.pdf (accessed January 6 2021).

276. Action on Smoking and Health (ASH): Use of E-Cigarettes (Vaporisers) Among Adults in Great Britain; 2019. Available at: https://ash.org.uk/wp-content/uploads/2019/ 09/ASH-Factsheet_Adult-ECigs-2019-Final-3.pdf (accessed January 6 2021).

277. Mayo Clinic: Quit-Smoking Products: Boost Your Chance of Success; 2020. Available at: https://www.mayoclinic.org/ healthy-lifestyle/quit-smoking/in-depth/quit-smokingproducts/art-20045599 (accessed September 7, 2020)

278. Bullen, C., C. Howe, M. Laugesen, H. McRobbie, V. Parag, J. Williman, and N. Walker: Electronic Cigarettes for Smoking Cessation: A Randomised Controlled Trial; Lancet 382 (2013) 1629-1637.

DOI: 10.1016/S0140-6736(13)61842-5

279. Farsalinos, K.E. and R. Niaura: E-Cigarettes and Smoking Cessation in the United States According to Frequency of E-Cigarette Use and Quitting Duration: Analysis of the 2016 and 2017 National Health Interview Surveys; Nicotine Tob. Res. 22 (2020) 655 662. DOI: $10.1093 /$ ntr/ntz025

280. Carter, L.P., M.L. Stitzer, J.E. Henningfield, R.J. O'Connor, K.M. Cummings, and D.K. Hatsukami: Abuse Liability Assessment of Tobacco Products Including Potential Reduced Exposure Products; Cancer Epidemiol. Biomarkers Prev. 18 (2009) 3241-3262. DOI: 10.1158/1055-9965.EPI-09-0948

281. Caponnetto, P., D. Campagna, G. Papale, C. Russo, and R. Polosa: The Emerging Phenomenon of Electronic Cigarettes; Expert Rev. Respir. Med. 6 (2012) 63-74. 
DOI: $10.1586 /$ ers. 11.92

282. Hajek, P.: Electronic Cigarettes Have a Potential for Huge Public Health Benefit; BMC Med. 12 (2014) 225. DOI: $10.1186 / \mathrm{s} 12916-014-0225-\mathrm{Z}$

283. Hatsukami, D.K.: Ending Tobacco-Caused Mortality and Morbidity: The Case for Performance Standards for Tobacco Products; Tob. Control 22 (2013) i36-i37. DOI: $10.1136 /$ tobaccocontrol-2012-050785

284. Institute of Medicine (IOM): Relieving Pain in America: A Blueprint for Transforming Prevention, Care, Education, and Research; National Academies Press, Washington, DC, USA, 2011.

285. Walton, K.M., D.B. Abrams, W.C. Bailey, D. Clark, G.N. Connolly, M.V. Djordjevic, T.E. Eissenberg, M.C. Fiore, M.L. Goniewicz, L. Haverkos, S.S. Hecht, J.E. Henningfield, J.R. Hughes, C.A. Oncken, L. Postow, J.E. Rose, K.L. Wanke, L. Yang, and D.K. Hatsukami: NIH Electronic Cigarette Workshop: Developing a Research Agenda; Nicotine Tob. Res. 17 (2015) 259-69. DOI: $10.1093 / \mathrm{ntr} / \mathrm{ntu} 214$

286. U.S. Department of Health and Human Services (DHHS), Center for Drug Evaluation and Research: Assessment of Abuse Potential of Drugs: Guidance for Industry; 2017. Available at: https://www.fda.gov/media/ 116739/download (accessed September 7, 2020)

287. Maloney, S.F., A. Breland, E.K. Soule, M. Hiler, C. Ramôa, T. Lipato, and T. Eissenberg: Abuse Liability Assessment of an Electronic Cigarette in Combustible Cigarette Smokers; Exp. Clin. Psychopharmacol. 27 (2019) 443-454. DOI: 10.1037/pha0000261

288. Liu, G., E. Wasserman, L. Kong, and J. Foulds: A Comparison of Nicotine Dependence Among Exclusive E-Cigarette and Cigarette Users in the PATH Study; Prev. Med. 104 (2017) 86-91.

DOI: 10.1016/j.ypmed.2017.04.001

289. Strong, D.R., J. Pearson, S. Ehlke, T. Kirchner, D. Abrams, K. Taylor, W.M. Compton, K.P. Conway, E. Lambert, V.R. Green, L.C. Hull, S.E. Evans, K.M. Cummings, M. Goniewicz, A. Hyland, and R. Niaura: Indicators of Dependence for Different Types of Tobacco Product Users: Descriptive Findings from Wave 1 (2013-2014) of the Population Assessment of Tobacco and Health (PATH) Study; Drug Alcohol Depend. 178 (2017) 257-266. DOI: $10.1016 /$ j.drugalcdep.2017.05.010

290. Rostron, B.L., M.J. Schroeder, and B.K. Ambrose: Dependence Symptoms and Cessation Intentions Among US Adult Daily Cigarette, Cigar, and E-Cigarette Users, 2012-2013; BMC Public Health 16 (2016) 814. DOI: $10.1186 / \mathrm{s} 12889-016-3510-2$

291. McNeill, A., P. Driezen, S.C. Hitchman, K.M. Cummings, G.T. Fong, R. Borland: Indicators of Cigarette Smoking Dependence and Relapse in Former Smokers Who Vape Compared with Those Who Do Not: Findings from the 2016 International Tobacco Control Four Country Smoking and Vaping Survey; Addiction 114 (2019) 49-60. DOI: 10.1111/add.14722

292. Kapan, A., S. Stefanac, I. Sandner, S. Haider, I. Grabovac, and T.E. Dorner: Use of Electronic Cigarettes in European Populations: A Narrative Review; Int. J. Environ. Res. Public Health 17 (2020) 1971. DOI: 10.3390/ijerph17061971
293. Levy, D.T., Z. Yuan, and Y. Li: The Prevalence and Characteristics of E-Cigarette Users in the U.S.; Int. J. Environ. Res. Public Health 14 (2017) 1200. DOI: 10.3390/ijerph14101200

294. Office for National Statistics: E-Cigarette Use in Great Britain; 2020. Available at: https://www.ons.gov.uk/ peoplepopulationandcommunity/healthandsocialcare/ drugusealcoholandsmoking/datasets/ecigaretteusein greatbritain (accessed January 6, 2021)

295. Piñeiro, B., J.B. Correa, V.N. Simmons, P.T. Harrell, N.S. Menzie, M. Unrod, L.R. Meltzer, and T.H. Brandon: Gender Differences in Use and Expectancies of E-Cigarettes: Online Survey Results; Addict. Behav. 52 (2016) 91-97. DOI: 10.1016/j.addbeh.2015.09.006

296. Andler, R., R. Guignard, J.L. Wilquin, F. Beck, J.B. Richard, and V. Nguyen-Thanh: Electronic Cigarette Use in France in 2014; Int. J. Public Health 61 (2016) 159-65. DOI: 10.1007/s00038-015-0773-9

297. Farsalinos, K.E., K. Poulas, V. Voudris, and J. Le Houezec: Electronic Cigarette Use in the European Union: Analysis of a Representative Sample of 27460 Europeans from 28 Countries; Addiction 111 (2016) 2032-2040. DOI: 10.1111/add.13506

298. Filippidis, F.T., V. Gerovasili, and A.A. Laverty: Commentary on Farsalinos et al. (2016): Electronic Cigarette Use in the European Union: Analysis of a Representative Sample of 27460 Europeans from 28 countries; Addiction 112 (2017) 544-545. DOI: 10.1111 /add.13553

299. Adams, J.M.: Surgeon General's Advisory on E-Cigarette Use Among Youth; 2018. Available at: https://ecigarettes.surgeongeneral.gov/documents/surgeongenerals-advisory-on-e-cigarette-use-among-youth2018.pdf (accessed September 7 2020).

300. Bauld, L., A.M. MacKintosh, B. Eastwood, A. Ford, G. Moore, M. Dockrell, D. Arnott, H. Cheeseman, and A. McNeill: Young People's Use of E-Cigarettes Across the United Kingdom: Findings from Five Surveys 20152017; Int. J. Environ. Res. Public Health 14 (2017) 973. DOI: 10.3390/ijerph14090973

301. Anic, G.M., M.D. Sawdey, A. Jamal, and K.F. Trivers: Frequency of Use Among Middle and High School Student Tobacco Product Users - United States, 20152017; MMWR Morb. Mortal. Wkly. Rep. 67 (2018) 1353-1357. DOI: $10.15585 / \mathrm{mmwr} . \mathrm{mm} 6749 \mathrm{a} 1$

302. National Institutes of Health (NIH), National Cancer Institute: Cancer Trends Progress Report: Tobacco Use Initiation; 2020. Available at: https://progressreport. cancer.gov/prevention/smoking_initiation (accessed January 6, 2021)

303. World Health Organization (WHO): European Tobacco Use: Trends Report 2019; WHO, Regional Office for Europe, 2019. Available at: https://www.euro.who.int/ data/assets/pdf file/ 0009/ 402777/Tobacco-TrendsReport-ENG-WEB..$p d f$ (accessed January 6, 2021)

304. Laverty, A.A., E.P. Vamos, and F. Filippidis: Uptake of E-Cigarettes Among a Nationally Representative Cohort of UK Children; Tob. Prev. Cessat. 4 (2018) 16. DOI: $10.18332 / \mathrm{tpc} / 89727$

305. Zhang, X. and J. Pu: E-Cigarette Use Among US Adolescents: Secondhand Smoke at Home Matters; Int. J. Public Health 61 (2016) 209-213. 
DOI: $10.1007 / \mathrm{s} 00038-015-0784-6$

306. Vu, T.-H.T., A. Goom, J.L. Hart, H. Tran, R.L. Landry, J.Z. Ma, K.L. Walker, A.L. Giachello, A. Kesh, T.J. Payne, and R.M. Robertson: Socioeconomic and Demographic Status and Perceived Health Risks of ECigarette Product Contents Among Youth: Results from a National Survey; Health Promot. Pract. 21 (2020) 148S-156S. DOI: $10.1177 / 1524839919882700$

307. Amin, S., A.G. Dunn, and L. Laranjo: Social Influence in the Uptake and Use of Electronic Cigarettes: A Systematic Review; Am. J. Prev. Med. 58 (2020) 129141. DOI: 10.1016/j.amepre.2019.08.023

308. Kozlowski, L. and E.W. Warner: Adolescents and E-Cigarettes: Objects of Concern May Appear Larger Than They Are; Drug Alcohol Depend. 174 (2017) 209214. DOI: 10.1016/j.drugalcdep.2017.01.001

309. Australian Government, Department of Health: Personal Importation Scheme; 2015. Available at: https://www.tga. gov.au/personal-importation-scheme (accessed January 4 2021).

310. O'Leary, R., M. MacDonald, T. Stockwell, and D. Reist: Clearing the Air: A Systematic Review on the Harms and Benefits of E-Cigarettes and Vapour Devices; Canadian Institute for Substance Use Research, Victoria, BC, 2017.

311. Royal College of Physicians: Nicotine Without Smoke: Tobacco Harm Reduction; Royal College of Physicians, London, UK, 2016. Available at: https://bit.ly/3677LeX

312. Mendelsohn, C.P. and W. Hall: Does the Gateway Theory Justify a Ban on Nicotine Vaping in Australia?; Int. J. Drug Policy 78 (2020) 102712.

DOI: 10.1016/j.drugpo.2020.102712

313. Kasza, K.A., K.C. Edwards, Z. Tang, C.A. Stanton, E. Sharma, M.J. Halenar, K.A. Taylor, E. Donaldson, L.C. Hull, H. Day, M. Bansal-Travers, J. Limpert, I. Zandberg, L.D. Gardner, H.T. Hammad, N. Borek, H.L. Kimmel, W.M. Compton, and A. Hyland: Correlates of Tobacco Product Initiation Among Youth and Adults in the USA: Findings from the PATH Study Waves 1-3 (2013-2016); Tob. Control 29 (2020) s191-s202. DOI: $10.1136 /$ tobaccocontrol-2020-055671

314. Khouja, J.N., R.E. Wootton, A.E. Taylor, G. Davey Smith, and M.R. Munafò: Association of Genetic Liability to Smoking Initiation with E-Cigarette Use in Young Adults: A Cohort Study; PLoS Med. 18 (2021) e1003555. DOI: 10.1371/journal.pmed.1003555

315. Hall, W. and G. Chan: The "Gateway" Effect of E-Cigarettes May be Explained by a Genetic Liability to Risk-Taking; PLoS Med. 18 (2021) e1003554. DOI: 10.1371/journal.pmed.1003554

316. Auf, R., M.J. Trepka, M. Selim, Z. Ben Taleb, M. De La Rosa, E. Bastida and M.Á. Cano: E-Cigarette Use is Associated with Other Tobacco Use Among US Adolescents; Int. J. Public Health 64 (2019) 125-134. DOI: $10.1007 / \mathrm{s} 00038-018-1166-7$

317. Evans-Polce, R.J., P. Veliz, C.J. Boyd, and S.B. McCabe: Initiation Patterns and Trends of E-Cigarette and Cigarette Use Among U.S. Adolescents; J. Adolesc. Health 66 (2020) 27-33.

DOI: https://doi.org/10.1016/j.jadohealth.2019.07.002

318. Walker, N., V. Parag, S.F. Wong, B. Youdan, B. Broughton, C. Bullen, and R. Beaglehole: Use of
E-Cigarettes and Smoked Tobacco in Youth Aged 14-15 Years in New Zealand: Findings from Repeated CrossSectional Studies (2014-19); Lancet Public Health 5 (2020) e204-e212.

DOI: $10.1016 / \mathrm{S} 2468-2667(19) 30241-5$

319. Government of Canada: Exploratory Research on Youth Vaping: Final Report / Prepared for Health Canada; Supplier Name: Quorus Consulting Group Inc., Ottawa, Canada, 2020. Available at: http://publications.gc.ca/ site/fra/9.886111/publication.html (accessed January, 6 2021)

320. Cunningham, A., S. Slayford, C. Vas, J. Gee, S. Costigan, and K. Prasad; Development, Validation and Application of a Device to Measure E-Cigarette Users' Puffing Topography; Sci. Rep. 6 (2016) 35071.

DOI: $10.1038 /$ srep35071

321. Slayford, S.J. and B.E. Frost: A Device to Measure a Smoker's Puffing Topography and Real-Time Puff-byPuff “Tar” Delivery; Beitr. Tabakforsch. Int. 26 (2014) 74-84. DOI: 10.2478/cttr-2014-0011

322. Jones, J., S. Slayford, A. Gray, K. Brick, K. Prasad, and C.A. Proctor: A Cross-Category Puffing Topography, Mouth Level Exposure and Consumption Study Among Italian Users of Tobacco and Nicotine Products; Sci. Rep. 10 (2020) 12. DOI: $10.1038 / \mathrm{s} 41598-019-55410-5$

323. Hammond, D., G.T. Fong, K.M. Cummings, and A. Hyland: Smoking Topography, Brand Switching, and Nicotine Delivery: Results from an In Vivo Study; Cancer Epidemiol. Biomarkers Prev. 14 (2005) 13701375. DOI: 10.1158/1055-9965.EPI-04-0498

324. Spindle, T.R., A.B. Breland, N.V. Karaoghlanian, A.L. Shihadeh, and T. Eissenberg: Preliminary Results of an Examination of Electronic Cigarette User Puff Topography: The Effect of a Mouthpiece-Based Topography Measurement Device on Plasma Nicotine and Subjective Effects; Nicotine Tob. Res. 17 (2015) 142-149. DOI: $10.1093 /$ ntr/ntu186

325. European Medicines Agency (EMA): Biosimilars in the EU: Information Guide for Healthcare Professionals; 2019. Available at: https://www.ema.europa.eu/en/documents/ leaflet/biosimilars-eu-information-guide-healthcareprofessionals_en.pdf (accessed January 6, 2021)

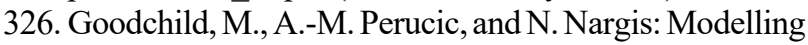
the Impact of Raising Tobacco Taxes on Public Health and Finance; Bull. World Health Organ. 94 (2016) 250-257. DOI: 10.2471/BLT.15.164707

327. Levy, D.T., J.L. Pearson, A.C. Villanti, K. Blackman, D.M. Vallone, R.S. Niaura, and D.B. Abrams: Modeling the Future Effects of a Menthol Ban on Smoking Prevalence and Smoking-Attributable Deaths in the United States; Am. J. Public Health 101 (2011) 12361240. DOI: 10.2105/AJPH.2011.300179.

328. Wallace, R., A. Geller, and V.A. Ogawa: Assessing the Use of Agent-Based Models for Tobacco Regulation. Consensus Study Report; National Academies Press, Washington, DC, USA, 2015. DOI: 10.17226/19018

329. Vugrin, E.D., B.L. Rostron, S.J. Verzi, N.S. Brodsky, T.J. Brown, C.J. Choiniere, B.N. Coleman, A. Paredes, and B.J. Apelberg: Modeling the Potential Effects of New Tobacco Products and Policies: A Dynamic Population Model for Multiple Product Use and Harm; 
PLoS One 10 (2015) e0121008.

DOI: 10.1371 /journal.pone. 0121008

330. Bachand, A.M. and S.I. Sulsky: A Dynamic Population Model for Estimating All-Cause Mortality Due to Lifetime Exposure History; Regul. Toxicol. Pharmacol. 67 (2013) 246-251. DOI: 10.1016/j.yrtph.2013.08.003

331. Levy, D.T., N. Nikolayev, E.A. Mumford, and C. Compton: The Healthy People 2010 Smoking Prevalence and Tobacco Control Objectives: Results from the SimSmoke Tobacco Control Policy Simulation Model(United States); Cancer Causes Control 16(2005) 359-371. DOI: 10.1007/s10552-004-7841-4

332. Lee, P.N., D. Abrams, A. Bachand, G. Baker, R. Black, O. Camacho, G. Curtin, S. Djurdjevic, A. Hill, D. Mendez, R.S. Muhammad-Kah, J.L. Murillo, R. Niaura, Y.B. Pithawalla, B. Poland, S. Sulsky, L. Wei, and R. Weitkunat: Estimating the Population Health Impact of Recently Introduced Modified Risk Tobacco Products: A Comparison of Different Approaches; Nicotine Tob. Res. 23 (2021) 426-437.

DOI: $10.1093 /$ ntr/ntaa102

333. Warner, K.E. and D. Mendez: E-Cigarettes: Comparing the Possible Risks of Increasing Smoking Initiation with the Potential Benefits of Increasing Smoking Cessation; Nicotine Tob. Res. 21 (2019) 41-47. DOI: $10.1093 /$ ntr/nty062

334. Levy, D.T., R. Borland, E.N. Lindblom, M.L. Goniewicz, R. Meza, T.R. Holford, Z. Yuan, Y. Luo, R.J. O'Connor, R. Niaura, and D.B. Abrams: Potential Deaths Averted in USA by Replacing Cigarettes with ECigarettes; Tob. Control 27 (2018) 18-25.

DOI: $10.1136 /$ tobaccocontrol-2017-053759

335. Bachand, A.M., S.I. Sulsky, and G.M. Curtin: Assessing the Likelihood and Magnitude of a Population Health Benefit Following the Market Introduction of a Modified-Risk Tobacco Product: Enhancements to the Dynamic Population Modeler, DPM(+1); Risk Anal. 38 (2018) 151-162. DOI: 10.1111/risa.12819

336. Cherng, S.T., J. Tam, P.J. Christine, and R. Meza: Modeling the Effects of E-Cigarettes on Smoking Behavior: Implications for Future Adult Smoking Prevalence; Epidemiology 27 (2016) 819-826.

DOI: 10.1097/EDE.0000000000000497

337. Soneji, S.S., H.-Y. Sung, B.A. Primack, J.P. Pierce, and J.D. Sargent: Quantifying Population-Level Health Benefits and Harms of E-Cigarette Use in the United States; PLoS One 23 (2018) e0193328.

DOI: 10.1371/journal.pone.0193328

338. Hill, A. and O.M. Camacho: A System Dynamics Modelling Approach to Assess the Impact of Launching a New Nicotine Product on Population Health Outcomes; Regul. Toxicol. Pharmacol. 86 (2017) 265-278. DOI: $10.1016 /$ j.yrtph.2017.03.012

339. U.S. Food and Drug Administration (FDA): Generally Recognized as Safe (GRAS); 2019. Available at: https://www.fda.gov/food/food-ingredients-packaging/ generally-recognized-safe-gras (accessed January 25, 2021)

340. Akiyama, Y. and N. Sherwood: Systematic Review of Biomarker Findings from Clinical Studies of Electronic Cigarettes and Heated Tobacco Products; Toxicol. Rep. 8 (2021) 282-294. DOI: 10.1016/j.toxrep.2021.01.014
341. Office for National Statistics: Adult Smoking Habits in Great Britain; 2020. Available at: https://www.ons.gov. $\mathrm{uk} /$ peoplepopulationandcommunity/healthandsocialcare/ drugusealcoholandsmoking/datasets/adultsmoking habitsingreatbritain (accessed January 6, 2021)

342. Jaccard, G., T. Tafin Djoko, A. Korneliou, R. Stabbert, M. Belushkin, and M. Esposito: Mainstream Smoke Constituents and In Vitro Toxicity Comparative Analysis of 3R4F and 1R6F Reference Cigarettes; Toxicol. Rep. 6 (2019) 222-231.

DOI: $10.1016 /$ j.toxrep.2019.02.009

343. O’Connell, G., T. Walele, C. Prue, G. Gillman, X. Cahours, O. Hibbert, and J.D. Pritchard: Chemical Composition of Myblu ${ }^{\mathrm{TM}}$ Pod-System E-Cigarette Aerosols: A Quantitative Comparison with Conventional Cigarette Smoke; presented at the $1^{\text {st }}$ Scientific Summit on Tobacco Harm Reduction, Kallithea, Greece, June 2018. Available at: https://imperialbrandsscience.com/ wp-content/uploads/2020/02/Chemical-Compositionof-blu-Pod-System-EVP-Aerosols-A-QuantitativeComparison-with-Conventional-Cigarette-Smoke.pdf (accessed May 8, 2021)

344. Farsalinos, K., K. Poulas, and V. Voudris: Changes in Puffing Topography and Nicotine Consumption Depending on the Power Setting of Electronic Cigarettes; Nicotine Tob. Res. 20 (2018) 993-997. DOI: $10.1093 / \mathrm{ntr} / \mathrm{nt} \times 219$

345. Yan, X.S. and C. D'Ruiz: Effects of Using Electronic Cigarettes on Nicotine Delivery and Cardiovascular Function in Comparison with Regular Cigarettes; Regul. Toxicol. Pharmacol. 71 (2015) 24-34.

DOI: 10.1016/j.yrtph.2014.11.004

346. Hajek, P., D. Przulj, A. Phillips, R. Anderson, and H. McRobbie: Nicotine Delivery to Users from Cigarettes and from Different Types of E-Cigarettes; Psychopharmacology 234 (2017) 773-779. DOI: $10.1007 / \mathrm{s} 00213-016-4512-6$

347. Vansickel, A.R., C.O. Cobb, M.F. Weaver, and T.E. Eissenberg: A Clinical Laboratory Model for Evaluating the Acute Effects of Electronic "Cigarettes": Nicotine Delivery Profile and Cardiovascular and Subjective Effects; Cancer Epidemiol. Biomarkers Prev. 19 (2010) 1945-1953. DOI: 10.1158/1055-9965.EPI-10-0288

248. Voos, N., L. Kaiser, M.C. Mahoney, C.M. Bradizza, L.T. Kozlowski, N.L. Benowitz, R.J. O’Connor, and M.L. Goniewicz: Randomized Within-Subject Trial to Evaluate Smokers' Initial Perceptions, Subjective Effects and Nicotine Delivery Across Six Vaporized Nicotine Products; Addiction 114 (2019) 1236-1248. DOI: 10.1111/add.14602

349. Lunell, E. and M. Curvall: Nicotine Delivery and Subjective Effects of Swedish Portion Snus Compared with $4 \mathrm{mg}$ Nicotine Polacrilex Chewing Gum; Nicotine Tob. Res. 13 (2011) 573-578. DOI: 10.1093/ntr/ntr044

350. Dautzenberg, B., M. Nides, J.L. Kienzler, and A. Callens: Pharmacokinetics, Safety and Efficacy from Randomized Controlled Trials of 1 and $2 \mathrm{mg}$ Nicotine Bitartrate Lozenges $\left(\right.$ Nicotinell $\left.^{\circledR}\right)$; BMC Clin. Pharmacol. 7 (2007) 11. DOI: 10.1186/1472-6904-7-11

351. Choi, J.H., C.M. Dresler, M.R. Norton, and K.R. Strahs: Pharmacokinetics of a Nicotine Polacrilex Lozenge; 
Nicotine Tob. Res. 5 (2003) 635-644.

DOI: $10.1080 / 1462220031000158690$

352. Kraiczi, H., A. Hansson, and R. Perfekt: Single-Dose Pharmacokinetics of Nicotine When Given with a Novel Mouth Spray for Nicotine Replacement Therapy; Nicotine Tob. Res. 13 (2011) 1176-1182.

DOI: $10.1093 / \mathrm{ntr} / \mathrm{ntr} 139$

353. Molander, L. and E. Lunell: Pharmacokinetic Investigation of a Nicotine Sublingual Tablet; Eur. J. Clin. Pharmacol. 56 (2001) 813-819.

DOI $10.1007 / \mathrm{s} 002280000223$

354. Lunell, E., K. Fagerström, J. Hughes, and R. Pendril: Pharmacokinetic Comparison of a Novel Non-TobaccoBased Nicotine Pouch (ZYN) with Conventional, Tobacco-Based Swedish Snus and American Moist Snuff; Nicotine Tob. Res. 22 (2020) 1757-1763. DOI: $10.1093 /$ ntr/ntaa068

355. Goldenson, N., I.M. Fearon, A.R. Buchhalter, and J.E. Heningfield: An Open-Label, Randomised, Controlled, Crossover Study to Assess Nicotine Pharmacokinetics and Subjective Effects of the JUUL System with Three Nicotine Concentrations Relative to Combustible Cigarettes in Adult Smokers; Nicotine Tob. Res. (2021) ntab001. DOI: 10.1093/ntr/ntab001

356. D'Ruiz, C.D., D.W. Graff, and E. Robinson: Reductions in Biomarkers of Exposure, Impacts on Smoking Urge and Assessment of Product Use and Tolerability in Adult Smokers Following Partial or Complete Substitution of Cigarettes with Electronic Cigarettes; BMC Public Health 16(2016) 543. DOI: 10.1186/s12889-016-3236-1

357. Campagna, D., F. Cibella, P. Caponnetto, M.D. Amaradio, M. Caruso, J.B. Morjaria, M. Malerba, and R. Polosa: Changes in Breathomics from a 1-Year Randomized Smoking Cessation Trial of Electronic Cigarettes; Eur. J. Clin. Invest. 46 (2016) 698-706. DOI: $10.1111 /$ eci.12651

358. Pulvers, K., A.S. Emami, N.L. Nollen, D.R. Romero, D.R. Strong, N.L. Benowitz, and J.S. Ahluwalia: Tobacco Consumption and Toxicant Exposure of Cigarette Smokers Using Electronic Cigarettes; Nicotine Tob. Res. 20 (2018) 206-214.

DOI: $10.1093 / \mathrm{ntr} / \mathrm{ntw} 333$

359. Behar, R.Z., M. Hua, and P. Talbot: Puffing Topography and Nicotine Intake of Electronic Cigarette Users; PLoS One 10 (2015) e0117222.

DOI: 10.1371 /journal.pone.0117222

360. Norton, K.J., K.M. June, and R.J. O’Connor: Initial Puffing Behaviors and Subjective Responses Differ Between an Electronic Nicotine Delivery System and Traditional Cigarettes; Tob. Induc. Dis. 12 (2014) 17. DOI: $10.1186 / 1617-9625-12-17$

361. Lee, Y.H., M. Gawron, and M.L. Goniewicz: Changes in Puffing Behavior Among Smokers Who Switched from Tobacco to Electronic Cigarettes; Addict. Behav. 48 (2015) 1-4. DOI: 10.1016/j.addbeh.2015.04.003

362. Robinson, R.J., E.C. Hensel, P.N. Morabito, and K.A. Roundtree: Electronic Cigarette Topography in the Natural Environment; PLoS One 10 (2015) e0129296. DOI: 10.1371/journal.pone.0129296
363. Robinson, R.J., E.C. Hensel, K.A. Roundtree, A.G. Difrancesco, J.M. Nonnemaker, and Y.O. Lee: Week Long Topography Study of Young Adults Using Electronic Cigarettes in Their Natural Environment; PloS One 11 (2016) e0164038. DOI: 10.1371 /journal.pone. 0164038

364. Dawkins, L.E., C.F. Kimber, M. Doig, C. Feyerabend, and O. Corcoran: Self-Titration by Experienced E-Cigarette Users: Blood Nicotine Delivery and Subjective Effects; Psychopharmacology 233 (2016) 1-9. DOI: $10.1007 / \mathrm{s} 00213-016-4338-2$

365. Lee, Y.O., J.M. Nonnemaker, B. Bradfield, E.C. Hensel, and R.J. Robinson: Examining Daily Electronic Cigarette Puff Topography Among Established and Nonestablished Cigarette Smokers in Their Natural Environment; Nicotine Tob. Res. 20 (2018) 1283-1288. DOI: $10.1093 / \mathrm{ntr} / \mathrm{ntx} 222$

366. Levy, D.T., R. Borland, A.C. Villanti, R. Niaura, Z. Yuan, Y. Zhang, R. Meza, T.R. Holford, G.T. Fong, K.M. Cummings, and D.B. Abrams: The Application of a Decision-Theoretic Model to Estimate the Public Health Impact of Vaporized Nicotine Product Initiation in the United States; Nicotine Tob. Res. 19 (2017) 149159. DOI: $10.1093 / \mathrm{ntr} / \mathrm{ntw} 158$

367. Levy, D.T., Z. Yuan, Y. Li, A.J. Alberg, and K.M. Cummings: A Modeling Approach to Gauging the Effects of Nicotine Vaping Product Use on Cessation from Cigarettes: What Do We Know, What Do We Need to Know?; Addiction 114 (2019) 86-96. DOI: $10.1111 /$ add.14530

368. Petrović-van der Deen, F.S., N. Wilson, A. Crothers, C.L. Cleghorn, C. Garner, and T. Blakely: Potential Country-Level Health and Cost Impacts of Legalizing Domestic Sale of Vaporized Nicotine Products; Epidemiology 30 (2019) 396-404. DOI: $10.1097 /$ EDE.0000000000000975

369. Kalkhoran, S. and S.A. Glantz: Modeling the Health Effects of Expanding E-Cigarette Sales in the United States and United Kingdom: A Monte Carlo Analysis; JAMA Intern. Med. 175 (2015) 1671-1680. DOI: $10.1001 /$ jamainternmed.2015.4209

Corresponding author:

Oscar M. Camacho

British American Tobacco, R\&D Centre

Southampton, SO15 8TL

United Kingdom

E-Mail: Oscar_M_Camacho@bat.com 